\title{
WITHOUT WORDS YOU SPOKE: QUEER REPRESENTATION, EARLY PHOTOGRAPHY AND FEELING
}

\author{
By Steph Schem Rogerson \\ Master of Fine Arts, The School of Visual Arts, New York, New York, U.S.A, 1999 \\ Bachelor of Fine Arts, Ontario College of Art and Design University, Toronto, \\ Ontario, Canada, 1996
}

Dissertation presented to Ryerson University in partial fulfillment of the requirements for the degree of Doctor of Philosophy in the Joint Graduate Program in Communication and Culture at Ryerson University and York University.

Toronto, Ontario, Canada, 2015

(C)Steph Rogerson 2015 


\section{Author's Declaration for Submission of a Dissertation}

I hereby declare that I am the sole author of this dissertation. This is a true copy of the dissertation, including any required final revisions, as accepted by my examiners.

I authorize Ryerson University to lend this dissertation to other institutions or individuals for the purpose of scholarly research

I further authorize Ryerson University to reproduce this dissertation by photocopying or by other means, in total or in part, at the request of other institutions or individuals for the purpose of scholarly research.

I understand that my dissertation may be made electronically available to the public. 


\section{Abstract}

By examining historical queerness through the lens of photography, this dissertation examines how the past contributes valuable knowledge about where we have been and where we are going. The history of queer representation is laden with violence, erasure and shame, as well as survival and persistence. I approach this legacy by bringing together three principal topics that I argue are closely related: queer photographic practices, the politics of the archive, and affect theory. Through the analysis of social conditions that formed discourses of homosexuality and industrialism's development of photography in the late nineteenth century, the tension between oppressive laws and social change becomes clear: it reveals a cultural crisis of taxonomy and representation in queer visual history. The slippages between cultural economy and representation are exemplified in nineteenth century visual culture as political economy was increasingly entwined with the individual and the state. Out of this matrix comes the advent of photography. Inexpensive and accessible mechanical reproduction made it possible for the apparatus of photography to be both complicit in the categorization and repression of homosexuality, as well as a site of subversion of the status quo. Conventions in portraiture photography inscribed the construction of normativity through 'the cult of the empire,' yet queer subjectivities challenged these standards. A number of specific case studies involving women photographers and photographic subjects - such as Mabel Hampton, Bonnie and Semoura Clark, Alice Austen, and found photographs from my personal collection illustrate a symbolic defiance to hegemonic structures.

By investigating archival material with a specific focus on queer history and photography, the case studies illustrate how our affective lives are saturated with political meaning. Photography wields unusual power when examining the relationship between affect and feeling. The affect of photography derives from its insistence on the past. Yet, photography produces a here and now that can resist strictures of heteronormativity and patriarchy through politicized feelings. The approach to queer historization is firmly rooted in notions of social justice imperatives and anti-oppressive political strategies that include racism, gender inequality and classism. Queer archives evoke cultural persistence and knowledge through the affective context of remembering.

Keywords: Archives, Photography, Queer History, Affect Theory, and Phenomenology. 


\section{Acknowledgements}

I would like to thank Communication and Culture as the program that allowed me to follow my heart, and Paul Moore, Graduate Program Director (Ryerson), Interim GPD Izabella Pruska-Oldenhof and program administrator Jo Ann Mackie for all your support and assistance. My committee, Dr. Steve Bailey and Dr. Kate Eichhorn provided invaluable feedback that made for clearer writing and stronger analysis. Without my supervisor Dr. Sophie Thomas, I could not have done this. Sophie's kindness, wisdom and uncanny ability to bring out the best in me, not only provided me access to knowledge, but perhaps even more importantly, she supported and believed in me in times when I felt lost. For that, I am forever grateful. Sophie, you are a mensch.

My community of family and friends who had my back through thick and thin prove just how powerful love can be. Thank you, Mom for your unwavering belief in me. My sister Rebecca and her children Maia, Eve and Eli who bring immense joy in my life and make me a better a person. Dad, you are no longer here but thank you for making me a fighter. Thank you Ximena Griscti for afternoons in the park with lively debates on topics ranging from Adorno to Teen Mom, you are kick ass. Kelly McCray, my brother from another mother, thank you for listening and your boyish giggles. Cecilia Berkovic, thank you for soulful dog walks in every weather condition and your good cooking. Sarena Sairan, thank you for swims in a beautiful lake and intense squash games. Liz Fitting, you are a powerhouse, thank you for our 30 years of friendship. Keith Cole, thank you for always being inappropriate. Liss Platt, thank you for 'getting it.' Izida Zorde for being weird at the exact right time, and Catherine Clark for creating space to blow off stream. Thank you Anna Hoffmann for every glittery kiss sent from Berlin. Talia Mae Bettcher, thank you for a magical friendship of deep love and fiery debates.

Ken Moffatt, thank you for your support during my Comprehensive Exams. Graduate Program Director (York) Anne MacLennan, thank you for listening that time when it felt as though my life fell apart. Thank you to my external Dr. Jonathan David Katz, whose work I have long admired. Lychee Fan, Nathanial Wiener, Guy Hoskins, Joey Jacob and Lauren Divine for great discussions over food and drinks. 
Thank you Summer School for Sexualities, Cultures and Politics at IPAK in Serbia for creating a broader context to my work, this includes but is not limited to: Tomasz Sikora, Monica Guerreiro, Claire Finch, France Rose, Olga Kasyanova, Slavčo Dimitrov, Stanimir Panayotov, Jelisaveta Blagojević, Eszter Timár, Bracha L. Ettinger, Lazara Marinkovic and Jack Halberstam. Thank you Emma Ward for helping gain access to vital photographs in this dissertation, and the wild nights with Chris Lynch and Anne Moore. Thank you Dissertation Boot Camp and Natalya Androsova at the Student Learning Support at Ryerson University for creating a safe space to write.

Lastly, thank you to all the warriors and rebels who inspire me to live life to its fullest, and for the battles you continue to fight. This dissertation is dedicated to you. 
Table of Contents

Abstract and Keywords iii

Acknowledgements iv

List of Figures vii

$\begin{array}{ll}\text { Introduction } & 1\end{array}$

Chapter One: Political Power and the Archive......................42 42

$\diamond$ Archive Fever ....................................................47

$\checkmark$ The Body and the Archive........................................55

$\diamond$ Reverse Discourse................................................60

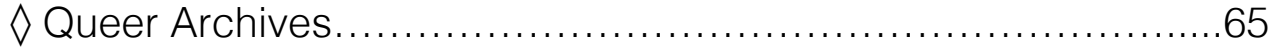

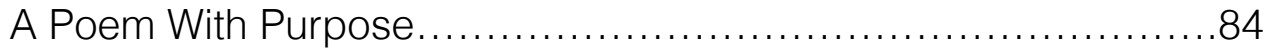

Chapter Two: Early Photography and Queerness...................85

$\checkmark$ Industrialization and Photography ................................ 89

$\checkmark$ Queering Conventions.......................................... 100

$\diamond$ Representing Politically ............................................ 110

Chapter Three: Political Emotions and Feeling......................125

$\checkmark$ Episteme of Queer and its Discourses.............................129

$\diamond$ Orientation, Affect and Misalignment.............................148

$\checkmark$ Queer Punctum..................................................... 154

Conclusion....................................................... 168

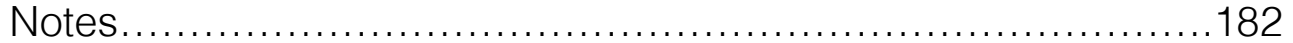

Works Cited ................................................... 197 


\title{
List of Figures
}

\author{
Introduction
}

0.1 Lena Valin and unknown subject. Toronto, Canada. 1920s. Personal Collection.

Political Power and The Archive

1.1. ONE National Gay and Lesbian Archives at the USC Libraries. Los Angeles, CA. 2013. Personal Collection.

1.2 Alphonse Bertillon (1853-1914), French criminologist. Sourced from Allan Sekula's, The Body and The Archive.

1.3 Jean-Martin Charcot (1825-1893). The Waring Historical Library's Caricature Collection, US.

1.4 British half-penny, 1874. Coins of Great Britain. http://www.coins-of-theuk.co.uk/values/halfp.html

1.5 Francis Galton (1822-1911), Illustrations of Composite Portraiture, "The Jewish Type." University College, London, UK. From The Body and The Archive.

1.6 Alphonse Bertillon. National Gallery of Canada, Ottawa. https://www.nlm.nih.gov/visibleproofs/galleries/biographies/bertillon.html

1.7 Oscar Wilde's Cell \#33, C Wing, Reading Prison, where Oscar Wilde spent the majority of his two year sentence after being found guilty of gross indecency. Sourced from Solitary Watch. http://solitarywatch.com

1.8 The door of Oscar Wilde's cell at Reading Gaol, displayed at Nottingham's Galleries of Justice Image from Voices from Solitary: Oscar Wilde's Cry from the Depths by Jean Casella and James Ridgeway. Sourced from Solitary Watch. http://solitarywatch.com

1.9 The official seal for the New York Society for the Suppression of Vice who burned A Well of Loneliness in the 1920s. Jake Ptacek http://viz.dwrl.utexas.edu/content/visualizing-censorship-seals-symbols-andvisual-rhetoric-vice 
1.10 Magnus Hirschfeld Archive in the Institute for Sexual Research in Berlin (1925). Sourced from the Institut für Sexualwissenschaft.

1.11 Nazis in Berlin burn works of Jewish authors, and the library of the Institut für Sexualwissenschaft on 10 May 1933.

1.12 Lesbian Herstory Archives, In Memory of the Voices We Have Lost. Reopening parade in Brooklyn on 20 June 1993. Photo by Saskia Scheffer — with Polly Thistlethwaite, Joan Nestle, Robin Riback, Paula Grant, Jenny Romaine, Judith Schwarz and Eve Sicular. Sourced from

http://www.lesbianherstoryarchives.org

1.13 GLBT Historical Society, San Francisco, CA. Sourced from http://www.glbthistory.org

1.14 Anne Lister (1791-1840). Sourced from Borthwick Institute for Archives, University of York UK.

1.15 Remembering the Stonewall Riots, 1969. From Our Archives: The Advocate. Michelle Garcia, The Advocate. 29 June 2012.

1.16 Leo Adams, Sudden Night, 1930. New York. Image from the New York Public Library, personally sourced in 2012.

1.17 Canadian Lesbian and Gay Archives. We Demand, 1971. Protest Parliament Hill, 28 Aug. 1971. Image from The August 28th Gay Day Committee. The Body Politic, Issue 1, Nov / Dec 1971. Reprinted in "Flaunting It!" in 1982.

1.18 Photographer Robert Giard, Mabel Hampton Sees the Pigeons at the Old Lesbian Herstory Archive, 1989. Image from exhibition Toward the Particular curated by Scott Rayter at UTAC, University of Toronto 2 Sept. - 15 Nov. 2014.

1.19 Mabel Hampton of the Lesbian Herstory Archive Newsletter, 1979. Original portrait from the 1920s.

1.20 Homosexual prisoners, recognizable by the pink triangles on their prison uniforms in Sachsenhausen concentration camp, 1938. Sourced from Anne Frank Guide. 
Early Photography and Queerness

2.1 Oscar Wilde and Lord Alfred Douglas, 1893. Sourced from

http://law2.umkc.edu/faculty/projects/ftrials/wilde/lettersfromwilde.html

2.2 The Queen's Sitting Room, 1867 by cartes-de-visite inventor André AdolpheEugène Disdéri. Sourced from the Getty Museum

Carte-de-visite of Queen Victoria and Prince Albert, 1861. Sourced from the Victoria and Albert Museum, London.

2.3 Two freed slaves who fought in one of the African American regiments (U.S Civil War) John and Frank are inscribed on the portrait. Carte-de-visite. Baton Rouge, Louisiana, 1863. Sourced from David Deitcher's Dear Friends.

2.4 Unknown subjects and date, Hand-tinted, Tintype. Sourced from the Internet. https://www. pinterest.com/dimitritoscas/gay-history/

2.5 Photographer Unknown, Subjects Unknown, Tintype in Paper Sleeve, 1885. Sourced from David Deitcher's Dear Friends.

2.6 Folder of findings. Yale Library. Personal Collection. Photo by Emma Ward.

2.7 Bonnie and Semoura Clark, date and exact location unknown. Sourced from Beinecke Rare Book and Manuscript Library, Yale University. Photo by Emma Ward.

2.8 Mother (as labeled on the back), Albumen print. 1890. Sourced from Women in Pants.

2.9 Young Couple, early 1900s. Sourced from Women in Pants.

2.10 Bonnie and Semoura Clark, date and exact location unknown. Sourced from Beinecke Rare Book and Manuscript Library, Yale University. Photo by Emma Ward.

2.11 Phil and [Cora] Black. Date unknown circa 1920s. Sourced from Beinecke Rare Book and Manuscript Library (online), Yale University.

2.12 James VanDerZee. Family Portrait, 1926. Sourced from Roland Barthes's Camera Lucida.

2.13 Augustine North and Mariam Babbitt, July 28th, 1899. Ontario, Canada. Personal Collection. 
Political Emotions and Feeling

3.1 Self-portrait of 26-year-old Alice, posing on the porch in her favorite yellow dress with red trim. (E.A.A., full length, with fan. Fine day, in shade on piazza. Monday, Sept. 19th, 1892. Seed 23, Perken lens, 32 stop, 3 secs). Sourced from The Alice Austen Historical Society.

3.2 Alice Austen's Home, Clear Comfort on Staten Island, NY. Sourced from The Alice Austen Historical Society.

3.3 Outdoor water pump at Alice Austen's Home, where she washed her photographic prints. Sourced from The Alice Austen Historical Society.

3.4 Alice Austen's camera at Clear Comfort. Sourced from The Alice Austen Historical Society.

3.5 Alice Austen. Organ Grinder. New York City, 1896. Sourced from The Alice Austen Historical Society.

3.6 Alice Austen. Violet Ward (left) and gymnast Daisy Elliott. Clear Comfort, 1892. Sourced from The Alice Austen Historical Society.

3.7 Alice Austen (left) with Gertrude Amelia Tate in 1951. Sourced from The Alice Austen Historical Society.

3.8 Alice Austen. LIFE Magazine 1951. Alice and 'friend.' Sourced from Alice's World.

3.9 Julia Martin, Julia Bredt and Self Dressed Up as Men, 4:40pm, Thursday, October $15^{\text {th }}$, 1891. Sourced from The Alice Austen Historical Society.

Conclusion

4.1. Andrea Geyer. Insistence. 2013. 15.21 minutes. Sourced from http://www.andreageyer.info/projects/insistence/Insistence.html

4.2. Sunil Gupta. Sourced from Queer: Sunil Gupta

4.3. Wendy Coburn. Anatomy of a Protest, 2015. Sourced from http://jmbgallery.ca/ExWendyCoburn.html 


\section{Introduction}

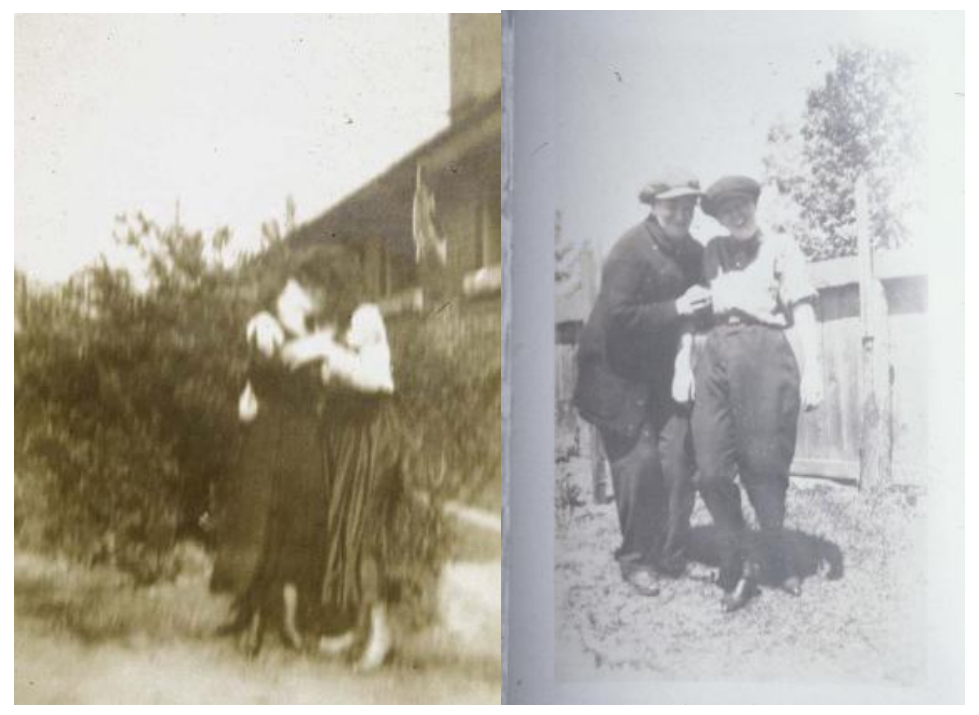

Figure 0.1

My great-aunt Lena, 1920s. Toronto, Canada

In 1997, I found a small shoebox in my parents' basement. In it were photographs of my great-aunt Lena Valin kissing another woman, likely taken with a point and shoot, lightweight Brownie camera, common for the 1920s. The image was taken in her backyard on Jones Ave in Toronto, where she lived until her death in the 1970s. In her collection of photos were friends in drag; they are subtle images, almost reflective in tone. Who was she in her private life? Was she straight, gay, bisexual? Do these terms even matter? Looking at her photographs, absorbing every detail, I will never know. If she were alive, would she tell me? Secrets are powerful, and these images were not tossed into a pile of other photographs but were separated and stacked in a shoebox. Why were these particular images singled out from the rest? Her photos like ghosts haunted my imagination. I remember seeing for the first time that photo of her 
kissing another woman; I was bewitched, sitting on my parent's carpet, surrounded by pictures. That moment, although I did not realize it at the time, initiated a journey into territory that has become both a personal and a scholarly pursuit.

Artists, curators and academics are currently exploring creative practices that examine issues of historical queerness across Canada, the U.S and Europe. Among some of the interesting ways these concerns are being addressed involve fresh approaches to the canon of Art History, artist's works that tackle the queer archive as artistic practice and curated exhibitions dealing expressly with historical queer images. Jonathan David Katz's project, cocurated with David C. Ward, Hide/Seek: Difference and Desire in American Portraiture was first exhibited at the Smithsonian's National Portraiture Gallery in Washington. The exhibition brought new scholarship to American art and sexuality, and revealed the historical influence of gay and lesbian artists to American modernism. Artists ranged from Thomas Eakins, Romaine Brookes, Paul Cadmus, Berernice Abbott, to contemporary artists such as Laura Aguilar, Glenn Ligon and Catherine Opie. While every artist in the exhibition may not have identified as queer or, for reasons of social ostracization, were not publicly 'out,' each artist examined the subject of sexual difference and desire. ${ }^{1}$

Further, artists' approaches to the queer archive have begun important and interesting discourses to creative practices and memory. Tammy Rae Carland's series "Archive of Feelings" (2008) shows emotion, connection, disconnection and trauma through the ephemeral objects of everyday life. The series was a creative response to Ann Cvetkovich's book An Archive of Feelings: Trauma, Sexuality and Lesbian Public Cultures. Toronto-based artist

${ }^{1}$ I wrote a review for this show for C Magazine in 2010. http://www.cmagazine.com/2009_104.htm 
Nina Levitt has been making artwork for several years that examines historic lesbians as part of her practice. Her series "Submerged (for Alice Austen)" (1991) takes historical images of Alice Austen and places them under new conditions by splicing, re-sequencing and re-ordering original photographs with contemporary meaning.

Curated exhibitions in which both curators and artists examine queer history through a contemporary lens are adding to discourses about queer artistic practice. In 2013, Kelly McCray and myself co-curated Rare \& Raw at Leslie Lohman Museum of Gay and Lesbian Art. The exhibition brought together eight artists who examined queer history through contemporary materiality and current threads of political concerns ${ }^{2}$. In the conclusion, I discuss more examples of contemporary approaches to unveiling queer history and its impact on current political trends. These examples show the current value being placed on queer historical research and creative practice. Although this is not an exhaustive list of exhibitions from around the world, I hope to show through these examples that, while I did not know it at the time, when I found Figure 0.1 I was part of a larger discourse of curiosity and concern that needed to reject silence and embrace the outness of slippery subjects and their representations.

Since finding Figure 0.1, I have travelled to archives across the United States, such as The One Institute and Archives in Los Angeles, The Lesbian HerStory Archive in Brooklyn, New York, and the New York Public Library, and have researched several international archives online, such as the Magnus Hirshfield Archive located in Berlin and the Beinecke Rare Book and Manuscript Library at Yale University, looking for photographs and stories of secret lives, of average queer folks and those I felt a kinship with. I have included images in

\footnotetext{
${ }^{2}$ https://www.leslielohman.org/exhibitions/2013/rare-and-raw.html
} 
this dissertation that were found in unlikely places, such as an ice-cream shop in Northern Ontario, where I found the Mariam Babbitt and Augusta North photographs (1899). My personal collection of found historical queer photographs is serendipitous. I haven't sought them out in any particular way, however when I find them, the affect is similar to seeing Aunt Lena's photographs for the first time. I am transfixed and spellbound. I have come to believe that it is queer magic, and that sometimes, when we are lucky, our research finds us, perhaps in multisensorial ways. Sarah Pink discusses ethnographic research in her book Situating Everyday Life. She states, "sensory ethnography attends to the mulitsensoriality of the ways in which ethnographers and research participants experience their lives and worlds, and to the tacit and unspoken as well as verbal actions and categories they use to classify and represent these to others" (34). Pink places the everyday under a new set of discourses, in which she extracts the reading of representation in phenomenological anthropology through textual analysis. She asserts:

A shift away from semiotic analysis toward analysing photographs and other representations through a theory of multisensoriality and place offers an alternative route to knowledge...this enables us to conceptualise ways to analyse the visuality of photographs in terms of their capacity to evoke multisensory experience that might be expressed or interpreted in terms of sensory categories such as visual, touch, sound, taste and smell. (35)

Photographs are central to this research because they offer invaluable insight into ideas of historical queer representation. Photographs document fashion, trends and specific points in time that can be both meaningless and meaningful. Although I am drawn to photographs that hold impact for me, I read these photographs, and key details they contain, for their socio-historical significance and their place in an unavoidably political recovery of queer visual 
culture. In Hermeneutics and the Human Sciences, Paul Ricoeur addresses dialectical problems of understanding of interpretation. He states, "To interpret is to explicate the type of being-in-the-world unfolded in front of the "text" (414). Text, in this case is an interrelationship between theory and visual culture, in which meanings are disclosed through interdependence with each other. What is seen and understood immediately requires the unfurling of time to assess and reassess photographs as I am in dialogue not only with the images but also with myself. Ricoeur points to this process by asserting:

To understand is to understand oneself in front of the text. It is not a question of imposing upon the text our finite capacity of understanding, but of exposing ourselves to the text and receiving from it an enlarged self, which would be the proposed existence corresponding in the most suitable way to the world proposed. (143)

A large part of the political meaning in the photographs I examine derives from how such images are demonstrative of broader issues of cultural homophobia and queer persistence. The concept of historical theory can be used in several different ways in cultural studies. Scholars in sexuality and history suggest that theories about historical events, and connections we attempt to make when reflecting on the past, may be predetermined by our impressions of the phenomena to be studied. In this way, we can think about theory as a hypothesis in order to create "an ability to read across periods and disciplines [which has become] more and more necessary" (Richlin 297). As my research progressed, it became clear to me that historical approaches to sexuality and gender are entrenched in heteronormative paradigms that shut down rather than produce questions regarding representation and subjectivity. The word 'no' as a determiner - 'there is no proof' or 'most certainly not' - has been consistent in this research. What is seen and what is said does not always 
correlate and vice versa. This dissertation has its origins in several years of looking, questioning, remaining curious and not taking no for an answer. 'No' as a discursive barricade to queer knowledge is part of the very testimony of queerness, we take 'no' and transform it into a site of resistance through persistence and our survival. Heterosexist assumptions about queerness often utilize 'facts' against us. For example, marriage and children have been historically employed to erase queer history. David Deitcher addresses factors connected to sexual categorization and heterosexism in his book Dear Friends. He states:

Countless gay men and lesbians have been coerced into acquiescing in this conspiracy of self-denial. Given how commonplace it has been for same-sexers to lead double lives, and the force of the terror that has fueled this masquerade, universal heterosexuality seems a more convenient than fitting conclusion to draw from the matrimonial glut. (41)

An obvious example of this is Oscar Wilde, a gay man married with children. If 'married with children' is the dividing line between 'straight' and 'gay,' it ignores the historical requirements of the time period, and assumes that everyone is straight until 'proven' gay. This approach to discourse, sexuality, and the production of photographic images closes the door to human complexity because, as I argue, such questions are inextricably bound to the assumption of heteronormativity and ignore the significance and value of symbolic defiance.

I have brought together a cross-section of discourses intended to explore political subjectivities in visual culture. This research uses an intersectional approach to critical theory and historical analysis in order to describe the ways in which oppressive institutions (racism, sexism, homophobia, transphobia, classism, etc.) are interconnected and cannot be examined separately from one 
another. In Mapping the Margins: Intersectionality, Identity Politics, and Violence Against Women of Color, Kimberlé Crenshaw discusses how critical theories, especially Feminist theory, draw on "shared experience" (2141) as a site of strength where the political demands of many can "speak more powerfully than a few isolated voices" (2141) when discussing systematic oppression. Cultural Studies as a field usefully provides methodological approaches to critical thinking as an "an interlocking set of leftist intellectual and political practices" (Rodman 345) that can bridge the historical and the contemporaneous by examining how "social power works to exclude or marginalize those who are different" (Crenshaw 1242). Within these paradigms of social power and erasure, I specifically examine queer representation as a site of social control, and how such regulatory systems, which were set out to squelch sexual and engendered difference have persevered. Persistence is at the heart of this research, whereby against the odds of hegemonic political powers, queerness in all its slippery, evasive, hard-to-find, hard-to-prove-ness, can still not only be recovered but is a locus of continual recuperation in both verbal and visual discourse. Where there are political powers aimed to erase queer history, there are those that incite political power through their life stories, photographs and their sheer existence.

By investigating archival material with a specific focus on queer history and photography, I illustrate how our affective lives are saturated with political meaning. What began as curiosity with my great-aunt's photographs has developed and influenced my path as a thinker, and through a long process of searching, reading, analysis and research I aim to contribute to the broader field of queer pedagogy. For queers, education and access to historical knowledge is complex and challenging to attain. I examine the reasons for this as involving issues of regulation, legislation and historical violence. Particular 
focus is placed on regulatory enforcement of sexuality in the long-nineteenth century as a location of what Michel Foucault calls "the invention of homosexuality" $(1977,101)$ and how its invention became a site to designate 'normalized' sexuality versus 'deviant' desire. By creating sites of difference and implementing legislation to combat historical queerness, the social sciences and sexology were institutional tools of 'truth' in the nineteenth century intended to control sexuality and to disseminate 'facts,' whereby such 'facts' could aid in the social control of queer sexualities.

I examine how the invention of homosexuality in the nineteenth century, as theorized by Foucault in The History of Sexuality, was a categorical device developed to illicit fear and activate social control. Further, I discuss how the discourse of oppression can be re-inscribed into an alternative discursive system that rejects and challenges oppressive discourses. The discussion of homosexuality as a category constituted through medicine and the social sciences demonstrates how the criminalization and public shaming of same-sex affection had far reaching components of cultural surveillance and social scrutiny (Foucault 1972, 1977). Historically, the social deviance associated with, and the criminalization of, homosexuality can be understood as occupying similar territory as racialization, misogyny, and other violent social phenomena. Siobhan Somerville in Queering The Color Line investigates the crisis of homo/heterosexual definitions in the late nineteenth century as being concurrent with conflicts over racial definition. Her examination of historical queerness and racial inequality as operating in tandem reveals the socio-political crisis of classification, where hegemonic principles of imperialism and the body collide.

In the late 1800s, sexology and most certainly eugenics and phrenology developed new categories that sought to re-envision knowledge by surveilling bodies. These categories were intended to show in 'scientific' terms what was 
outside the frame of normativity and conversely the affirm the expectations of conventionality, revealing how queerness and its regulation played a pivotal role in the construction of the social body as requiring control. The potential to provide a paradigm shift in terms of understanding queer knowledge, I argue, arises from how queer knowledge has been historically bound to the categorical force and violence of nineteenth century social sciences as well as coerced through social obligations. Suspicion of such evidence and, at times, outright disavowal of its methodologies, reflect its historical association with brutality. Evidence, as a site of truth-telling in the social sciences has been, and continue to be, used as a tactic to silence non-status quo sexualities through the historical circulation of hegemonic, patriarchal and heteronormative powers. This research takes up these concerns to expand on the discourse of queer history, in order to inform fresh understandings of legibility and meaning.

While the criminalization of homosexuality spread across the Americas and Europe, photographic practices and technologies rapidly developed during a time of overarching social and cultural change. The late 1800s was a time of unprecedented convergence between mechanical reproduction and the invention of homosexuality (Somerville 2000, McClintock 1995). The advent of inexpensive and accessible mechanical reproduction made it possible for the apparatus of photography to be complicit in the categorization and repression of homosexuality as well as a site of subversion of the status quo. What role did photography play in the dual positioning of repression in early social sciences and categorization, and the social implications of early queer representation?

Examining historical queer visual culture under such conditions is complicated by social and theoretical paradigms utilized to discredit queer history, and to hinder its reclamation. My approach to these concerns is to interrogate the notion of desire and sexuality beyond straight or gay toward 
questions of symbolic defiance (Butler 1993). Regardless of the temporality of desire exposed in the discussed photographs or any validation of the subjects' biographies, the term Queer is not viewed as a fixed position of sexuality but rather as a socio-political spatial term, as in to "twist" or to tend away from the social ordering of normativity (Ahmed, Merleau-Ponty).

The two branches of phenomenology examined in this research investigate phenomenological processes in terms of philosophy, where phenomenology is described as embodied, sensitive and situated (Ahmed 2006), and in photographic theory, where the phenomenological is described as the affect of the physical order of the image (Barthes 1982). While both approaches differ in how they are discursively implemented, both branches of phenomenology consider the implications of perception, receptivity and emotional embodiment. The philosophical notion of phenomenology as sensitive and situated speaks to concepts of directionality and orientation, which are shaped by both repetition and consciousness. In terms of queerness, to twist or tend away from compulsory heterosexuality is to disorient from the social ordering of normativity, where derailment fails to orient in accordance with the status quo. What is queer orientation, and how do we find it in directionality and locality? The failure to uphold normative directionality and orientation is a politicized act formed by the repetition of negating compulsory heterosexuality (Ahmed 2006, Halberstam 2011). Because orientation relates to what surrounds it, sexual orientation can be examined as both relational and socially positioned (Merleau-Ponty 1958, Ahmed 2006).

In photo theory, phenomenology is described as the affect of the physical order of photography, i.e. the past. Because every photograph speaks of the past while simultaneously being of the present, photo theorists view this as a symbolic return of the dead. The "that-has-been" (Barthes 1982) is the eidos or 
essence of photography, thus making the photographic image an affective site (Barthes 1982, Batchen 2009). The photograph produces signs that indicate a physical resemblance (however unstable or problematic). These signs of resemblance inform an indexical relationship to the image, and for leading photo theorists; indexicality is described as embodied and carnal (Barthes 1982, Burgin 1986, Batchen 2009). As I argue, the photograph wields unusual power when examining the relationship between affect and feeling. While the pre-discursive nature of affect may produce awareness, regardless of length of time or intensity, the affect of photography is contingent on the indexicality of resemblance as well as the insistence on the past. Affect in photography can develop into an interaction or encounter that produces memories, feelings, desire, etc. My focus on this phenomenon is intended to show how photography can produce emotional responses that involve the dissemination of queer knowledge by seeking untapped, hidden or undervalued queer histories.

While disciplines dealing with these topics have opened new discourses on queer visual history, there are gaps that require further analysis. A great deal of phenomenology does not examine photography. Sara Ahmed, for example, examines phenomenology through a queer lens in order to shed light on queer conscious and embodiment. Ahmed investigates the notion of phenomenological processes as a location that requires an orientation and discusses 'queer' as derived from the Indo-European meaning, "to twist" to or from alignment. She affirms that veering from an axis of normativity is to 'queer' or usurp compulsory heterosexuality. Ahmed calls into question how objects and notions of perception are shaped through philosophical methods, asserting that queer desire is a turning away or derailment of the straight line of hegemonic social ordering. Yet these concepts, in spite of their helpfulness, have not been extended to queer representation in photography. My research 
takes into account the complexities of embodiment in the photograph to reveal how queer visual culture can be understood.

For Roland Barthes, reading photographs is indeed a phenomenological process permeated with affective conditions. He examines the fundamental roles of emotion and subjectivity in the experience of photography by defining an irreducible singularity of the photographic image, which he calls, "that-hasbeen" (77). Barthes relates the phenomenological with the photographic canon, yet he evades notions of sexuality and the impact of photography on queer history. Barthes's notion of "that-has-been" and his concept of "punctum" (4546) as an emotional hook to the image offer my research an invaluable theoretical foundation, but one that also needs to be rethought in terms of queer knowledge and its histories.

Photo theorists such as Geoffrey Batchen and Shawn Michelle Smith address the historical role of photography as mediating social relations, and its function in performativity at the turn of the century. For Batchen, nineteenthcentury photographic conventions such as backdrops, props and curtains reflect ideological systems of middle class values that were displayed to connote respectability, and he reveals through his analysis the slippages between cultural economy and representation. For Smith, the convergence of scientific and commercial photography coincided with a rise in the middle class, where class distinction, gender transformation and racial re-inscription established social hierarchies in visual technologies. Smith's conceptual framework speaks to my research interest in social codifications of the body in photography, although her thoughtful analysis does not include queer representation. 
Ann McClintock and Judith Butler examine gender and sexuality through similar but different modalities. For McClintock, nineteenth century visual culture exemplified the cult of the empire. By examining fetishization of both gender and race as social discipline, the staging of social hierarchies informed the performativity of cultural signs and social spectacle. For Butler, gender and sexuality are implicated in social norms that are bound to questions of power. She states that to have a critical relation to social and cultural norms requires "an articulation of an alternative," $(2004,3)$ in order to advance agency and transformation.

In terms of queer history, photography and the archive, the work of authors such as David Deitcher, John Ibson, Thomas Waugh and Ann Cvetkovich have been helpful for my research. Deitcher looks at photographs from the long-nineteenth-century and examines the roots of transformation of romantic male friendship as involving the social relations of production and displacement of labour. While his book is key to my research because of its examination of both the development of mechanical reproduction and nonstatus quo sexuality, Deitcher focuses entirely on the male experience. Similarly, Ibson and Waugh examine photography as a complex cultural process. For Ibson, the segregation of the sexes combined with the division of labour forced the mobility of work and labour, where isolation and loneliness led to intense friendships. For Waugh, homosexuality as a category was constituted through medicine, whereby the historical social deviance of homosexuality as a crime can be understood as occupying similar territory as racialization and other violent social events. Because of the tension between subjective intimacy and social threat, Waugh confirms these images as testifying toward a site of resistance. While these authors offer important insights for my research, the absence of women in queer historical analysis confirms the meaningful nature of 
my work, which places value on the experience of women.

Ann Cvetkovich, however, analyzes queer history through archival practices with specific attention to lesbians. Cvetkovich examines the affective power of queer archives as forging emotional knowledge regarding LGBT lives. By investigating queer pedagogy and tracing the trauma of LGBT communities that have faced erasure and invisibility, she asserts that queer archives are "repositories of feeling" (Cvetkovich 7) that evoke both the past and queer durability. My research develops these concepts to elucidate how photographs of early queer representation invite deeper analysis and fresh critical discourses. Such approaches directly challenge heteronormative, patriarchal structures of both the archive and the historization of queerness. The contributions of these authors flesh out the complexities of historical injury and violence, and why queer knowledge continues to be a vital discourse.

In chapter one of this dissertation, Political Power and The Archive, the archive is discussed as a site of historical constraint, and as a symbol of power and memory. Drawing on Derrida, Sekula, Rancière and Foucault, among others, an interdisciplinary approach is taken to unpack the archive, as a location of requirements that enforces historical wounds of sublimation, yet can be a place of that challenges oppression. Such binaries between the repressive and the liberative are tied to the conditions of sexuality, gender, race and class distinction, revealing how, historically, these subjectivities have transcended violent apparatuses. Concepts laid out by Derrida in Archive Fever provide the groundwork for how archives have been historically structured. For Derrida, "gathering together" and "consignation" informs "unification, identification and classification" (10), which are examined as foundational principles of the archive. Whether successful or not, the archive as a historical site of memory and knowledge has been bound to the "hermeneutic right and competence" 
(10). Archive Fever considers how the archive is historically structured: as Derrida argues, "without control of the archive, if not memory" (4). What effects do these structures have on social control and knowledge as well as political power in histories of the oppressed? While Derrida implicitly offers a critique of hegemonic structural power, he none the less marginalizes the only feminist perspective expressed. Although Sonia Combe's (Archives Interdites, 1994) is cited in Archive Fever, her valuable contribution on archives and patriarchy is buried in a footnote. She states, "well-known historians of contemporary France [are] essentially, apart from a few exceptions, masculine" (Derrida 10, note 17). In his section "Exergue," Derrida examines the notion of the exergual, where the slice on minted coins delineates its time and place. Further, the exergue is discussed as akin to the inscription with circumcision, a site of coven that "leaves a trace of an incision right on the skin: more than one skin, at more than one age" (19). I argue that his analogy foregrounds the privileged position of both economy and corporeality, and an inscription that adheres to politics of capital and politics of masculine dominance. By contrast, women, people of colour, queers and those not operating in white male privilege, are continually footnoted and cursory throughout history, which perpetuates their erasure.

Marlene Manoff's Theories of the Archive and her analysis of Derrida's Archive Fever confirms the historically structured significance of the archive, yet lays bare the limitations of Archive Fever by exposing the calculated effectiveness of the archive as a site of hegemonic control. In the constitution of the archive, whether through law, state and regulation of socio-cultural constraints, political power, and/or cultural interpretations of that power, oppressed histories are rendered taciturn and obscure. What I have strived for in this research is to unpack and recover the hidden, damaged, forgotten and/or 'irrelevant' queer subjectivities in queer archives and public holdings- 
not in the name of triumph or exultation, but rather from a standpoint emphasizing the value of lost potentialities, and the political importance of such reclamation of the past. I believe there are issues in Derridean notions of political power and the archive that can be elucidated by a dialogue with Jacques Rancière and his concept of political power as well as Allan Sekula's work on the social body. I argue that Archive Fever metaphorically reinforces the archive with patriarchal authority by placing an emphasis on legitimacy, where social order is a nomological principle of the archive, and the rules of reasoning are embedded in notions of empire. I bridge Derrida's position on archival practices, such as "gathering together" (10) with Rancière's notion of political power in order to examine the sanctioning of the state, and resistance to heteronormative and patriarchal structures of dominance. Jacques Rancière's Ten Thesis on Politics provide concepts of the "axiomatic of domination" (23) and the "logic of the Arkhé" (23) to flesh out important ideas examined by both Derrida and Allan Sekula, particularly involving state power. Sekula unpacks the significance of nineteenth century social sciences and archival practices while providing context for the creation and invention of the social body. The social body was the triumph of bourgeois order, where the political economy of industrialism, capitalism and imperialism were entwined with the individual and the state, and where sexual conduct was converted to economic and political behaviour. Within the often-divergent ways cultural studies can be employed, this research discusses notions of knowledge, history and meaning making through a politicized paradigm in which "there is no such thing as a politically neutral" (Rodman 343). This concept of politicization is fundamental to this work as neutrality has been part of hegemonic systems intended to control, whereby the body became a site of social regulation during massive industrialization, and the notion of 'truth' and its manifestations on the 
body became culturally realized through systematic ideologies.

In chapter one of The Body and The Archive, Sekula examines the bureaucracies of surveillance and control as institutional systems. By the nineteenth century there were two strategies aimed towards gaining control over both the archive and social behaviour. Historical violence in the archive functioned primarily in two ways. The first was the cataloguing of criminals, slaves and hysterical women to protect the imperatives of the bourgeoisie, where citizens were able to see and promote the rationalization of 'the other'. Second is the material logic of the archive, where the tools of the archive, such as photography, index cards and the filing cabinet, created organization and logic of order. These instruments of science and knowledge revolved around concepts of nation-building, stability and control, and are considered in regards to state power.

By examining the work of Allan Sekula's The Body and The Archive along side other thinkers, I attempt to reveal the cultural crisis in the taxonomy of classification in the nineteenth century, and why this crisis continues to affect queer knowledge. Sexuality, gender and race in the nineteenth century were based on complex ideological positions, whereby socially constructed boundaries of sexuality, gender and race were embedded in an anxious effort to control language and representation. These controls have been manifested not only in law, state and industrialization, but have been enforced with social regulations where the archive was not simply a placeholder of power, but an aid to ideological systems of cultural value that were socially internalized.

The invention and categorization of sexuality and its regulation has direct correlation to the classification of gender and race at the turn of the century. The advent of photography is a historically significant, cultural moment that intersected with ideological classification, yet created an innovative site of 
cultural change. For those involved in same-sex affection or non-normative sexuality, the relationship to these technologies had potentially layered and coded meanings. The social construction of homosexuality and the significance of inexpensive and accessible mechanical reproduction reveal the apparatus of photography as implicit to the categorization and repression of homosexuality as well as a site of subversion of the status quo. What are the impacts of such a history on the social implications of early queer representation? Through the analysis of both the social conditions that formed discourses of homosexuality, and Industrialism's development of photography in the late nineteenth century, I show how the duality between oppressive laws and social change leads to a cultural upheaval in taxonomy, visibility and representation that is important for queer visual history. My research considers the implications of these factors for early photographic practices and archival queer visual culture, from the late 1800 s into the early twentieth century.

The complexity of uncovering queer history speaks to a variety of tactics necessary for survival. The historical evidence of concealed, hidden and double lives of same-sex affection has placed queer history in a precarious and obscure position that requires further scholarship and research. To understand why queer history can be opaque and challenging to uncover, it is important to note that the invention of homosexuality was a categorical device meant to control, regulate and generate fear. The proliferation of categorical research by sexologists of the time period, and the debate around homosexuality informs how this early discourse not only became institutionalized by medical devices and enforced by laws, but also how these discourses were socially maintained. These concerns are approached through Foucauldian analysis of "reverse discourse," (1977 101) where coerced social imperatives of control, in order to demand normativity, can be challenged. The alternative paradigm to the 
heteronormative institutionalization of history functions through power struggles of control, to discursive revolt where "homosexuality began to speak in its own behalf" (Foucault 101).

Foucauldian methods in the discursive power of knowledge and memory whereby top-down power can establish reverse discourses are invaluable to queer epistemologies. This chapter considers how reverse discourse operates relationally to hegemonic power, yet functions as a refusal of oppressive power structures. Heather Love's Feeling Backwards takes up this paradigm by suggesting that reverse discourse is predicated on embracing the wounds of a queer past. Love considers Foucauldian analysis of reverse discourse as a call to move beyond the structural forms of power and a disavowal of historical pain that paralyzes, to a political model that adopts a violent past and its injuries as a site of resistance.

The final section of chapter one, Queer Archives, attempts to show how the historical advancement of social control has been recouped by political imperatives of social justice and visibility, through a re-constitution of 'unification' that recognizes violent history by empowering queer voices that have been silenced. Historical wounds of homophobia are examined as shifting from secrecy, the hidden or forgotten, to non-secrecy and accessibility as revealed by case studies such as The Lesbian HerStory Archives in Brooklyn, NY, or the GLBT Historical Society in San Francisco, CA. It is due to historical erasure that creating archives of those forgotten, unnamed or oppressed speaks to the significance of queer archives and value of collective memory. By reclaiming a queer past, I embrace Love's proposal that feeling backwards is a position that resists capitalist, imperialist and neoliberalist notions of 'progress.' Rather than propel queer thought into the consistent ideologies of 'the cult of the new,' let us look back, not to revel in pain, but to participate in histories that 
have been overlooked.

Queerness needs to be a political tool that challenges the historical record from a position of marginalization and exclusion, towards a unification constituted by shared critical concerns. This strategy is part and parcel of how critical and cultural studies functions "to intervene productively in social, cultural, and political struggles in the larger world, especially... on behalf of (or alongside) those... who are unjustly disenfranchised, oppressed, and/or silenced" (Rodman 345). Here we can understand how the 'reverse discourse' of queer history as argued by Heather Love reflects "politics forged in the image of exile, of refusal, even of failure" (71), which offers this research a significant stake in persistence and survival. Mabel Hampton (sourced from the Lesbian Herstory Archive, NY) is a case study for this chapter, where I argue that her existence and survival were tangled into historical violence of racialization, classism and homophobia. Hampton offers symbolic political power and defiance that may not dissolve trauma but can act as a visual symbol of persistence. Where a past is violent, there is also persistence.

Ann Cvetkovich explores issues of historical trauma and erasure in An Archive of Feelings by examining queer emotional knowledge in archival practices, where loss and suffering are not the end of the line but allow for a kind of mapping of queer communities. While she acknowledges the erasure and invisibility faced by historical representations of queerness, she asserts that queer archives preserve histories of traumatic loss that support queer memory. Queer archives, although not utopian spaces provide a site of memory that historically has been entrenched in prohibition, silence, violence and erasure. Cvetkovich examines the affective power of queer archives as forging emotional knowledge in LGBT lives; my research further expands on these concepts to elucidate how photographs of early queer representation 
require deeper analysis and critical discourse.

Archives provide rich sources of information yet produce their own problems as well. Everything housed in a city or state archive is not heterosexual, conversely, everything housed in a queer archive, such as The Lesbian HerStory Archives is not ironclad queer. I am not seeking the 'truth' of the subjects or aligning myself with a grand narrative of people's lives, rather I aim to examine photographs that push at the boundaries of a queer history that can be inclusive of ordinary people without simply reinvigorating the 'Queer Art' canon. This is necessary in order to create a broader field of queer knowledge that can operate alongside historically famous queer lives, but is not solely contingent on them. The goal of chapter one is to create a location of intersectionality between historic violence against queer bodies, and its potential reclamation for queer futurities. The notion of intersectionality is bound to cultural patterns of oppression, particularly in black feminist thought ${ }^{3}$. In terms of archives, I unpack examples of how historical archival practices upheld dominant approaches to queer bodies, and how that violence and subordination can shift, most notably with the archival approach of the Lesbian Herstory Archive, where radical feminism recognizes interlocking and systematic oppression. My case study of Mabel Hampton, of a black lesbian woman who overcame cultural, social and economic brutality, reveals how "demands [for] change that do not reflect... dominant ideology... will probably be ineffective (Crenshaw 1367, footnote 3). Heterosexism, much like misogyny, racism and ablism are so deeply entrenched in culture and our consciousness that to fight against them requires political engagement. The key to this work is reflectivity that is action based.

${ }^{3}$ Patricia Hill Collins. Black Feminist Thought: Knowledge, Consciousness and the Politics of Empowerment, Routledge, 2008 
By examining the archive as a site of inscription for visibility versus silence, the photograph and early photographic processes allow for a closer look at representation and historical details of time and place. In chapter two, Early Photography and Queerness, I tackle the divide between discursive technology and representation by examining the social conditions of same-sex affection and mass production in the nineteenth century. This chapter consists of three parts: Industrialization and Photography, which looks at the 'cult of the empire' as produced through photography and the processes in which industrialization and empire were imaged; Queering Conventions, which examines how queer subjectivity both subverted and acquiesced to dominate photographic structures; and Representing Politically, which places photographic representation and subversive queer subjectivity as a site of active political engagement.

Chris Brickell examines two photograph albums gathered by Robert Gant in New Zealand during the 1880s. In his text, Visualizing Homoeroticism: The Photographs of Robert Gant, 1887-1892, Brickell addresses how early photography provided a complex site where unnamable sexuality could take shape. He states:

Visual sources can show us much about the relationship between individual lives and cultural worlds in a range of times and places; they are valuable resources with which to address questions of subjectivity, including sexual self-understanding, where the worlds of meaning on which they draw are deeply social as well as profoundly personal. (137)

Symbolic codes gesticulate towards forming networks where hidden meanings could be read by 'those in the know'. Such photographs provide "culturally conditioned visual communication systems" (Ruby 67) that allowed unnamable sexuality to speak. Brickell discusses this process in regards to 
Robert Gant's (1887-1892) photographs as:

Tell[ing] us something about masculinity, desire and longing in the past; of intimacy, romance and eros. In the absence of a rich vocabulary, visual representations allowed Robert Gant to codify and express same sex desires. A homoerotic sensibility emerged through the manipulation of ideas about male comradeship, embodiment and eroticism, and their subjection to a homosexually inclined gaze. (Brickell 152)

The cultural artefacts of early photographic practices index complex cultural processes. For those involved in same-sex affection, such cultural codes teeter between intimacy and memory, and social threat. Photography played a pivotal role in the dissemination of data collection involving the social sciences. This included a vast array of ethnographies informed by race, class, sexuality, gender and criminology. The body as a site of social regulation collided with massive industrialization, and corporeal manifestations became culturally discursive through systematic ideologies. I am particularly drawn to carte-de-visites, cabinet cards and albumen prints, as a location of mass culture and representation. However, other photographic processes, such as black and white photography, are not necessarily excluded as examples of photographic practices that are informed (and inform) this important period of change.

Part one, Industrialization and Photography, examines the role played by conventions of photography and the construction of normativity. The long nineteenth century provides for a rich debate about mass production and the industrialisation of picture-taking and its dissemination, and how the cult of the empire shaped the conventions of portraiture. Carte-de-visites of the long nineteenth century were the products of an accessible photographic technology that allowed for multiples of a single image. Because costs were relatively low 
and studio photographers were readily available, carte-de-visites were the business cards of their day. While carte-de-visites followed formulaic conventions of imperialist traditions, this research shows subjects busting out of conventionality and rupturing normativity through gender performativity, samesex affection and roused racialized subjectivity. The value in this is to illustrate how photographic procedures can potentially give voice to alterity and sexual difference. By seizing conventions of photographic practices, and utilizing the traditions informed by mass production, queer subjectivities subvert and transform the cult of the empire into visible queer history.

Geoffrey Batchen's research offers insight into the industrialization of photography and its function in modernity and early capitalism through the materiality of the photograph. The cult of the empire is discussed as a fetishization of social discipline, whereby the staging of social hierarchies informed cultural signs of social spectacle. Shawn Michelle Smith addresses the historical role of photography as mediating social relations, and its function in performativity at the turn of the twentieth century. For Batchen, photographic conventions were the ideological markers of bourgeois values that were intentionally displayed to connote respectability, revealing disparities between cultural economy and representation. For Smith, the convergence of scientific and commercial photography established social hierarchies in visual technologies. Although her meticulous analysis does not include queer representation, Smith's conceptual framework speaks to my broader concerns with the social codifications of the body in photography.

Part two of this chapter, Queering Conventions, discusses the nature of early photography in relation to queer subjects. David Deitcher considers romantic friendship in the nineteenth century as correlated with the social relations of industrial capitalism. Industrial production required the physical 
proximity of workers, where the mechanization of labour intensified divisions of labour that fragmented lives across continuums of gender, class and race. Case studies for this chapter include Bonnie and Semoura Clark, sourced from Beinecke Rare Book and Manuscript Library at Yale University, providing archival findings of African-American performers and queerness. My interest in the images of Bonnie and Semoura Clark is in how the conventions of industrial capitalism and bourgeois tropes of class are both employed in the photograph as well as superseded conventions through gender, race and sexuality. Due to the challenges in finding photographs of people of colour that are engaged in themes of 'queerness' from the long nineteenth century, I have broadened my scope in order to include images of Bonnie and Semoura Clark to ensure the inclusion of queer racialized representations in this research.

Representing Politically, the third and final part of chapter two, addresses issues of knowability and presence in photography. I examine Barry Goldstein's text Every Photograph Lies, which implies that the photograph speaks of nothing more than deception. While photography does not always authenticate reality, it does represent and document a temporal moment. My interest is not in determining the 'truth' of subjectivity but rather in photography's ability to capture a moment in time, and how intentionality reveals a broader spectrum of visual history. The temporality of the medium is where photography's indexicality or ability to point towards a subject simultaneously conjures both the presence of a subject/moment and the absence of hard truth. My method in dealing with such binaries that imbue photography is through the interdisciplinary approach of cultural studies where the "impulse is to examine the object in ways that... approximate the complex nature of its existence and the intricate network of mutually determining relationship with the larger world" (Rodman 348). Further, we may turn to Mieke Bal who views visual culture as 
both in and outside of other disciplines, yet states that studying "'visual culture' carries over - from one of the dogmatic elements of its predecessor and antagonist - the 'history' element of art history" (6). This argument adds valid tensions to the study and research on visual culture as a site of what Bal calls "visual essentialism" (6). ${ }^{4}$

Photo historian John Tagg suggests that the "invention of means of cheap and unlimited photomechanical reproduction transformed the status and economy of image-making methods" (60) through institutional and social ideologies that became "techniques and procedures for extracting and evaluating truth in discourse" (60). Tagg asserts that the highly coded methods of representation in photography at this time could never be impartial due to its relationality to other apparatuses of state power. I argue that in many cases of historical queer subjectivity, it is less a burden of representation that requires criticality as much as it is 'the burden of lack of representation,' as many have acquiesced to remain in the shadows due to systemic brutality.

In Camera Lucida, Roland Barthes examines the fundamental roles of emotion and subjectivity in the experience of photography by defining an irreducible singularity of the photographic image, which he calls the "that-hasbeen." Barthes relates the phenomenological with the photographic canon, yet as mentioned above, he evades notions of sexuality and the impact of photography on queer history. Barthes's notion of "that-has-been" along with his

\footnotetext{
4 The context of Bal's quote about "visual essentialism" is linked further to Roland Barthes and his position on interdisciplinarity. "Roland Barthes, one of the heroes of cultural studies, that other direct ascendant of visual culture, wrote about interdisciplinarity in a way that distinguished that concept sharply from its more popular parasynonym 'multidisciplinarity'. In order to do interdisciplinary work, he cautioned, it is not enough to take a 'subject' (theme) and group several disciplines around it, each of which approaches the same subject differently. Interdisciplinary study consists of creating a new object that belongs to no one." (Bal 7)
} 
concepts of "punctum," the subjective "pierce" of the photographic image and "studium," the cultural inscription of photography, requires rethinking in terms of queer pedagogy and social justice. I examine some oversights in Camera Lucida, particularly involving race. In the re-examination of James VanDerZee's Family Portrait photograph from 1926, I explore important issues of reading race, class and social expectation. Although these issues aren't queer per se, they involve a queer politic of anti-oppression that requires our critical attention. This example works usefully to extend my discussion of cultural inscription undertaken by photography, and the problems and possibilities for interpretation.

My intention in investigating some problems in Camera Lucida is in no way to discredit the significant contribution of Barthes's work. Rather, my intentions are to explore the limits of his theory of punctum, and how affect theory may offer political strategies to counter the messiness of representation, photography and feeling. Problems arise with Barthesian approaches to punctum when race and class are involved, where the affective quality of punctum and the cultural inscription of studium collide. The question of race eludes Barthes, in my view due to the weight of his grief losing his mother; punctum is given too much individual permission, overlooking political signification.

In The Emancipated Spectator, Jacques Rancière comments on Camera Lucida by analyzing the condition of "indeterminacy" (113) and Barthes's "detachable elements" (111) of punctum and studium as producing a "shortcircuit between the past of the image and the image of death" (113). As affirmed by Rancière, "according to Barthes, the subject who views must repudiate all knowledge, all reference to that which in the image is an object of knowledge, in order to allow the affect of transport to be generated" (110). By 
positing punctum and studium as only a system of binaries, Barthes neutralizes elements of politicization, descriptive knowledge and meaningful inscription from historical photographs. The case studies for this section are drawn from my personal collection of found photographs of Augustine North and Mariam Babbitt from Northern Ontario in 1899. These allow for, what Rancière calls "the material rearrangements of signs and images, relationships between what is seen and what is said, between what is done and what can be done" (39). What is seen/said and what is/can be done are explored through notions of the political subject as a location for articulation and discourse.

Affect and its methodologies are thoroughly discussed in chapter three, Political Emotions and Feeling, where investigations of queer affect provide a methodological approach to understanding queer as both a disputed and locally conditional term. The investigation of queer affect and its methodologies pays close attention to the intersections of queerness as not simply a scholarly, conceptual or theoretical approach, but alive with a steadfastly political perspective. Chapter three is broken into four sections: Episteme of Queer and its Discourses, Queer Phenomenology and Orientation, Affect and Misalignment and Queer Punctum. While the focus of chapter three remains firmly in philosophical approaches of affect and phenomenology, cultural materialism informs this research with a pointed and critical political paradigm with regards to photographic and archival practices. This position is vital to the historicization of queer representation and potential knowledge, as well as informs broad contemporary debates and concerns in queer communities. Orientation as a political paradigm for envisioning difference is investigated through the phenomenological processes of embodiment, sensitivity and situated-ness. 
In Episteme of Queer and its Discourses, discourse is examined through Judith Butler's investigation of queer as a "paralyzing slur" (Butler 138), Michel Foucault's notion of the "sayable/seeable" (Grossberg 314) and through Raymond Williams' concept of the "articulatable/livable" (Williams 318). Here, I examine how such phenomena are both very real yet socially constructed. These three sets of concepts; "paralyzing slurs," the "sayable/seeable" and the "articulatable/livable" provide the groundwork for examining discursive systems that can subjugate and/or liberate. Articulation in this dissertation is intended to be understood both as "an attempt to explain how something that seems ethereal and ephemeral—language, discourse, media representation can...acquire...solidity and stability to have...consequences in the material world" (Rodman 349). Cultural studies takes up these concerns by suggesting that we are not simply represented by discourse but constructed through and by it. As stated by Stuart Hall, "articulation is thus the form of the connection that can make unity of two different elements, under certain conditions. It is a linkage which is not necessary, determined, absolute and essential for all time" (53). The complexities of these issues reside in the public and private nature of discourse, its relationality to the world, and how under even the most violent language, discourse can be recouped and reinscribed with empowered meaning.

The second section, Queer Phenomenology, takes up Sara Ahmed's argument that the emergence of the term sexual orientation coincides with the production of the homosexual as a type of person who "deviates" from heterosexuality (65). To deviate from the straight line of social ordering is to pervert normative structures of the status quo, thereby queering it. By not following the straight line of social ordering, the "queer effect" (66) disorients or tends away from compulsory heterosexuality. As discussed in this section, the 
episteme of queer was originally a spatial term, meaning to twist or bend, that became a socialized term, mostly notably at the trial of Oscar Wilde. Ahmed further elaborates on the slanted line of queerness by examining lesbian contingency as "tending toward other women" (102), as both a social experience and lesbian desire. The orientation of compulsory social ordering is challenged through cultural and social deviation of verbal and non-verbal discourse, and specially includes visual discourses.

In the third section of chapter three, Orientation, Affect and Misalignment, I bridge thought and action through a politicizing of affectation. By advocating for affects as corresponding with "the messiness of the experiential, the unfolding bodies into worlds" (Ahmed 30), as well as with "proximity" (32), "Iocation" (33) and "orientation" (35), I examine how derailing from the straight line of social ordering is to steer away from compulsory heterosexuality, thus informing the political potential of orientation. This dissertation seeks to challenge normativity in terms of queer historical representation and to destabilize power relations set out to expunge complex and contested histories. While Kath Browne and Catherine J. Nash decline to create terms to define queerness in their book Queer Methodologies, I offer context beyond hetero/homonormative binaries, and to explore how queerness is contingent on affect, and how affect and phenomenology are valuable sites for developing queer knowledge.

The final section of this chapter, Queer Punctum, addresses the problems the affective quality of punctum by suggesting that through the collision of cultural inscriptions (studium) and affect (punctum) that queer feelings arise. I propose that this collision of affect and cultural knowledge offers an invaluable site for the recuperation of queer political feelings. In fact, the collision offers a new stratum of feeling queerly that rejects the binary opposition 
of punctum (feeling) and studium (inscription). Here emerges what I call "Queer Punctum," a potential site of feeling and political engagement that extends beyond personal grief and mourning loss to activate queer knowledge.

Queer Punctum, as I argue, requires this collapse to augment the commitment to inclusivity, queer knowledge, and its critical discourses. Queer history has and will continue to embody a mass diversity of race, gender, class distinctions and sexual practices. If we consider the ever-growing acronym of LBGTTQQIA2, ${ }^{5}$ access and commitment to articulation is a political foundation of the derailment from the straight line of social ordering. How can punctum and affect articulate queer feelings, and how can we understand the differences between affect theory and punctum? I argue that Queer Punctum is the sociopolitical, oblique, skewed, off-centre line of lived experience that is manifested in the reading of photographs. Queer Punctum is the photographic wound of the specific that strays from hegemonic social ordering and reinscribes the burden of the non-status quo into politicized emotions that signals queer embodied knowledge. Queer Punctum reveals the socio-cultural manifestations of historical knowledge, whereby interpretations can be constituted through prediscursive sensation into potential political action.

Queer Punctum asks the photographic image to feel thought and to think through feeling, thus, providing punctum with a political paradigm that acknowledges sexual difference and understands its historical complexity, while seizing the impact of such discourses on queer futurities. Feeling meaning in photography through the ever-changing landscape of language and cultural knowledge collapses differences between studium and punctum. By revealing that studium and punctum are contingent upon each other, a political

${ }^{5}$ Lesbian, Gay, Bisexual, Transgender, Transsexual, Queer, Questioning, Intersexed, Asexual, Two-Spirited. 
engagement is forged between the affective site of photography and the emotional flesh and blood of queer history.

By placing Sara Ahmed's notion of situating oneself and one's relationship to "orientation" (68-70) and Roland Barthes's notion of "punctum" (44-46) in dialogue with each other, I attempt to bridge gaps between sociocultural manifestations and historical knowledge of queerness. Orientation and the notion of tending toward one thing over another are examined as a politicization of historical queerness. By allowing for orienting oneself off centre, or off the beaten track of normativity, photography is explored as a visualization of political meaning. How we view the world, navigate it, and the choices we make, are for all intents and purposes, political. By suggesting that our experiences and sensations are not simply founded on what is in front of us but what is also around and behind us, this chapter seeks to broaden the field of queer methodologies. Photography is examined as a location of queer political feeling, whereby historical knowledge is mined from both philosophical concepts and close readings of photographs.

The case studies examined for this final chapter reveal "an inventory of shimmers" (Seigworth and Gregg 1) that show the affectations of reading, feeling and encountering queer visual history. The truth of a subject's sexuality, desire and/or lifestyle is not the concern of this research. Rather, queer embodiment is examined as a state of becoming. As stated by Judith Butler, "the queer movement was anti-institutional with a critique to normalization: that you don't have to be normal to become legitimate, ${ }^{6}$, reveals that queerness is not static but in flux, forever changing with and against the tides of culture, hegemony and notions of power. Queer bodies function in-between binaries of

${ }^{6}$ Butler, Judith and Regina Michalik (Interviewer). "The Desire for Philosophy. Interview with Judith Butler." Lola Press. May 2001. 
gender and sexuality that become over time, through time and/or against time.

The in-between-ness of queerness is a political embodiment that positions itself in relation to the world around itself. The affectations of this relationality are through both how we orient ourselves, and the forces of such encounters. I discuss two archived images by Alice Austen, 1866-1952 (from The Alice Austen Historical Society in Staten Island, NY) as case studies to extend Sara Ahmed's concept of orientation and tending away from compulsory heterosexuality, and Barthes's ideas about being pierced or wounded by an image.

By claiming that the subjective is always oriented and affectual, the status quo of sexuality and gender is challenged, thus allowing for broader terms in uncovering queer history and understanding queer futurities. The experience of photography as not distinct from our affective lives reveals a methodology of emotional knowledge. The examination of how visual culture, particularly photographic practices are entwined with queer history, affect and knowledge is explored as part of how we orient ourselves. This pathway to emotional knowledge is inspired by Kath Browne and Catherine J. Nash book Queer Methods and Methodologies where they state:

There is, in fact, no 'queer method,' in the sense that 'queer' lives can be addressed through a plethora of methods, and all methods can be put to the task of questioning normativities - a political positioning that infuses research processes with ethical considerations. In particular, where queer is taken to destabilize particular understandings of the nature of the human subject and subjectivities, power relations, the nature of knowledge and the manner of its production, a 'queering' of methods themselves might pose particular difficulties as well as possibilities for traditional data collection methods. (12) 
Kath Browne and Catherine J. Nash offer valid arguments in regards to contemporary gayness within "neoliberal privatised norms" (6). Their argument in terms of privilege and "the increasing political and social assimilation of some lesbians and gay men" (6) reveals that such legislative gains in fact "privilege certain forms of 'homosexual' expression and regulates bodies and practices within; closing off contestation of normativities themselves" (6). Further, they state, "gay marriage is read as a homonormative institution that regulates, normalizes and assimilates same-sex couples, valuing monogamous 'wealthy' couples over other forms of queer kinship" (6). These disputes point out that the homonormative/queer binary neglects how we are all complicit in the reproduction of power relations.

I place several theorists in dialogue with each other to elucidate and expand on their concepts as well as flesh out new perspectives through crosspollination. My interdisciplinarity takes up cultural theory, photo theory, archival theories, queer theory, and phenomenology and affect theory. As stated by Halberstam, I have intentionally attempted "to combine methods that are often cast as being at odds with each other" $(1998,13)$. Methodologies as a set of rules and procedures of investigation refer to qualitative research, yet queer method, much like cultural studies, deliberately challenges coherence and reliability because of its rejection of stable forces. If as stated by Browne and Nash in Queer Methods and Methodologies, there is, "in fact, no 'queer method,' (38) then how do I employ a methodology that has no method, refuses disciplinary coherence and rejects truth? First and foremost, there is no reconciliation for all queer peoples to fundamentally agree on A Queer Method. For this reason, there is suspicion of its possible limits as boundaries could produce the exclusion of genders, sexualities, etc. However, my approach to Queer Method and Affect Theory is to intersect conceptual and theoretical 
approaches of how the political left and anti-oppression can function in time and space.

These destabilized approaches of queer methodologies offer my research principles associated with queer conceptualizations of knowledge. By consciously seeking to articulate anti-normative frameworks that share a focus with several scholars, including feminist, gay/lesbian, anti-racist and postcolonial thought, 'queer' as a theoretical approach provides a political perspective in the "assemblage of practices of the self" (Browne and Nash, 8). Yet, as queer theory scholars have argued, "queer subjects and subjectivities are fluid, unstable and perpetually becoming," whereby to understand "queer as a contested and locationally contingent term" (4) has come to be central in the underpinnings of queer theory. Rather than avoid the messiness and instability of these complex issues, my research is positioned within conceptual frameworks that highlight such instabilities and "taken-for-granted meanings and resulting power relations" (Browne and Nash, 4).

My approach to the discussion of the images in this dissertation is interdisciplinary, whereby various pedagogies, particularly the interpretive tradition within cultural studies helps inform the overall model of examination. The goal toward understanding historical photographs is examined, particularly in this chapter as inter-relational, where "the moment of 'understanding' corresponds dialectically to being in a situation: it is the projection of our own most possibilities at the very heart of the situations in which we find ourselves" (Ricoeur 142). For example, in the analysis of Alice Austen's photographs, attention and thick description are used to examine the content of the actual pictures, in the way art historians consider pictorial representation, yet social aspects of politics and cultural developments are observed to understand the broader significance of representation, which is closer methodologically to the 
field of Cultural Studies. My approach to social history, culture and politics is intersubjective, which can be understood as an overlap that on one hand rejects the idea that a "completely objective and unbiased understanding of the world is possible" (Rodman 348), yet on the other recognizes there is a real world. Context places research into several avenues that can, and must be renegotiated and re-evaluated over time, which can challenge dominant and historical power, as stated by Gilbert B. Rodman:

The cultural studies scholar recognizes that the very same historical facts can be stitched together to create very different stories depending on the context(s) in which the scholar chooses to place those facts... and that there are always a multiplicity of 'legitimate' contexts available for the scholar to chose from. (350)

My analysis takes this one step further by reflecting on philosophical paradigms of theory to expand on the locations of implication and value. Additionally, my method is inclusive of feminist paradigms that trouble, challenge and investigate systems of power, hegemony and patriarchy. Interdisciplinary approaches to image, thought and meaning, in this research, are inextricably and actively tied to social history and materiality as relational, and how these connections are made and where they can be remade. Such claims are intended to show complexity and contingency on what cultural studies refers to as "radical contextualism," which in the case of this particular work, at this moment in time, views as action and expression relative to context, and context as a "multidimensional concept" (Barthes 1986 53).

I seek to unpack power relations in regards to how social activities like photography are evocative of their time, and how notions of the social are saturated with the humanness of thinking and feeling. As asserted by Annette Kuhn in Family Secrets: Acts of Memory and Imagination, "memories evoked by 
a photo do not simply spring out of the image itself, but are generated in a network, an intertext, of discourses that shift between past and present, spectator and image, and between all these and cultural contexts, historical moments" (12). Such networks and discourses between photography and the social are entangled in a matrix of oppression and liberation. As stated by H.G Cocks, biopolitics in the nineteenth century had created a modern vernacular for sexual perversion in 1885, masochism, sadism and paedophilia, all in 1890 into distinct types, each requiring specialists to study, cure and/or punish. Cocks states, "sexuality as a way of knowing ('the will to knowledge') coalesced in particular ways of thinking, acting and being, an apparatus of thought and action that functions through discourse" (43) were implicated into photographic practice. However, sets of administrative processes intended to protect nations and statehoods in the rise of biopower and disseminating what Foucault called scientia sexualis also informed alterity. Photography could also be a tool for queer memory. As Brickell asserts about the Robert Gant photographs:

Photographs, paintings and other visual traces tell us of their makers and their audiences, and reveal contextdependent and more generally applicable themes and symbols. They also offer up antecedents, and gesture toward modes of understanding and social organization. Private photographs are also public objects, as the worlds of meaning on which they draw are deeply social as well as profoundly personal. (137)

In my research, images of affectionate men holding hands or draping themselves onto each other are far more readily available than images of women. Seeking out photographic representations of women from the long nineteenth century is challenging. While I cannot answer why this is with a definitive response, I do have theories, explanations and questions as to why this is the case, and why it is politically charged. If we consider the roles of 
women throughout history where bodies were scrutinized and socialization was segregated, women's sexuality has been either ignored or demonized. The exile of Sappho might be a starting point. When her work was first collected in the third century it filled nine volumes; today fewer than 1,000 stanzas survive. Public utterance for women has historically been inaccessible. As scholar Mary Beard points outs out that in Homer's Odyssey that Telemachus, the son of Odysseus and Penelope states, "Mother, go back up into your quarters, and take up your own work, the loom and the distaff ... speech will be the business of men, all men, and of me most of all; for mine is the power in this household." (Citation from Beard's lecture Odyssey 1, 358-9). Mary Beard points out that this example is:

A nice demonstration that right where written evidence for Western culture starts, women's voices are not being heard in the public sphere; more than that, as Homer has it, an integral part of growing up, as a man, is learning to take control of public utterance and to silence the female of the species. (From her lecture Oh Do Shut Up Dear, BBC Four March 2014)

Iconography of male desire in Greece and Rome are not only readily available, but has been taken up repeatedly throughout modern history. As Brickell notes in the images of Robert Gant:

Through these visual traces, we see something of the mutability of these lines between intimacy, friendship and sexual desire. For some of these men romantic friendship was a glue that stuck together the homoerotic and the homosocial, and Gant reinformed the connection by sometimes adopting the symbolism of ancient Greece and Rome. (154) 
This example is tied to a much larger paradigm of women's erasure from social consciousness. Menstrual blood and the medieval woman was viewed with disgust that not only infected nature, killed children and enforced misogynistic beliefs of inferiority, but also signaled a kind of evil magic, where menstruation emitted through the eyes of woman and she could blind men and children; the female body was "a disabled body, and the abject body" (Pearman 109). Helen Rodnite Lemay's book Women's Secrets examines how medieval men interpreted female body and how misogyny, particularly using Aristotelian sources, laid the groundwork for persecution of women. Aristotle's position on women and reproduction "were accepted in Western intellectual circles for at least fifteen centuries" (Parsons) ${ }^{7}$. Gerda Lerner quotes Aristotle in her book The Creation of Patriarchy, "the courage of man is shown in commanding, of a woman in obeying" (25) .

These cases are intended to give context to both why women's history is difficult to access as well as why nineteenth and twentieth century feminists are so significant to the discussion of women's erasure; we have been constructed through an endless systematic sea of secrecy. Feminists such as Mary Wollstonecraft and her text A Vindication of the Rights of Woman (1792) represented a significant call for equality and change in social attitudes towards women. Harriet Taylor's Enfranchisement of Women (1851) wrote about the inequities of family law. Since the birth of the Suffrage Movement and into second and third wave feminism, authors continue to address concerns of erasure with invaluable texts that question inequality, fight misogyny and expose systemic patriarchal violence.

7 This quotation is from an online source. See: Women's Studies Encyclopedia http://gem.greenwood.com/wse/wsePrint.jsp?id=id49

8 See Richard McKeon (ed. and trans.), The Basic Works of Aristotle (New York, 1941) 
While patriarchy and misogyny are at the heart of women's expurgation there may be other reasons for why finding images of same-sex affection of women are challenging to find. Sharon Marcus's book Between Women: Friendship, Desire, and Marriage in Victorian England addresses how women were "not included in the legal definition of sodomy and were less likely than men to be arrested for public sex acts" (13) and that Sapphic desire was tied to a woman's husband. Marcus states, "a woman's emotional and sensual connection to another woman helped unite her to her beloved husband" (15). Rich histories of women-loving-women can more readily be found in life-writing, which could take the form of unpublished diaries, memoirs and personal correspondence. Same-sex affection, romantic friendship and marriage between women could exist for Victorian women through the act of life-writing. An example that I touch on is Figure 1.15 Anne Lister (1791-1840). Although there is no photographic evidence of her queerness, I include her in chapter one as an example of "reverse discourse" (Foucault 1977, 101) in the archive. Lister was explicit about her lesbianism and sexual desire, and her writings offer valuable discourse to women's sexuality in the nineteenth century.

My aim throughout this dissertation is to examine historical issues of queer visibility through a lens of cultural theory and criticism by placing several concepts of 'the representational' in critical dialogue with each other. The limited or relatively small sample of materials that are examined in this dissertation is intended to give greater depth to each case study, and to create interpretive practices through specific examples. My approach to concerns about limited sampling is very much relational to the tension between the distance of the past and its proximity to the here-and-now. Ricoeur views interpretation as "interplay between question and answer" (107), where structure and understanding "corresponds dialectically to being in a situation" 
(142). This paradigm of interpretation is an active relationship between textual analysis of theory and how meaning can be produced in visual culture through interdisciplinarity. Further to this point, we might understand dialectical interplay between question and answer as part of the study of the visual and its relation to culture; I have chosen, over a period of time and with great thought, the small samples examined in this research, in order to aid in the clarity of method and methodology. Mieke Bal affirms this position by stating that "the object domain consists of things we can see or whose existence is motivated by their visibility; things that have a particular visuality or visual quality that addresses the social constituencies interacting with them" (2003 8).

This research hopes to harvest key concepts from authors who have inspired me, and whose work allows for the intersection of ideas and the possibility of forming new approaches. I aim to position my work within discourses that I believe are socially significant, as well as contribute to the scholarship of queer thought. 


\section{Chapter One: Political Power and the Archive}

"There is no political power without control of the archive, if not of memory." Derrida, Archive Fever.

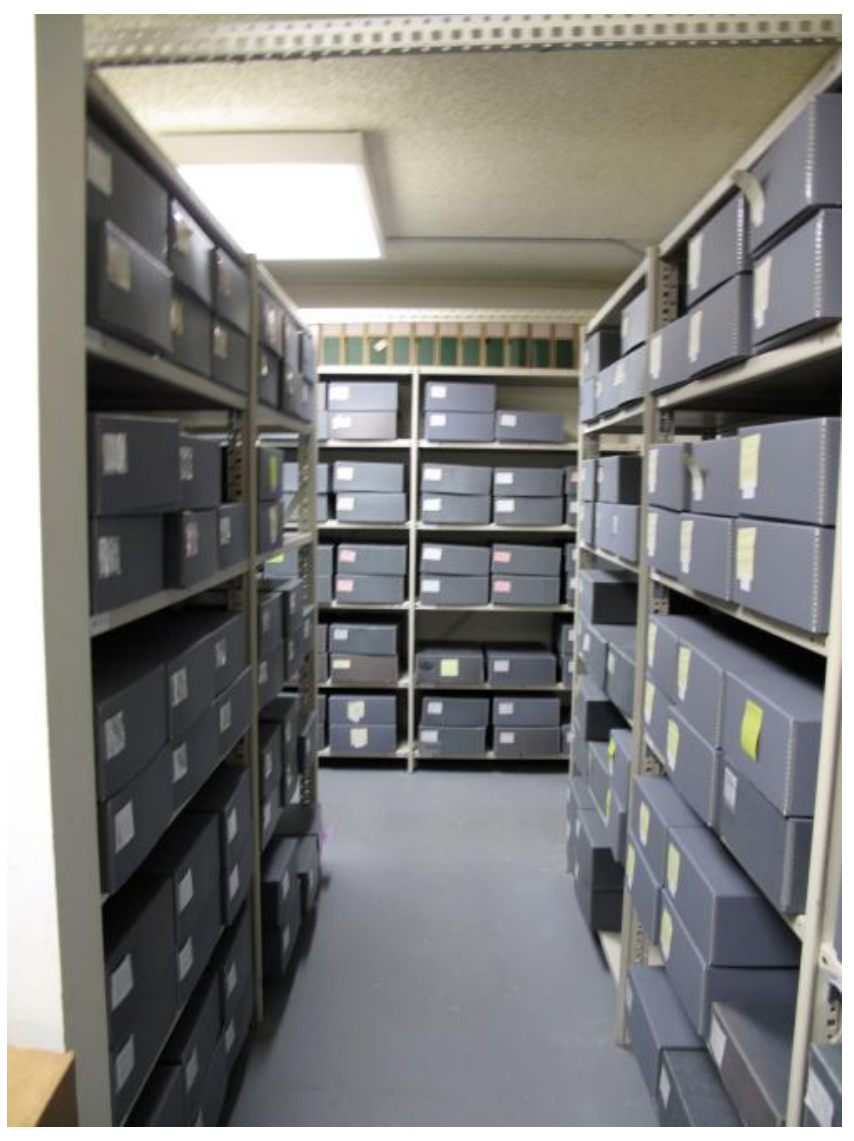

Figure 1.1

ONE National Gay and Lesbian Archives ${ }^{9}$ at the USC Libraries is the largest repository of Lesbian, Gay, Bisexual, Transgender, Queer (LGBTQ) materials in the world.

${ }^{9}$ Founded in 1952, ONE Archives currently houses over two million archival items including periodical, books, film, video and audio recordings, photographs, artworks, organizational records and personal papers. ONE Archives has been a part of the University of Southern California Libraries. 
What creates an archive? What is the difference between an institutional archive and a personal collection? How is political power bound up in the archive? And what role does intention play in the conceptual framework of an archive? The relationship between the historical production of the archive and the construction of social bodies are wounds of engendered, sexual, racial and caste violence that were informed and enforced through the nineteenth century's social sciences. While Political Power and the Archive focuses on the explosion of archival practices in the nineteenth century, the intent is not to examine specific nineteenth century archives, but rather to consider the cultural implications arising from the historical production of the archive, and the sociocultural influence on the construction of the social body, particularly of queer, gendered and racialized bodies. In the nineteenth century, sexology and most certainly eugenics and phrenology developed categories of social surveillance, whereby ideological imperatives were bound to technological articulations of truth and order. Social sciences of this time emphasized normativity, thereby enforcing conventionality through social obligations.

I investigate the effects of these historical constructions on queer pedagogy, and how these issues remain relevant to queer knowledge and thought in the twenty-first century and its futurities. For those operating on the margins or outside the status quo approaches to the archive as remembrance and visibility functioned through a lens of secrecy and complex codes due to historically imposed heteronormative, hegemonic structures. This research examines how meaning and significance are assigned to the archive and how the past can influence the future of queer studies. This chapter seeks to explore how such categorization has been implicit in the silencing of non-status quo sexualities through historical violence and the circulation of hegemonic, patriarchal and heteronormative power. My method borrows from cultural 
studies approaches to cultural mapping, where "cultural mapping [and] mapping the field [as] a kind of laying out theoretical frameworks... around a certain topics [such as] approaches to ideology, views on art and politics" (Johnson [et al] 31). Questions, such as how is political power structured into the archive, require mapping differences in the field of archival practices. This type of combination is part of cultural studies 'method' as well as in its form of political analysis. I am interested in both how meaning is assigned, and how archival practices can reveal queer representation regardless of historical implications.

I explore the historical construction of the archive through Jacques Derrida's Archive Fever in order to outline concepts of the archive. Derridean approaches can be both helpful in understanding the politics of power in archival practices, as well as limiting in terms of queer historization and feminist pedagogy. Allan Sekula's text The Body and The Archive will assist in the historical examination of the archive through the relationship between the social body and the cultural manifestations of order and its systematic ideologies.

An alternative perspective to the heteronormative institutionalization of historization will be examined through Michel Foucault's History of Sexuality, Volume 1: An Introduction, which brings the concept of "reverse discourse" to queer epistemologies. Further, Heather Love's insight into the politics of queer history and its historical injury in Feeling Backwards: Loss and Politics in Queer History offers pivotal arguments about abjection, pain and loss. Ann Cvetkovich analyzes queer history in An Archive of Feelings: Trauma, Sexuality, and Lesbian Public Cultures by examining affect as an invaluable aspect of reconstructing queer emotional knowledge in archival practices. 
I have created a cross-section of discourse intended to explore political subjectivities. Specifically, historical analysis of queer representation as a site of social control and how such regulatory systems set out to squelch sexual and engendered difference have persisted. Persistence is at the core of this research, whereby against the odds of hegemonic political powers, queerness in all its slippery, evasive, hard-to-find, hard-to-prove-ness can still not only be found but also can potentially be a reenergized discourse. Where there are political powers that aim to erase queer history, there are those that incite political power and a sense of historical radicalism by being embodied, either through photographic representation and/or their life stories.

Through the analysis of both social conditions that formed discourses of homosexuality and the social sciences of the nineteenth century, the duality between oppressive laws and social change reveals a cultural crisis of taxonomy, visibility and representation in queer visual history. Queer representation in the archive is a location for memory that historically has been entrenched in erasure. Due to historical violence and expurgation, queer archives inscribe both the archives and their users with political power and queer affect. Based on historic institutional and governing archival practices, I utilize the political paradigm of The Lesbian Herstory Archive in Brooklyn, NY among several other queer archives as case studies to propose spaces of resistance to both heteronormative and patriarchal sites of remembrance by concentrating on lesbian knowledge and queer discourse. I specifically look at Mabel Hampton, an African-American lesbian, who against all odds has an archived voice that speaks directly to historical violence and survival.

Searching out history that has been hidden, secret, not spoken of or culturally erased are examined through "discursive formations" (Foucault 1969, 126). As stated by Foucault in The Archaeology of Knowledge, there is political 
power in "otherness" (130) that functions in a "system of enunciability" (129). For Foucault, the relationality between the binaries of the construction of law and "reverse discourse" show "multiple relations" that are "maintained or blurred in accordance with regularities" (129). Discourse is fundamental for all disciplines, however if we consider discursive formations as discussed by Foucault as spiralled systems of power that are, and/or are becoming, cultural studies approaches to articulation offer a layered meaning to discursive constructions by situating the notion of articulation as a political engagement. The archive is a broad area that is intended to show historical constraints and to utilize the notion of the archive as a metaphor for power and memory. Drawing on Derrida, Sekula, Rancière and Foucault, among others, a multidisciplinary approach is taken to understand the historical requirements of the archive, and how the conditions of sexuality, gender, race and class distinction can transcend violent apparatuses through political engagement.

This chapter is not an exhaustive analysis of archival theory; rather the focus of this chapter is to examine texts that explore archival theories and to create a cross-dialogue of ideas. Derrida provides groundwork on key terminology, such as "consignation," "unification" and the notion of "gathering together" (10). In conjunction with Rancière's concept of the logic of the archive and how such forms of logic have been utilized historically to advance social control, Sekula's The Body and The Archive demonstrates the impact of consignation and violent logic to historic archival practices. The intended result of this chapter is to illuminate the problems of the historical implementation of archival practices and how, through anti-oppressive frameworks, they can be recouped into a site of queer political memory. 


\section{Archive Fever}

Derridean approaches to the question of the archive are based on the rules of reasoning or the nomological principle of the archive ${ }^{10}$. I will focus on specific issues raised in Derrida's Archive Fever involving consignation, which include how systems are put into place through the principle of "gathering together" (Derrida, 10) and how consignation informs "unification, identification and classification" (10). I am particularly interested in how these concepts were embedded in the nineteenth century's formation of the social body through the social sciences and the control social discipline had on 'the cult of the empire'.

The archive for Derrida regulates, whether successfully or unsuccessfully, the social and cultural manifestations of order. The "hermeneutic right and competence" (10) of the archive historically intersects with the state and law that privileges heteronormative patriarchal structures. How order is created and how meaning is consigned, suggests that consignation informs who and what is represented. Historical visibility for those on the margins complicates the historical imperative of the archive as systems of power and control that authorize social, cultural and political strategies of knowledge. The principle of "gathering together" (10) commanding legitimacy, security and unification has a long history in the social sciences of sanctioning racist ideologies, supporting gender inequality and surveilling sexuality.

${ }^{10}$ Arkhé - Greek, meaning "the beginning" or origin. Arkhé is the principles of knowledge, which can also be "to command" authority and notions of empire. Derrida bases his argument on Aristotelian philosophy as "the root to things". 


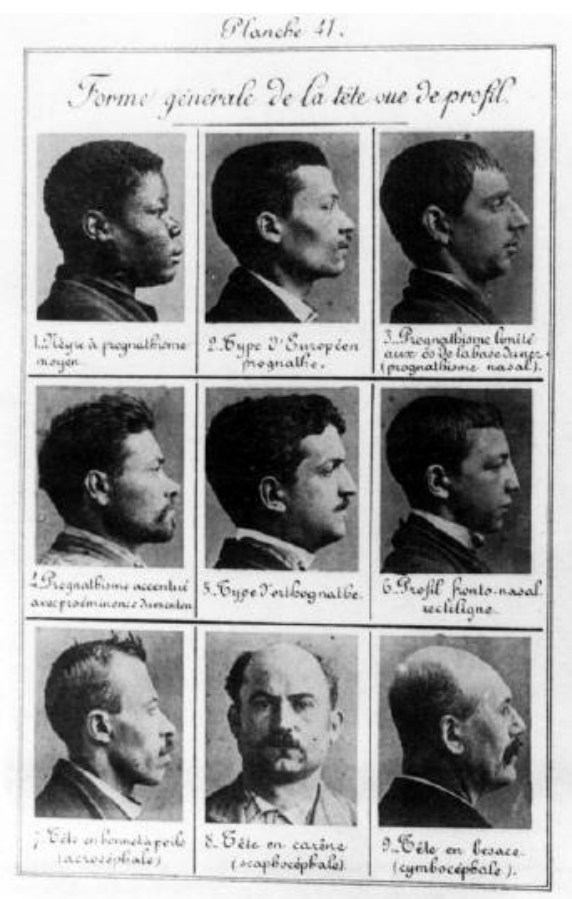

Figure 1.2

Alphonse Bertillon ${ }^{1}$ (1853-1914), French criminologist. Sourced from Allan Sekula's, The Body and The Archive

Consignation of law, order, nature and history was granted almost omnipotent power in nineteenth century social sciences, and were intended to authorize morality and public safety through the regulation of gender difference, sexual deviance, hierarchical racial structures, criminal activity and mental illness. For example, Allan Sekula addresses these issues by examining the work of criminologist Alphonse Bertillon, whereby the Bertillon system of categorization was an anthropometric identification system set out identify criminals, for which he was an important figure in the anti-Semitic conviction of Alfred Dreyfus ${ }^{11}$.

${ }^{11}$ See Émile Zola, J'accuse! January 13, 1898

http://www.telegraph.co.uk/news/worldnews/europe/france/9045659/France-is-stillfractured-by-the-Dreyfus-Affair.html 
Marlene Manoff describes Derrida's claims that Freudian psychoanalysis offers us a theory of the archive premised on two conflicting forces: the death drive and the pleasure principle ${ }^{12}$. Although this research does not examine Freudian approaches to the archive, Manoff's text offers in-depth analysis of Archive Fever that both confirms its significance to this research as well as illuminates on the limitations of Archive Fever when discussing queer history and knowledge. In Theories of the Archive from Across the Disciplines, Manoff asserts that "the archive affirms the past, present, and future; it preserves the records of the past and it embodies the promise of the present to the future" (3) through methods of shaping knowledge and its production.

For Manoff, Derrida's most valuable contribution is that the structure of the archive determines its technical methods through 'archivization'. She states "Derrida's work has contributed to scholarly recognition of the contingent nature of the archive - the way it is shaped by social, political, and technological forces. If the archive cannot or does not accommodate a particular kind of information or mode of scholarship, then it is effectively excluded from the historical record" (8). What is in an archive declares what is not in an archive. My approach to these issues are based less on the methods employed in 'archivization,' and more on the cultural and political meanings of "consignation" and "unification" (Derrida 10). Particularly, in the cases of "the distortions and manipulations of the historical record" (Manoff 8) where women, people of colour, queers and class distinctions are either erased or heralded as

12 While psychoanalysis is not discussed in this dissertation and is not a focal point, I feel it is valuable to include these "conflicting forces" as a marker to understanding the point-of-view of Archive Fever. "The death drive and the pleasure principle are linked to the archival drive as the archive affirms the past, present, and future, it also preserves the records of the past and embodies the promise of the present to the future. Derrida claims that what Freud posited as a death drive "not only incites forgetfulness, amnesia, the annihilation of memory... but also the eradication of the archive, its consignation and the documentary or monumental apparatus" (Manoff 11). 
paradigms for social control. These concerns are addressed by examining the notion of political power as both a site of hegemonic control as well as through a feminist lens of self-determination.

Derrida argues, "there is no political power without control of the archive, if not memory" (4). I believe there is a fissure between Derridean notions of political power and the archive, and what I am proposing. Archive Fever reinforces the archive with patriarchal authority by placing emphasis on legitimacy, where social order is a nomological principle of the archive, and the rules of reasoning are embedded in notions of empire. Political rule and empire are entwined in Archive Fever.

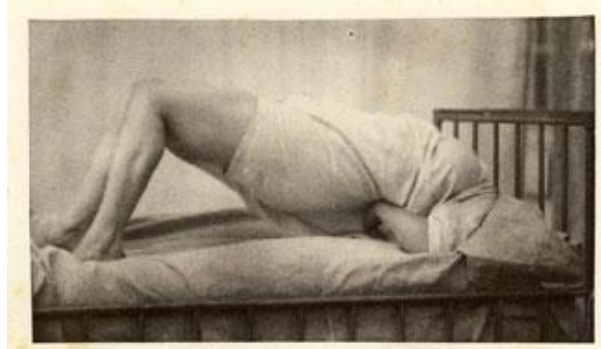

Manche III ATTAQUE HYSTERO-EPILEPTIQUE ARC DE CRRCLE

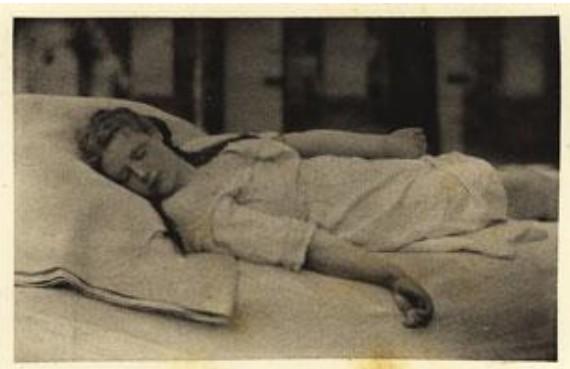

Planche 11.

ATTAQUE HYSTEERO-ÉPILEPTIQUE ทั่TANISM:

Figure 1.3

Jean-Martin Charcot (1825-1893), A French neurologist and professor, instrumental in developing modern understanding of hysteria as a psychological disorder. Sourced from the Waring Historical Library's Caricature Collection, US.

Derrida's deconstruction of hegemonic approaches to the critical analysis of the historical archive are found deep in the footnotes. Sonia Combe's Forbidden Archives (Archives interdites: Les peurs françaises face à I'histoire contemporaine) is acknowledged by Derrida as "gather[ing] a considerable collection of material, to illuminate and interpret it; she asks numerous essential 
questions about the writing of history, about the "repression" of the archive as "power of the state over the historian" (Derrida 4). Sonia Combe is cited as a contributor to archival discourse, and as the only woman mentioned in Archive Fever she is footnoted. Combe addresses patriarchal constructs by stating, "I hope to be pardoned for granting some credit to the following observation, but it does not seem to me to be due to pure chance that the corporation of wellknown historians of contemporary France is essentially, apart from a few exceptions, masculine...But I hope to be understood also..." (Derrida 10, note 17). Although she is cited, her contribution is buried at the bottom of a page. This is political for me as a feminist and queer researcher, where women, people of colour, queers and those not operating in white male privilege are continually footnoted throughout history. Yet, citation is pivotal to Derrida as a reference to the economy of the archive.

For Derrida, citation is an inscription that is structured on politics of capital, and politics of masculine dominance through the exergue -an inscription below the principal emblem on coins as well as the cut of circumcision. Whether it is "the intimate mark... on the so-called body"(12), or "the exergue capitalizing on an ellipsis...preparing the surplus value of an archive" (12). The exergue as examined in Archive Fever as a marker of dominance. As stated by Derrida, "in this way, the exergue has at once an institutive and a conservative function: the violence of a power (Gewalt) which at once posits and conserves" (12). The exergue can and needs to be critiqued under the rubric of violence. If the Arkhé is of the covenant, the Word, the Beginning and the Law, it is built on structures of heteronormative patriarchy that requires critical attention and interrogation. 

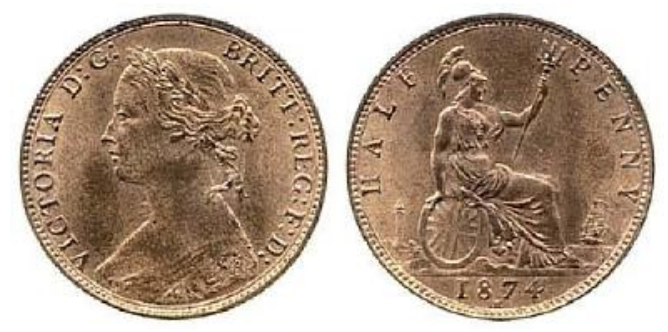

Figure 1.4

British half-penny, 1874. Sourced from Coins of Great Britain. This image is intended as a view of an exergue, the slice of archival capital.

Politics is not the exercise of power. Politics ought to be defined on its own terms, as a mode of acting put into practice by a specific kind of subject and deriving from a particular form of reason. It is the political relationship that allows one to think the possibility of a political subject(ivity) (le sujet politique), not the other way around. (Jacques Rancière. Ten Theses on Politics, 1)

Political power, as I am addressing it in this research, is not contingent on rule. Governance, contrary to my position, reduces the political to the state. Political power, in terms of the archive, and the knowledge of historical queer subjects and accessibly to queer history is a politicized relationship between the exercising of power on historical queer subjects, their subjection to prohibitions, and the recouping of histories.

The dilemma with Derridean approaches to the archive is that the unification of materials are constituted as legitimate without critical concern of what is on the margins or how the collection of information can trouble the status quo. If the archive cannot or does not contain a particular kind of information or mode of scholarship, then it is effectively excluded from the historical record. If there is no political power without control of the archive, and historical queerness was regulated and condemned then it appears that political power can only be acquired within hegemonic structures of knowledge, power and cultural acceptance. Official records of people of colour, women and queers 
have created gross omissions in the historical configuration of the archive. Those outside the margins of authoritative power are poised precariously between being written out of history or are proclaimed through dominance, such as in the case of African slaves, hysterical women, the insane and/or marginal. The duality between secret and declaration are historic systems of eradication: the records of the non-status quo whether hidden, burned or tossed away, secrecy does play a role in inaccessibility but much less so then the biased, violent and cruelty of homophobic, racist and misogynistic annals. Women and gender studies, among other disciplines, have taken up the call of historical knowledge by acknowledging these concerns as paramount to future pedagogies. Colonial and imperial powers have controlled the archive and influenced the dissemination of history by wielding political power through law, the state, order and regulation.

I argue through a paradigm of queer and feminist thought that queer archives and their users are imbued with political power because their voices have surfaced or are cared for beyond the consignation of law and state. Where Derridean methods cite historicity and the cult of the empire as the origin of the archive and thus political power, this research examines the potential of political power in spite of the sanctioning of the state, and political power as a sense of resistance to heteronormative and patriarchal structures of dominance.

For Derrida, "effective democratization" is "measured by the essential criterion: of the participation in and access to the archive, its constitution, and its interpretation" (4). While I agree that participation, access, its constitution and its interpretations are key to archival practices, I would argue that its "democratization" is, in fact, ineffective and too often contingent on cultural domination. The "logic of the Arkhé" is discussed by Rancière in terms of selecting some element—wealth or birth—and making it the basis for the right to 
rule. "The principle of this kind of being-together is simple: it gives to each the part that is his due according to the evidence of what he is" (Rancière, 20). Rancière describes the Aristotlean Arkhé as a distribution determined by the proportion of dissimilarity between people. He explains how different classes lobby for different criteria: " they do not identify worth in the same way, for supporters of democracy say it is free citizenship, while supporters of oligarchy say it is wealth and others noble birth, and supporters of aristocracy say it is virtue" (22). In addition to outlining the various claims on part-taking (avoir-part), he addresses how Aristotle also tells us something essential about democracy that it invents a title for being counted and participating. As Rancière states "'the 'freedom' of the people that constitutes the axiom of democracy has as its real content the rupture of the axiomatic of domination, that is, of the correlation between a capacity to command and a capacity to be commanded" (23).

How can we partake in effective democracy without control of our histories? What systems have been historically put in place to consistently adhere to the logic of the archive that deems what or who is remembered and who is forgotten? If, as stated by Rancière, politics require being understood as "a mode of acting put into practice," that are determined by "a specific kind of subject," how can we understand historical relationships to representation? Further, what do these relationships tell us about political subjectivity and the necessity to represent ourselves? 
The Body and the Archive

By the nineteenth century a vast array of ethnographies based on racialization, class, sexuality, and gender ${ }^{13}$ had become the cornerstone of the social sciences. The body became a location of social regulation, where 'truth' could be manifested and culturally realized through ideologies. The cult of the empire was exemplified by the fetishization of gender, sexuality and race to delineate purification as social discipline and the staging of social hierarchies informed the performativity of cultural signs and social spectacle ${ }^{14}$. The social body was achieved through bourgeois order, where political economy was entwined into industrialism, capitalism and imperialism. Sexual conduct was converted into economic and political behaviour between the individual and the state. The invention of homosexuality as a categorical device was meant not only to control sexuality but also regulate how gender was enacted.

The bureaucracies of surveillance and control were institutional systems bridging the connection between professionalized police work and the social sciences. According to Sekula, in the nineteenth century there were two strategies aimed towards gaining control over both the archive and social behaviour. Alphonse Bertillon (1853-1914) developed not only what have since become the prevailing standards for police portrait photography, he also developed a complex classification system that operated with index cards and

${ }^{13}$ These ethnographies were often founded through the device of criminology and mental illness. For example, men of colour as criminals, women who had survived sexual trauma as hysterical or same-sex affection or desire as predatory, deviant and criminal.

${ }^{14}$ Ann McClintock's Imperial Leather: Race, Gender and Sexuality in the Colonial Contest thoroughly examines the visualization of the imperial empire through both advertising and photographs. She investigates the imperial spectacle of gender, sexuality and race in the nineteenth century by exploring case studies from visual culture. In the Victorian era, advertisements, particularly for soap, pioneered pictorial advertising while exemplifying imperial notions of commodity and social meaning. McClintock states that soap became synonymous with social semiotics of purification. Victorian advertising explicitly reinvented notions of race, in order to distribute evolutionary racism. 
which was meant to enable picking a particular individual case out of the enormous number of images contained in the archive.

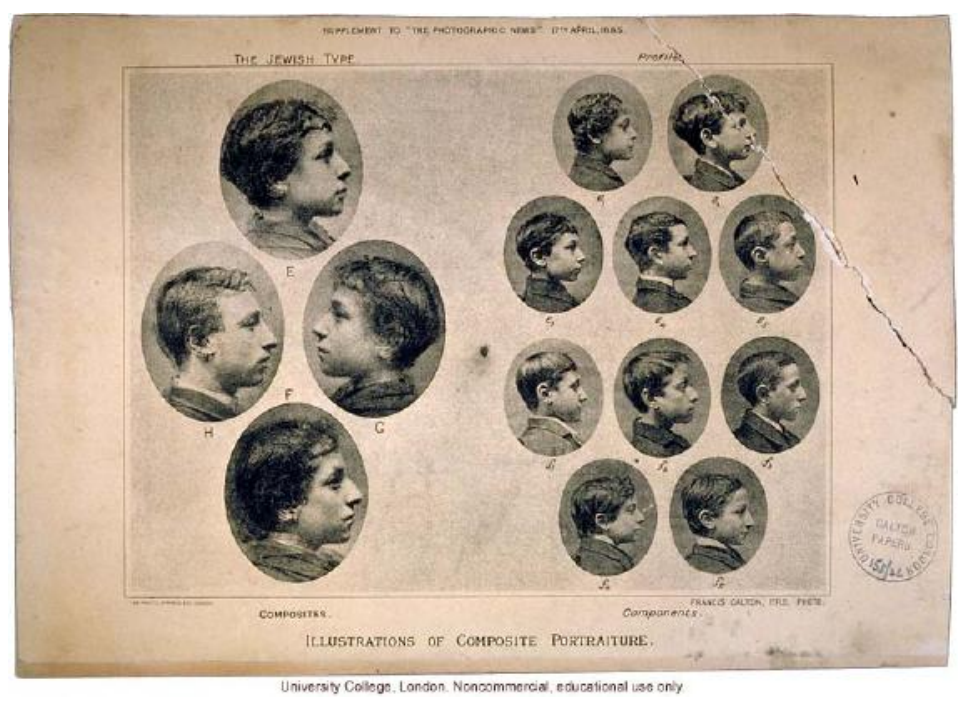

Figure 1.5

Francis Galton (1822-1911), Illustrations of Composite Portraiture, "The Jewish Type." Sourced from The University College, UK. Sourced from The Body and The Archive.

In contrast, Francis Galton (1822-1911) condensed numerous photographs by superimposing them to create an ideal composite image, which was meant to cause individual traits to disappear and the characteristics common to the superimposed portraits to manifest, thus making typical attributes of the criminal and of race more visible. Sekula states, "Bertillon sought to embed the photograph in the archive. Galton sought to embed the archive in the photograph" (32). According to Sekula, these methodologies of the archive soon became the "dominant institutional basis for photographic meaning" (33). 
While this chapter analyzes the role of archival practices and queerness, photography cannot be separated from the evaluation of the archive, as photography is both a material found within the archive and a tool within archival methods. However, a more thorough examination of queer history and photography is discussed in chapter two: Early Photography and Queerness, which rigorously investigates the significance and meanings imbued in photographic practices and their effect on queer representation.

As outlined by Allan Sekula in The Body and The Archive, the historical violence of the archive functioned primarily through mensuration and tabulation, both serving as tools as control. Mensuration was quickly implemented into the cataloguing of criminals, slaves and hysterical women, among others to protect bourgeois imperatives. By offering citizens information of what a criminal looked like through detailed measuring systems, citizens were able to see and promote the rationalization of 'the other'. Disorganization had been replaced with collections of standardized information to ascertain abnormality and criminal behaviour. In a famous quote, Bertillon states, "every measurement slowly reveals the workings of the criminal. Careful observation and patience will reveal the truth" ${ }^{15}$. The tools of the archive, such index cards and the filing cabinets provided logic to arrange, sort and track offenders, where cross-referencing could ensure control. These instruments of science and knowledge revolved around concepts of nation-building, stability and control. Through both Derrida's underlining of patriarchal structures of consignation and Sekula's case studies, historical archival meaning is predicated on systems of power and authority rendering what is understood as visible, and conversely what is invisible. The opposition between visibility and invisibility can only maintain such systems

${ }^{15}$ Quote from the Visible Proofs: Forensic Views of the Body (2008) exhibition at the National Library of Medicine, US 
through the multidimensional location of articulation. Because social moments of production are articulated through power relations, contexts and cultural forms "may be both joined, separated, speaking and silent, hinged together and swinging apart" (Johnson [et al] 155). This cultural studies approach to power, discourse, production and social relations is foundational to understanding how the archive produced knowledge and how such knowledge can be recouped.

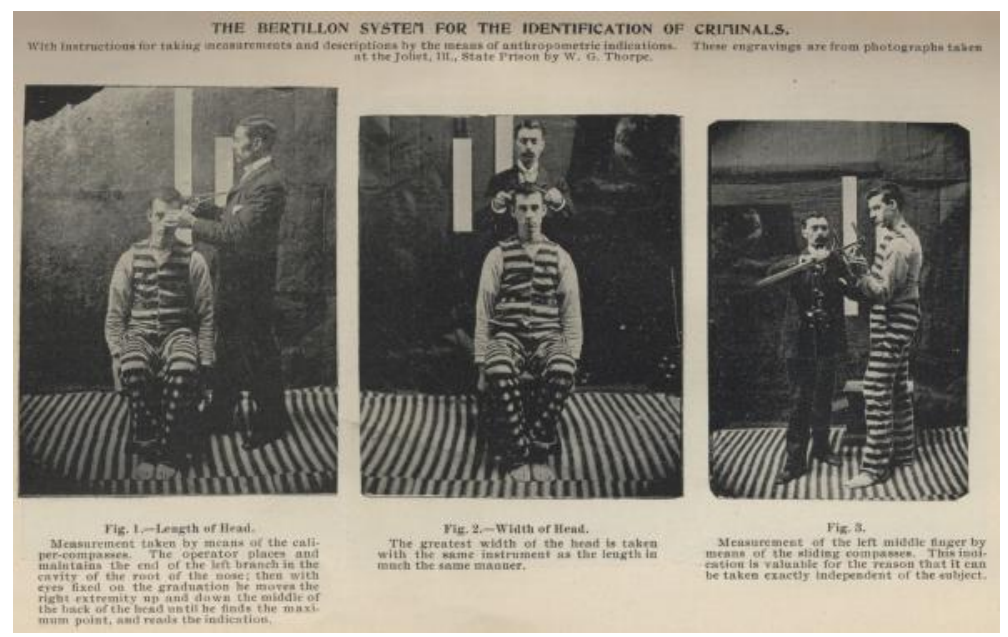

Figure 1.6

The Bertillon System: Science and Crime in the Global Information Age. Sourced from http://historyapolis.com

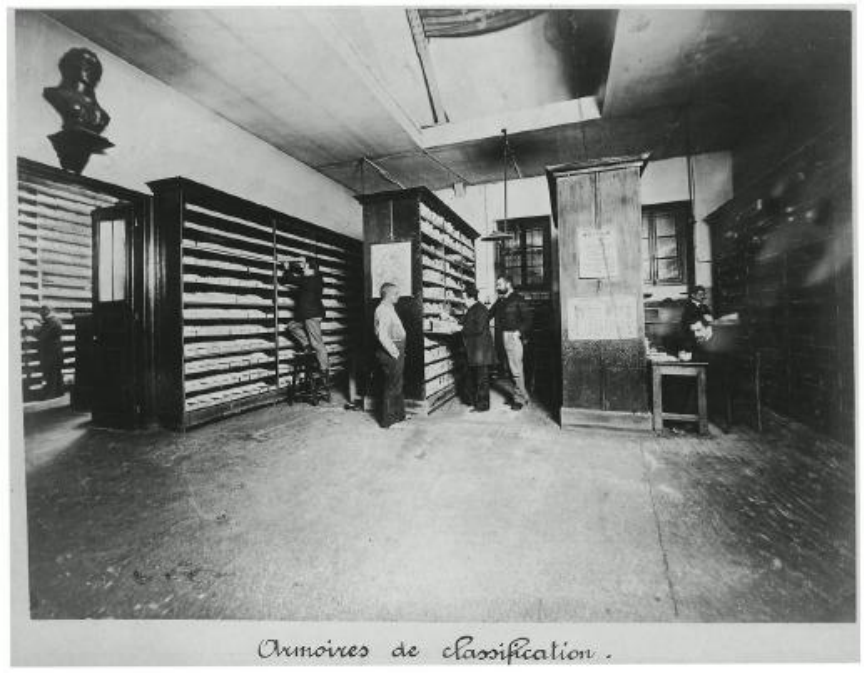

Figure 1.7

Bertillion's repository of classification (1893) Sourced from http://historyapolis.com 
Sekula's The Body and The Archive contributes invaluably to the discourse of the "social body" (6) and its "invention" (6). Sekula outlines how systems of nineteenth century archival practices were enforced through Social Darwinism and "positivist attempts to define and regulate social deviance" (19). Criminologist Alphonse Bertillon, Eugenicist Francis Galton and Neurologist Jean-Martin Charcot (1825-1893) founded techniques to systematize and rationalize the social body throughout Europe and North America. Bertillon invented the mugshot in the 1870s, Galton created systems for what we now understand as racial profiling and Charcot was a leading scientist in female hysteria; all three, among others created sites of order and control that offered industrial modernism a precarious normalcy by revealing in rational terms 'the other'.

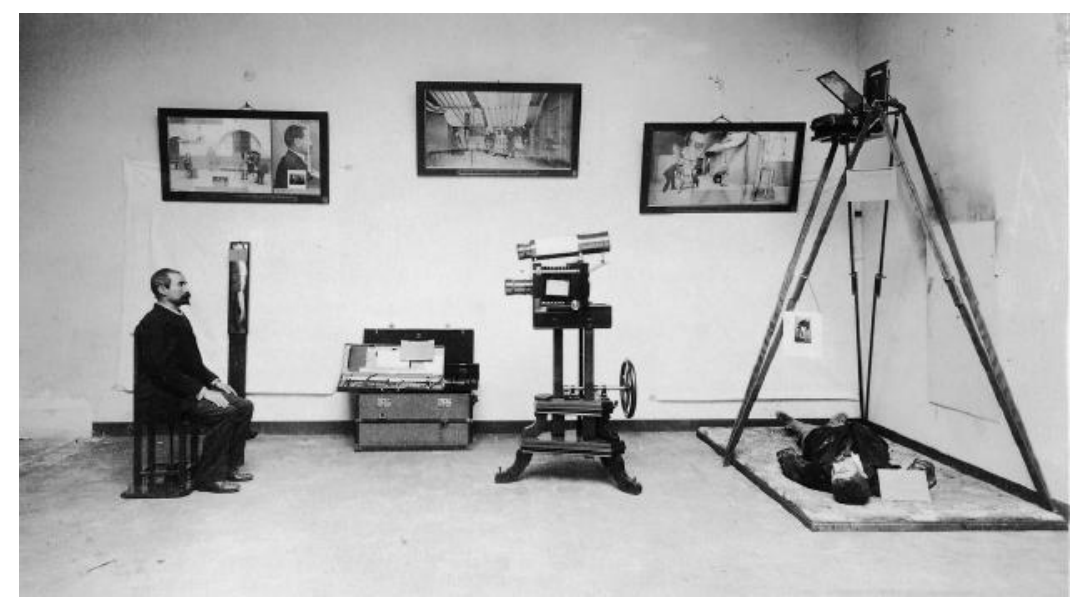

Figure 1.8

Alphonse Bertillon. A photograph from his personal photo album exhibited at the World's Columbian Exposition in Chicago, 1893. Sourced from the National Gallery of Canada, Ottawa

Photography played a fundamental role in the distribution of data collection in the social sciences, including a vast array of ethnographies such as race, anti-Semitism, class, sexuality and gender. The categorization of 
sexuality and its regulation had a direct correlation to the classification of gender and race at the turn of the century. The body was not simply possessed by the individual but rather was socially constructed through medicine, law and social regulation. The overarching social and cultural changes in the late 1800s gave rise to the convergence between mechanical reproduction and the invention of homosexuality as a psychiatric disorder in 1870. The social construction of homosexuality as illness and the significance of inexpensive and accessible mechanical reproduction reveal the apparatus of photography as both implicit to the categorization and repression of homosexuality as well as a site of subversion of the status quo. How has history been positioned by the repressive powers of early social sciences and categorization, and what is the impact of such a history on the social implications of early queer representation?

\section{Reverse Discourse}

Same-sex affection and love is as old as time itself, as examined by several cultural and queer theorists, such as David Halperin's One Hundred Years of Homosexuality, Jeffrey Weeks's Invented Moralities, Eve Kosofsky Sedgwick Between Men: English Literature and Male Homosocial Desire and Jonathan Ned Katz's The Invention of Heterosexuality, among others. However, the categorical device of homosexuality was invented in the nineteenth century to enforce normativity for the purpose of maintaining bourgeois order through the social body as an ideological imperative that was knotted into the political economy of industrialism, capitalism and imperialism. Here, we might see more clearly how and under what conditions "interlocking forces (cultural, economic,

political, etc) [are] at play in the world" (Rodman 348) and how these forces are exemplified in the notion of 'the social body' as a site of control. 


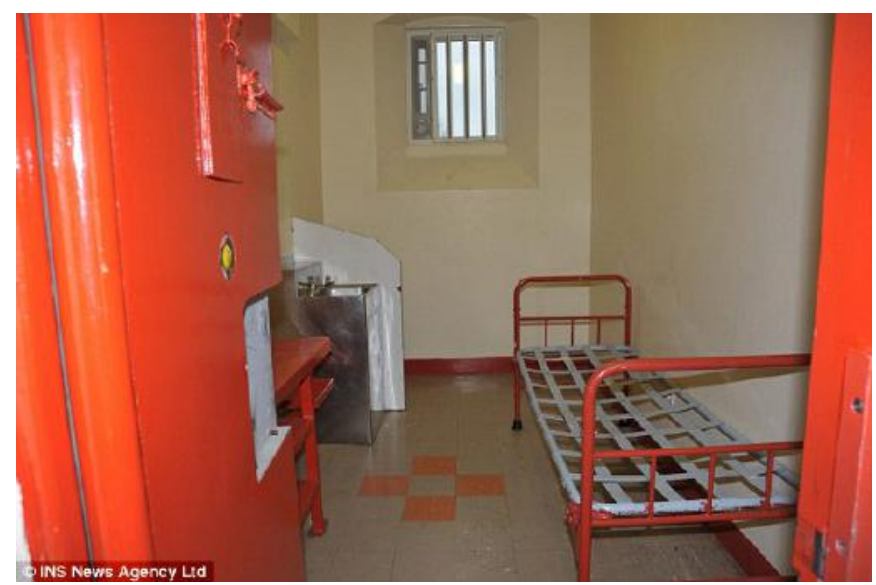

Figure 1.9

Oscar Wilde's Cell \#33, C Wing, Reading Prison, where Oscar Wilde spent the majority of his two-year sentence after being found guilty of gross indecency.

As stated by Foucault, Carl Friedrich Otto Westphal ${ }^{16}$ is responsible for the birth of modern homosexuality in 1870 . This appears to be one of the first medical accounts of sexuality as a psychiatric disorder where sexual relations directed one's sensibility and approach to the world that both inverted masculinity and femininity as well as inscribed "a kind of interior androgyny, a hermaphrodism of the soul" (43). For Foucault, Westphal's concept of homosexuality as a "contrary sexual feeling" converted "the sodomite [from] a temporary aberration [into] a species" (Foucault 43). The coercion of social imperatives to enforce control and order informed this paradigm shift from an interiority of queerness to an exteriority of repugnance and profound social fear of homosexuality. The systemic union of the social body and nation-building were not simply theoretical but regulated through law, the state and social behaviour.

${ }^{16}$ Westphal (1833-1890) was a German neurologist and psychiatrist who coined several terms dealing with nervous disorders, among them agoraphobia and narcolepsy. For Westphal, homosexuality was as much a nervous disorder as any other mental illness or anxiety condition. 


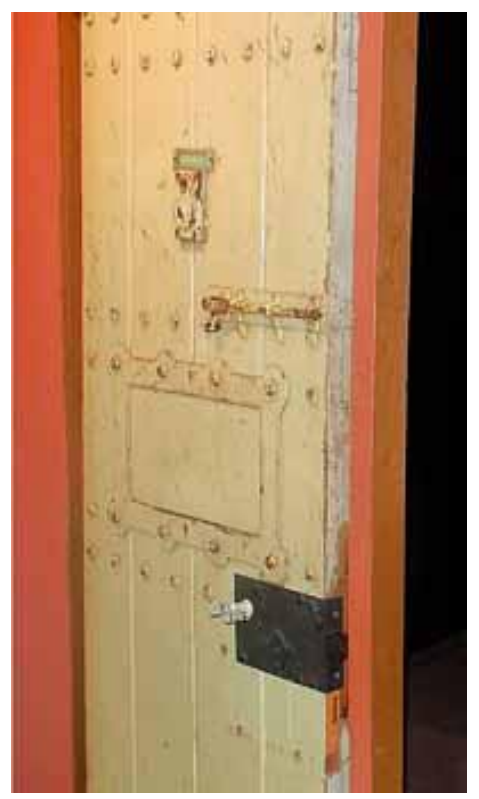

Figure 1.10

The door of Oscar Wilde's cell at Reading Gaol, displayed at Nottingham's Galleries of Justice Image from Voices from Solitary: Oscar Wilde's Cry from the Depths by Jean Casella and James Ridgeway. Sourced from Solitary Watch, June 27, 2010.

In 1886, Richard von Krafft-Ebing's Sexual Psychopathy: A ClinicalForensic Study was published in German with the English translation being published in 1892. While Krafft-Ebing protested Paragraph 175, Germany's legal code criminalizing homosexuality in 1871 , he maintained that homosexuality was an illness that required a cure. Further, Krafft-Ebing's believed sexual inversion in women as occupying a 'masculine soul'. In England, author Oscar Wilde was sentenced to two years of hard labour for gross indecency (homosexuality) on May 25, 1895. This prison sentence played a massive cultural role in the 'identification' of the homosexual.

English reformer Havelock Ellis published Sexual Inversion in 1897, it was considered the first text to examine homosexuality 'objectively,' without deeming it a crime, immoral or a disease. In this text, intra- and intergenerational homosexual relationships were explored. However, the majority of the cases studied were comprised of members of the same age group. The author refused to criminalize or pathologize the acts and emotions that emerged in these relationships. Instead, Ellis argued that same-sex love rose above the 
mundane restrictions of society. The subject was so controversial and so offensive to the Victorian English society that at least one bookseller was brought up on criminal charges for carrying copies of the book. The term homosexual came to be closely associated with Havelock Ellis and his work. Although considered a reformer, Ellis served as vice-president to the Eugenics Education Society and was a star witness at the Radclyffe Hall's obscenity trial England on November 9, 1928 to which he did not turn up. Hall was charged under the Obscene Publications Act of 1857 for her book The Well of Loneliness that was later banned in the UK.

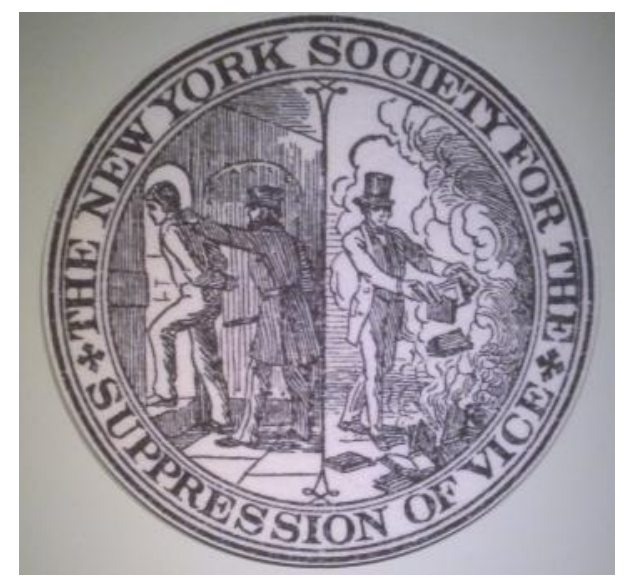

Figure 1.11

The official seal for the New York Society for the Suppression of Vice who burned A Well of Loneliness in the 1920s. I find the exergue on this seal. It gives a context to the delineation created and enforced through imperial tradition of economic and social control. 


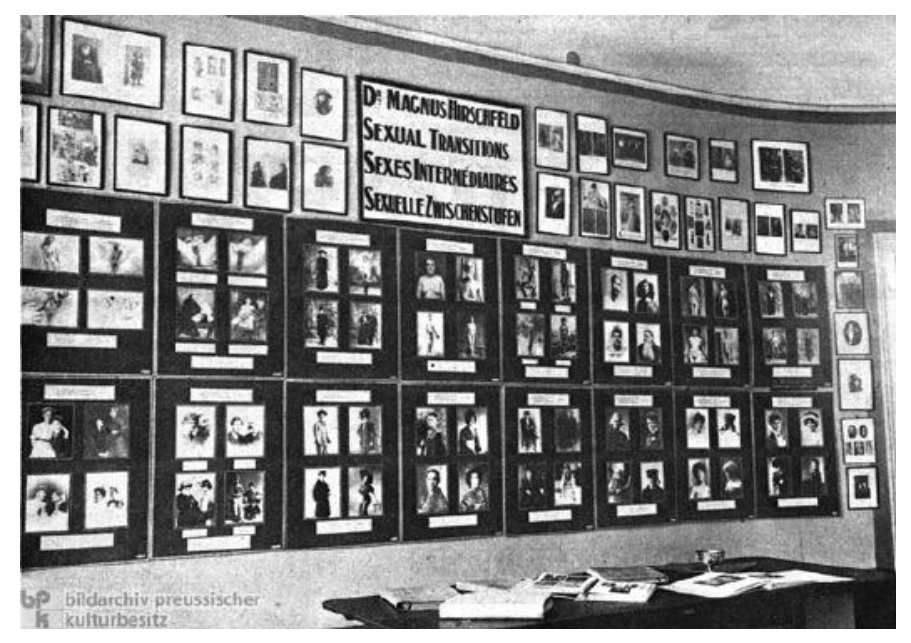

Figure 1.12

Magnus Hirschfeld Archivein the Institute for Sexual Research in Berlin (1925). The Institut für Sexualwissenschaft was an early private sexology research institute in Germany from 1919 to 1933.

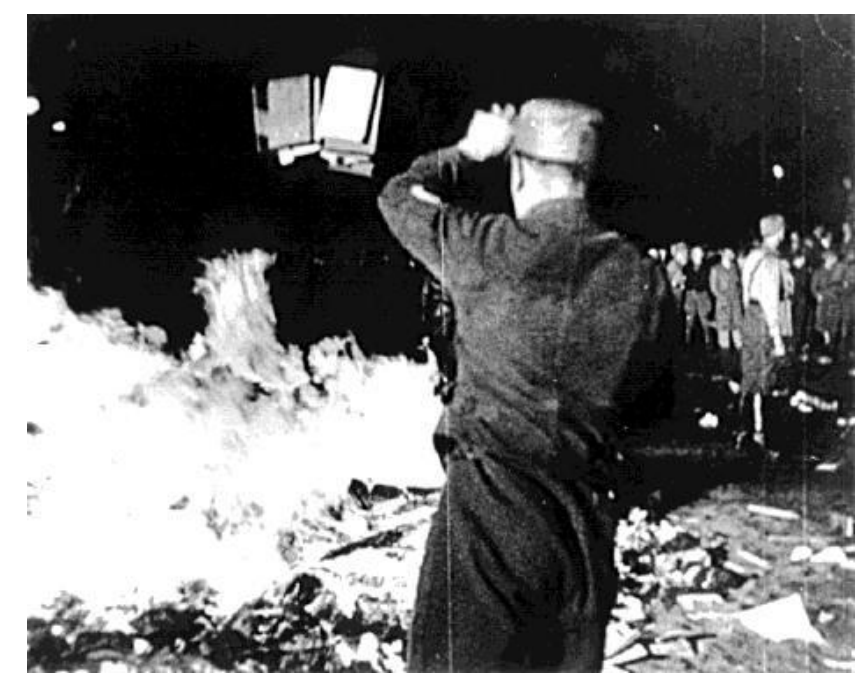

Figure 1.13

May 10, 1933, Nazis in Berlin burn works of Jewish authors, and the library of the Institut für Sexualwissenschaft ${ }^{17}$

${ }^{17}$ Magnus Hirschfeld (1868-1935) was a gay German Jew physician, and significant sex researcher, who founded of the world's first gay rights movement, the Scientific-Humanitarian Committee. The goal was the elimination of Section 175 of the Penal Code, which punished sexual acts between men. A year after the foundation, a first petition was submitted calling for the abolition of Section 175 , but without success. A coalition of various sexual reformers actually succeeded through their lobbying work so the Reichstag Committee decided in 1929 to abolish the Special Criminal Law section. But the application did not reach the Reichstag in time. Sourced from The Federal Foundation Magnus Hirschfeld, http://mh-stiftung.de/en/about-the-foundation/ 
The complexity of uncovering queer history speaks to a variety of tactics necessary for survival. The historical evidence of concealed, hidden and double lives of same-sex affection has placed queer history in a precarious and obscure position that requires further scholarship and research. To understand why queer history can be opaque and challenging to uncover, it is important to note that the invention of homosexuality was a categorical device meant to control, regulate and generate fear. The proliferation of categorical research by sexologists of the time period, and the debate around homosexuality informs how this early discourse not only became institutionalized by medical devices and enforced by laws, but also how these discourses were socially maintained.

\section{Queer Archives}

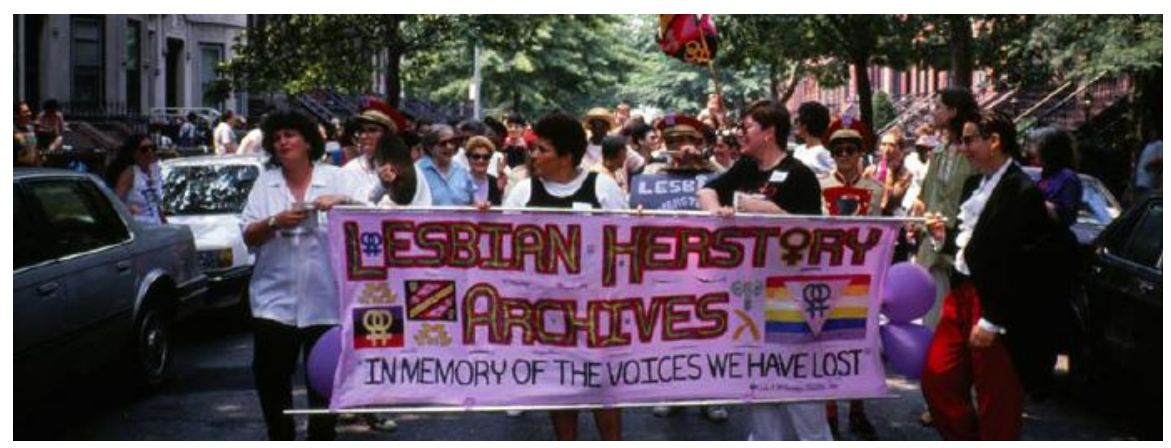

Figure 1.14

Lesbian Herstory Archives, In Memory of the Voices We Have Lost. Reopening parade in Brooklyn on June 20 1993. Photo by Saskia Scheffer - with Polly Thistlethwaite, Joan Nestle, Robin Riback, Paula Grant, Jenny Romaine, Judith Schwarz and Eve Sicular.

In An Archive of Feelings: Trauma, Sexuality, and Lesbian Public Cultures, Ann Cvetkovich analyzes queer history through archival practices and examines the affective power of queer archives as forging emotional knowledge in LGBT lives. Cvetkovich investigates queer pedagogy as tracing 
the trauma of LGBT communities that have faced erasure and invisibility. She asserts that queer archives preserve histories of traumatic loss to support queer memory and affect, whereby the context of remembering is emotional, affective and sensory. For Cvetkovich, queer archives are not simply repositories of classification but rather of feelings that evoke both the past and queer persistence. By forging emotional knowledge in LGBT lives and the affective power of queer archives, Cvetkovich investigates queer pedagogy by tracing the trauma of LGBT communities that have faced erasure and invisibility, in order to evoke both the painful past and the possibility of queer persistence.

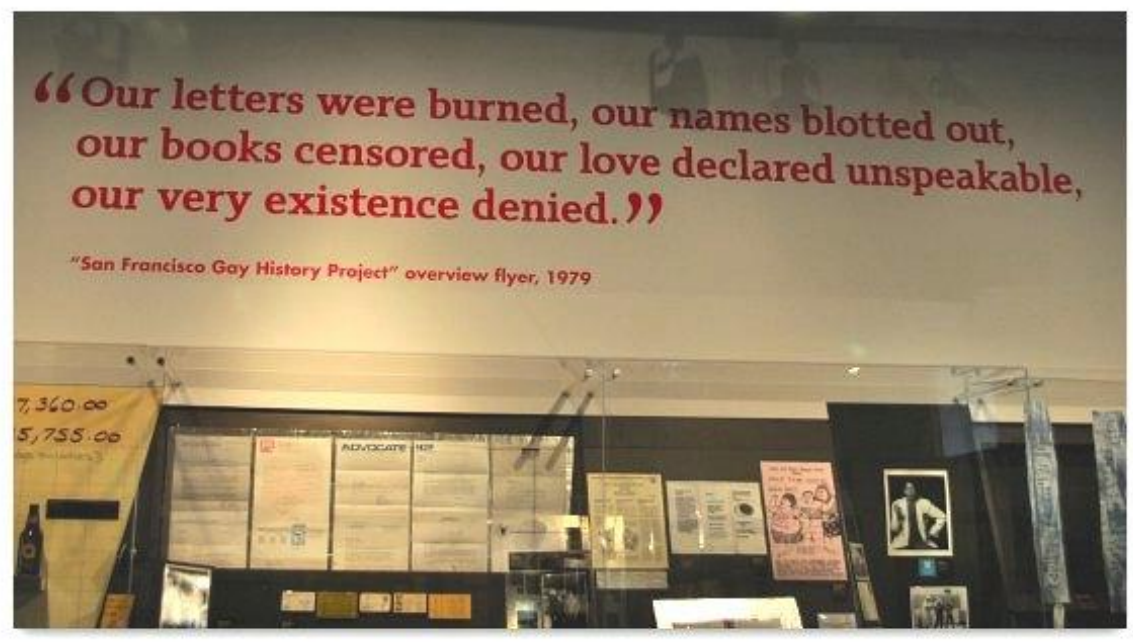

Figure 1.15

GLBT Historical Society, San Francisco, CA

Queer archives provide a site of memory that historically has been entrenched in prohibition, silence, violence and erasure. Without knowledge of the past, what can we expect of future queer subjectivities? By shifting queer subjectivities from secrecy to non-secrecy, what are the effects on discourse and knowledge? The complexity of uncovering queer history speaks to a variety 
of socio-political tactics designed to culturally oppress homosexuality as well as socially inhibit queer epistemologies. Secrecy as a methodology of survival troubles queer history, and what is archived and how it is archived. Those who lived in secret either did not participate in institutional systems of archiving, or did so through complex coding or were archived outside of the mainstream. As stated by Jeffrey Weeks:

I want to restore agency to the process by which some individuals attempt to create a sense of self as something that has to be worked on, invented, and reinvented...the modern self... is a reflexive process, made and remade by the person in terms of his or her own experience. (2013, 17)

The history of the queer archive as an institutional space is recent, and complicates traditional and institutional issues of law, order and state. It is due to this historical erasure that creating archives of those who have been forgotten, unnamed or oppressed becomes significant.

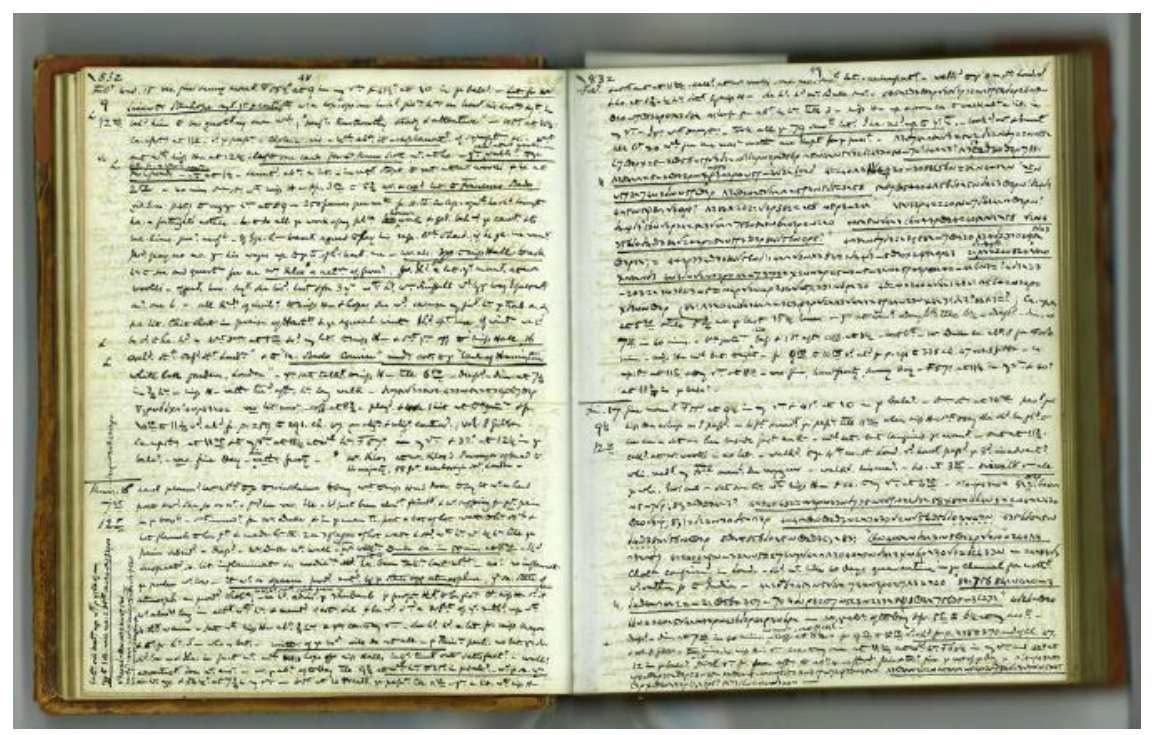

Figure 1.15

Anne Lister (1791-1840) 
Ann Lister was a Yorkshire landowner, diarist, mountaineer and traveller. She kept diaries throughout her life chronicling the details of her daily life, including her lesbian relationships, her financial concerns and industrial activities. Her diaries contain more than 4,000,000 words and about a sixth of them-those concerning the intimate details of her romantic and sexual relationships all written in code. Based on Greek, Lister's codes began with her first love affair when she a young girl. She and Eliza Raine, and later Marianna Belcomb used the code to write love letters to each other, which Anne often copied down in her journals. The code was used for sexual matters, where she puts symbols, such as a cross in the margins to indicate orgasms. ${ }^{18}$

Ann Cvetkovich examines queer trauma by connecting the importance of recognizing - and archiving — accounts of trauma to the ordinary and everyday domain of queer lives by revealing how the archive can transform the conditions of trauma. Cvetkovich investigates that-which-has-been pushed to the peripheries by defining new principles to activate the creation of cultural archives and political communities. The damaged and compromised subjectivity of queer desire in history can also be viewed through a libratory standpoint of challenging structures that intended to oppress by staging riots, such as the Stonewall Riots of 1969 and public demonstrations, such as ACT UP in the 1980s/90s that were produced to respond to both immediate issues as well as future resistances. Where "pride and visibility offer antidotes to shame and the legacy of the closet...[q]eerness is structured by this central turn; it is both abject and exalter" (Love 2).

\footnotetext{
${ }^{18}$ Lister is often called "the first modern lesbian" for her clear self-knowledge and openly lesbian lifestyle. Called "Fred" by her lovers and "Gentleman Jack" by Halifax residents, she suffered from harassment for her sexuality. Lister' wrote, "my manners are certainly peculiar, not all masculine but rather softly gentleman-like. I know how to please girls." (Clark 43).
} 


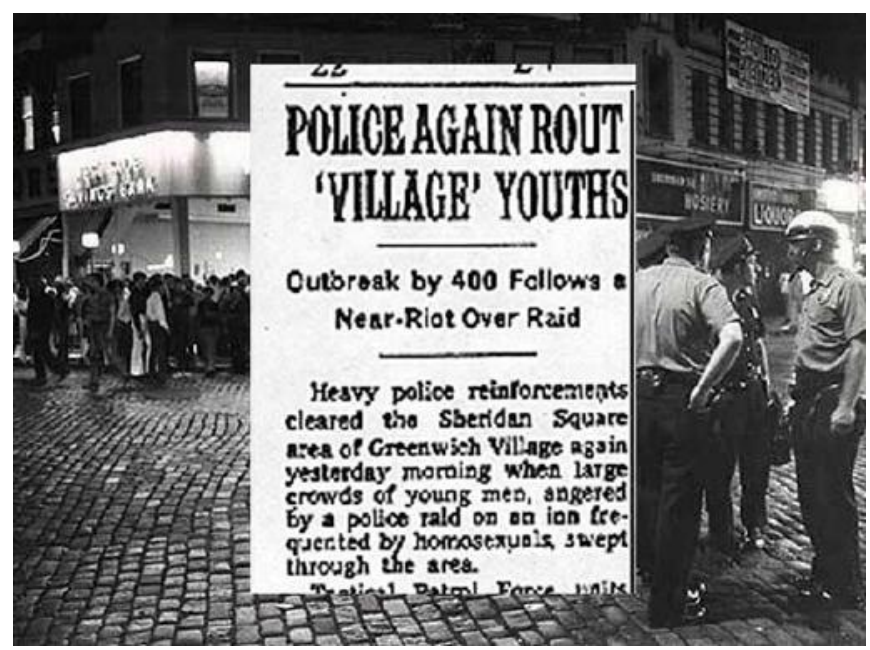

Figure 1.16

"Remembering the Stonewall Riots, 1969." From Our Archives: The Advocate. Michelle Garcia, The Advocate. 29 June, 2012.

Heather Love's insight into the politics of queer history and its historical injury in Feeling Backwards: Loss and Politics in Queer History offers crucial arguments to the affect of abjection and memory as well as proposes why the painful affect of historical violence is a site of value when examining queer history. This chapter observes queer affect as a liminal focal point that is specific to archival practices and queer history. Painful affect and abjection is considered in this chapter under broad terms of archival engagement, the social body and its significance to queer archive discourses. Love suggests "embracing loss" and "risking abjection" because the "modern homosexual identity is based on...the experience of social damage" (29). For Love, the abject, the pain, the damage and the exclusionary implications of queer historical injury is motivation to recall, remember, and "engage with the past without being destroyed by it" (1).

Heather Love's work reveals the ghosts of a queer past, who have refused to behave or remain silent. Love offers invaluable insight into 
Foucauldian reverse discourse as she examines how the ideology of gay pride transforms sexual shame into social affirmation, which has resulted in a critical blind spot. I would argue that this blind spot is due to historical erasure of a queer past, and that the prohibitions on historical queer sexualities and alternative paradigms to heteronormativity has rendered queer knowledge opaque and armed with only some historical reference, such as the AIDS movement. Further, because 'queer history' is limited by prohibitions, the 'history' of queer voices has become bordered by the 1980s/90s, suggesting to both queer communities and youth that 'our history' is simply a 'retro' or 'vintage' vision of the past. Why this is troublesome is that without access to queer knowledge that has intersected with broader strata of cultural and social phenomena, such as imperialism, capitalism and industrialization, queer communities have a limited scope of historical representation of repression and thus, are constrained to the continued disavowal of political power.

To envision a queer future, a resistance to the idealization of queer history is rooted in what Love calls a "backward future" (Love 147), which is both a rigorous and critical embrace of the past that orients itself towards the future by looking back. As contemporary queer subjects continue to experience shame and stigma, Love argues that what is needed is not necessarily an affirmative genealogy but "a politics forged in the image of exile, of refusal, even of failure" (71). Queer archives provide sites of persistence and survival through painful affections of exile, refusal and failure. The significance of archival knowledge and queer history beyond the borders of the twentieth century exhume the unknowable into tangible evidence of difference, protest, conflict and perseverance.

In archival research, there are always problems and uncertainty in understanding the subjects. For example, not everything housed in LGBT 
archives is queer - dressing in drag does not necessarily mean homosexuality, and conversely, not everything housed in a city or a national archive is solely heterosexual. Lives are complicated and studying queer history requires peeling back the surface and some intuition. The archivable content of queer history is far from a utopian space but offers a counter-space, a place of resistance, remembrance, knowledge and discourse.

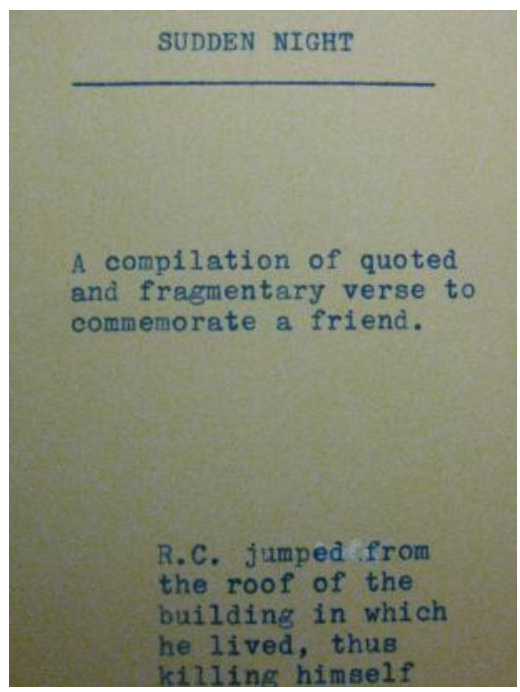

Never has a word revealed All that a heavy heart concealed. The quiet falling of a leaf Must tell the depth of Autumn's grief. And from the doe about to die There comes no more than one hushed cry. Even the earth can show no pain Beneath the pressure of the rain. So am I burdened just as they, With all that I can never say. Only in silence can it live, This love that was so hard to give.

Figure 1.16

Leo Adams. Sudden Night, 1930s New York. Image from the New York Public Library, personally sourced in 2012. 
A Sudden Night was included in Becoming Visible: The Legacy of Stonewall, an exhibition curated by Molly McGarry and Fred Wasserman at the New York Public Library's Gottesman Exhibition Hall in 1994. Sudden Night has never been published; in Adam's letters he gave his friend Wesley Lea a copy in 1944, and stated, "I want you to have a copy of Sudden Night. Since I don't know when I shall finally have the money to print it, I may as well get a few copies of it judiciously distributed around so it won't be inevitably lost to posterity... Fifty years from now, if a privately printed copy is rediscovered in the New York Public Library, I should love to have prominent speculation in the magazines and newspapers as to just who this could refer to (June 21, 1944). In the years from 1928-1952, the period covered by the Leo Adams Papers at the NYPL, "the "gay world" that Adams's letters reveal existed largely under ground - buried in medical, ecclesiastical, and criminal justice discourses, and masked behind doctrines of inversion, perversion and vice." (For detailed information, see Notes Political Power and The Archive \#1).

For the Lesbian Herstory Archive and other queer archives, creating order and systems require some Derridean principles of the archive through order, physical preparation, classification and shelter. However, I would argue that not all archival principles are founded on patriarchal structures of gender dominance or imperialistic traditions of racism and sexism, and that particularly Lesbian Herstory, among others such as the GLBT Historical Society (CA), The One Institute and Archive (CA) the CLGA Archive in Toronto, and others in North America and Europe, contravene traditional hegemonic positions of power, which results in community-based social justice imperatives and perspectives. For example, the Leo Adams: A Gay Life in Letters, an exhibition curated by Michael S. Miller, treats his papers as contributing to a kind of genealogy of knowledge about the gay past. Spanning a twenty-four year period (1924-1952), Leo Adams: A Gay Life in Letters divulges a gay man's private life in New York City leading up to the Great Depression through World War II and into the 
McCarthy Era, signalling the private joys of love, the profound pain of living in the closet and surviving major moments in American history.

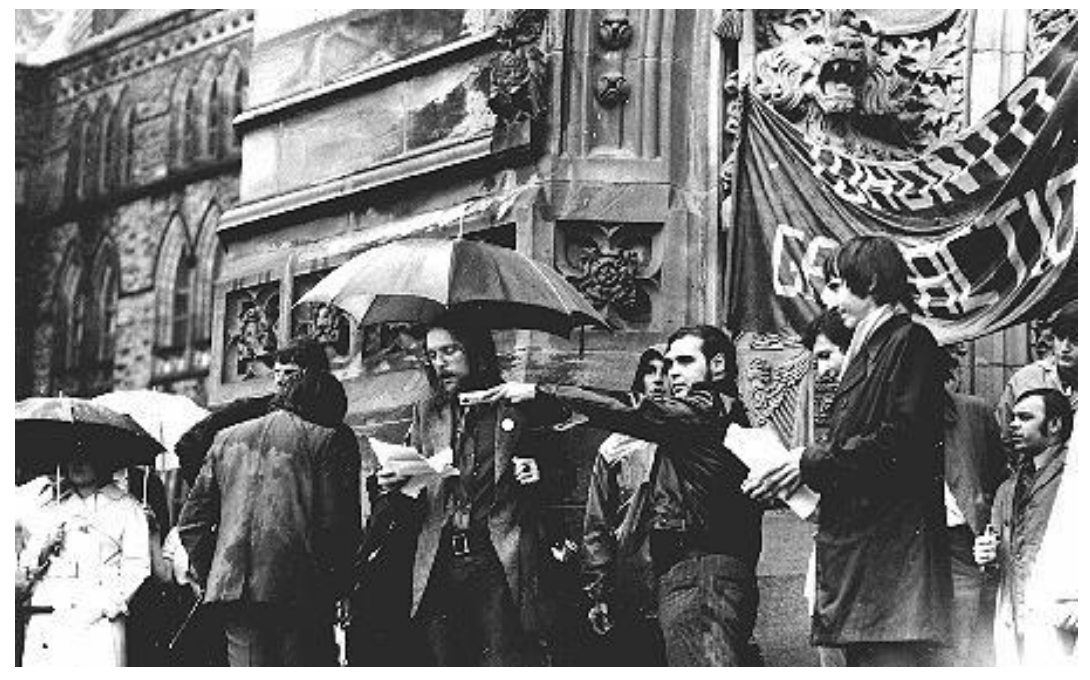

Figure 1.17

Canadian Lesbian and Gay Archives. We Demand, 1971. Protest Parliament Hill, Aug 28, 1971. Image from The August 28th Gay Day Committee. The Body Politic, Issue 1, Nov / Dec 1971. For detailed information, see Notes Political Power and The Archive \#2. WE DEMAND, 1971. From CLGA Archive in Toronto.

Herstory's online mission statement ${ }^{19}$ preserves and gathers information that was "denied to us previously by patriarchal historians" and "to encourage lesbians to record their experiences in order to formulate our living herstory." Further, their mission statement affirms, "archival skills shall be taught, one generation of lesbians to another, breaking the elitism of traditional archives" and "the Archives will never be sold nor will its contents be divided." By breaking from a tradition that sought to deny the existence of queer subjects, queer archives profoundly impact queer knowledge and reveal historical trauma as both not forgotten and sites for potential future recovery.

${ }^{19} \mathrm{http}: / /$ lesbianherstoryarchives.org/history.html 
Joan Nestle, among many others including Mabel Hampton (1902-1989), were closely connected with the Lesbian Herstory Archives beginning in the early 1970s. ${ }^{20}$ Mabel Hampton, a woman who had lived her long life in the African-American Lesbian community, donated her extensive collection of 1950s lesbian paperbacks and ephemera from her life. Many women came to volunteer nights to hear Mabel tell her tales of drag balls in Harlem and her version of the wild parties of the Harlem Renaissance.

This research attempts to be corrective in method rather than in historical record. By corrective in method, I mean challenging dominant forces that say, "you can't think this way" or "that isn't how you should do it." Forces of essentialization close the door on thinking and its potentialities. Seeing the unspoken calls for methodological re-alignment that does not seek truth but rather ways of seeing that are active and political in the face of erasure. This could be understood as a kind of visual literacy. Mieke Bal discusses such issues as a field between language, power and knowledge, she asserts that these kinds of re-alignments are:

Not between essences, but between situations in the field of power/knowledge. Hence, of what needs to be studied specifically, visuality is precisely that which makes vision much like language. This is necessary, not to reduce the former to the latter, as visual essentialists fear, but, on the contrary, to make its specifics stand out on the same terms, so that the two can be productively compared and responsible methodological exchanges can lead to true interdisciplinarity (14).

${ }^{20}$ (For detailed information, see Notes Political Power and The Archive \#3). 


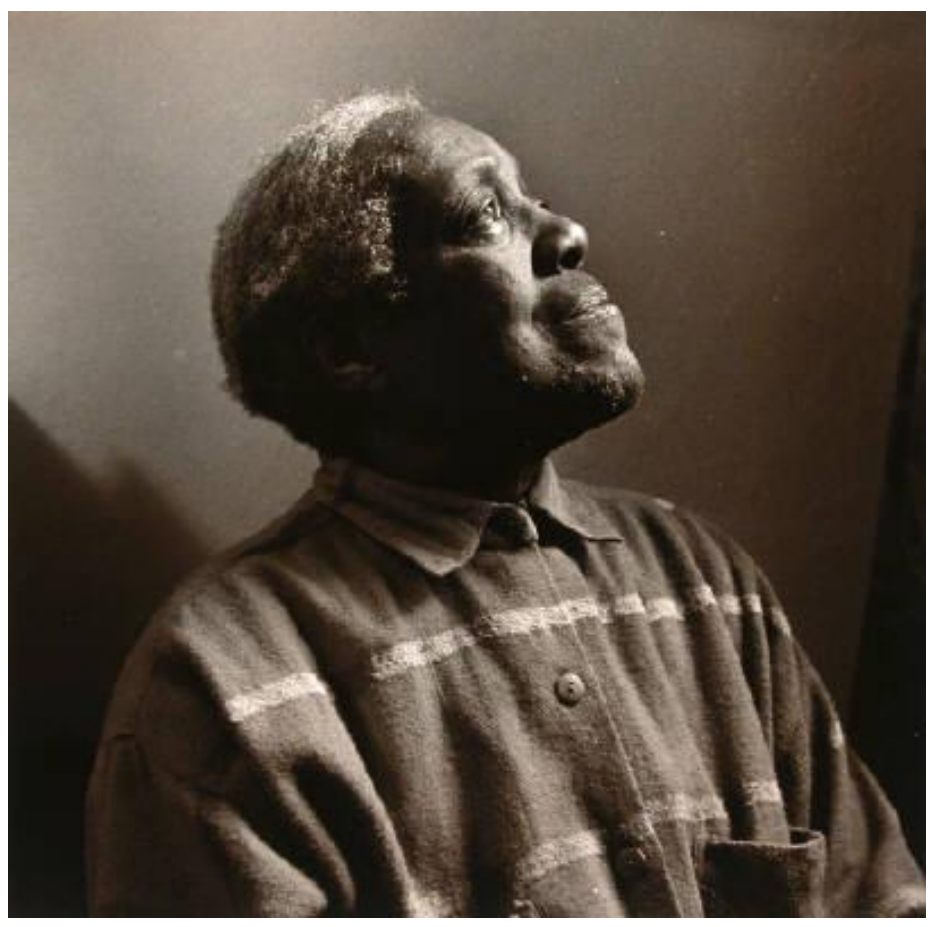

Figure 1.18

Photographer Robert Giard, "Mabel Hampton Sees the Pigeons at the Old Lesbian Herstory Archive, 1989." Image from exhibition Toward the Particular, curated by Scott Rayter at UTAC, University of Toronto September 2 - November 15, 2014

Born in Salem, North Carolina on May 2, 1902, Mabel Hampton was only two months old when her mother died. Her grandmother, who died when Hampton was seven years old, briefly raised her. In 1909, the seven-year-old Hampton went to New York City, where she went to live with her aunt and uncle. She ran away due to sexual and physical violence. She states, "my aunt went out one day and he raped me. I said to myself, 'I've got to leave here.' ... So this day, I got tired of that. I went out with nothing on but a dress, a jumper dress, and I walked and walked." Often living on the edge of poverty, she was wrongfully imprisoned for prostitution. She served a two-year sentence in Bedford Hills Reformatory and was incarcerated again after a neighbour told the authorities that Hampton was attending women's parties in New York City. Upon 
her second release, Hampton continued to live in the company of women who loved women and worked as a dancer in Coney Island for a women's troupe.

Although Mabel Hampton was not a queer body in the nineteenth century, I would argue that her existence was continually based on the survival from historical violence of racialization, classism and homophobia. Her recovery in/by the archive makes it possible to show how the memory of trauma in historical queer lives are entwined in symbolic political power that reveals the significance of defiance that may not dissolve trauma but can act as a visual symbol of persistence. Where a past is violent, there is also persistence. It is valuable to place the notion of the seen in a complex relation to the unseen, where the seen is considered evidence of truth and fact as it establishes a specific subject in relation to reality. 'Evidence' that was used against Mabel Hampton to put her in prison, or whatever instance 'evidence' was used to infringe, ruin, or wound her is turned on its head in her archived collection to give her credence, voice and visibility, where she is recalled on her terms. Her evidence as a black lesbian body can be recalled beyond the violence she endured and where the notion of 'evidence' becomes meditated and recuperated. The multiple dimensions in which black women face misogyny requires the notion of intersectionality to grasp, if not the whole picture, a much clearer one. To reinforce this point, Kimblere Crenshaw affirms:

The experience Black women face are not subsumed within the traditional boundaries of race and gender discrimination as these boundaries are currently understood, and that the intersection of racism and sexism factors into Black women's lives in ways that cannot be captured wholly by looking at the race or gender dimensions of those experiences separately... Race and gender intersect in shaping structural, political and representational aspects of violence against women of color (1244). 
When Mabel Hampton talked about her prison experiences, she states where she found kindnesses in a sea of injustices, "It was summertime and we went back out there and sat down. She (another prisoner) says, 'I like you.' 'I like you too.' She said no more until time to go to bed. We went to bed and she took me in her bed and held me in her arms and I went to sleep. She put her arms around me... and I went to sleep."

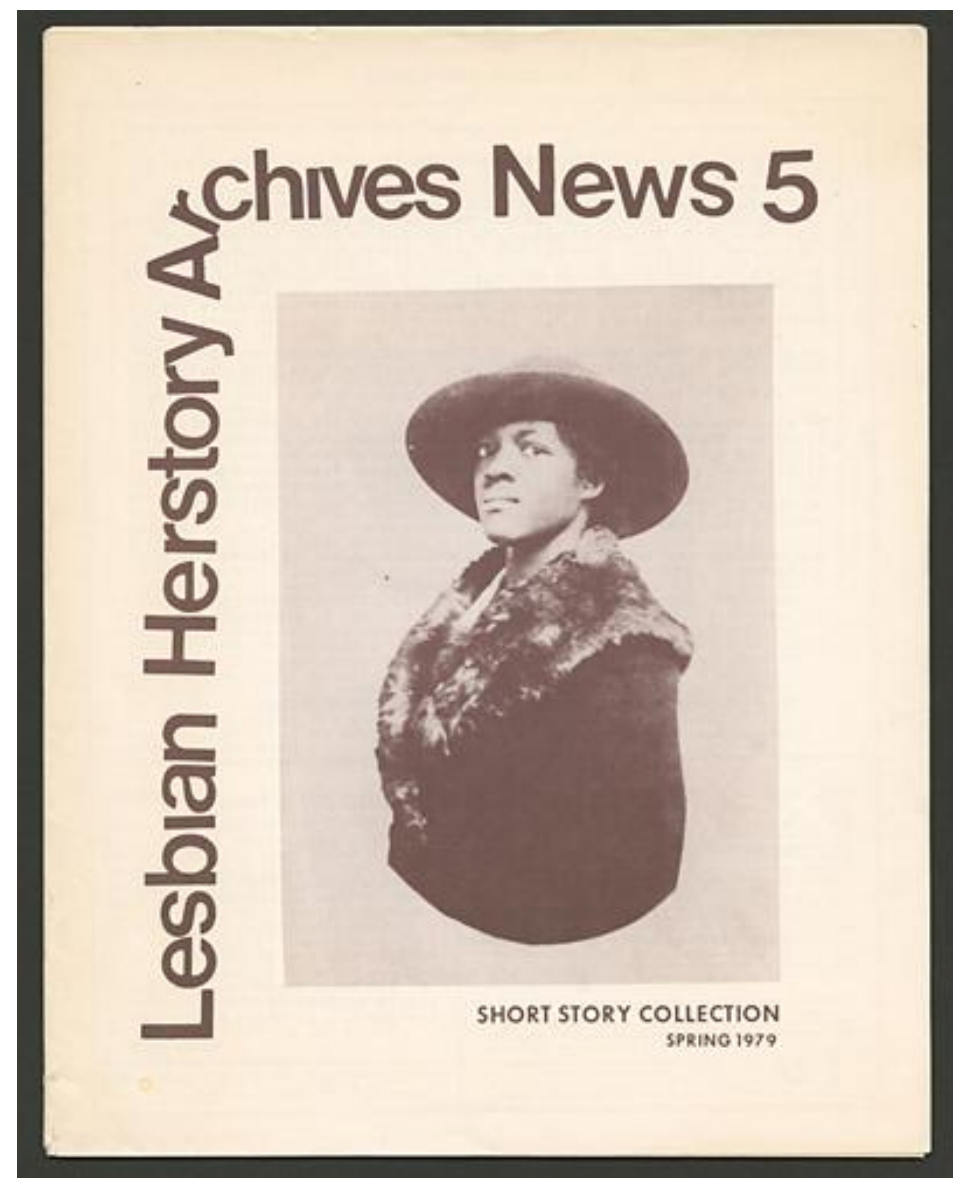

Figure 1.19

Mabel Hampton of the Lesbian Herstory Archive Newsletter, 1979. Original portrait is from the 1920s. 
Hampton's archive at the Lesbian Herstory Archive includes a vast array of documents from the Harlem Renaissance, personal ephemera of her lesbian loves and a broad view of queer community in New York. Mabel Hampton began working in the Housekeeping Division of Jacobi Hospital from 1948 until her retirement in 1972, where she earned the nickname "Captain". At Jacobi Hospital, she met Christine Jorgensen, a pioneer transsexual and paid nightly visits to her hospital room. Hampton carefully cut and saved newspaper articles on Jorgensen. In Hampton's archive, one finds Daily News article, December 1, 1952, "Ex- GI Becomes Blond Beauty," which contains a letter written by Jorgensen explaining to her parents why there is so much consternation about her case. Jorgensen explains, "It is more a problem of social taboos and the desire not to speak of the subject because it deals with the great hush, hush, namely sex."

Class and race are not synonymous with deprivation. However, it cannot be denied that class, race, gender, and sexual orientation are key factors in contemporary and historical violence and oppression. Hampton's collection at Herstory shows great sources of joy and communal strength. In 1932, Hampton met Lillian Foster. She states ${ }^{21}$, "And Lillian of course, Lillian was my wife." They were together for forty-six years (Lillian died in 1978). "There is nobody like you to me," wrote Lillian to Mabel when Mabel was away from home in search for employment.

As a couple, they were known as Mabel and Lillian Hampton. Hampton had a vision of what life should be; it was a grand, generous vision, filled with good friends and good food, a warm home, her Saturday afternoon opera broadcast from the Metropolitan, and Lillian by her side 22 . "She gave all she

${ }^{21}$ Quotes directly from Hampton archive in Herstory

${ }^{22}$ Mabel Hampton met Lillian Foster in 1932. The two remained a couple until 
could to doing the best she could. The sorrow is in the fact that she and so many others have had to work so hard for such basic human territory." In 1984, she gave a speech at The New York City Lesbian and Gay Pride Parade:

I, Mabel Hampton, have been a lesbian all my life, for 82 years, and I am proud of myself and my people. I would like all my people to be free in this country and all over the world, my gay people and my black people..$^{23}$

Heather Love addresses the complexity of reclamation by asserting, "rather than disavowing the history of marginalization and abjection, I suggest that we embrace it, exploring the ways it constitutes to structure queer experience in the present" (Love 29). Mabel Hampton and her archive at Herstory speaks directly to how marginalization and abjection can reverse traumatic discourse, and shift the disavowal of historical queer knowledge into a significant structure that reaches beyond, yet in tandem with social damage. "Modern homosexual identity is formed out of and in relation to the experience of social damage" (29). The "homosexual species" as stated by Foucault began to speak in its own behalf. However, due to historical damage of hegemonic structures of power, LGBT communities require sites of accessibility in order to develop and maintain queer discourse. To know your past is in someway to connect to your future. For queer folk around the world the experience of social damage, pain and loss demands our subjectivities to be viewed by us and for us. Where 'archivable content' embraces our losses, we face a dichotomy

Foster's death in 1978. Their letters and cards for over forty years is a discourse between lovers. Lillian addressed Mabel as "My Dear Captain", and Mabel addresses her "My Little Bear". The intimacy scrawled with hand-written pen is so intense that as I looked through them in 2012, I shook. They are inanimate objects that breathe as though they are alive, and it was as though I was with them in the same room. Even to think about them, I am almost moved to tears. ${ }^{23}$ Quote from the Mabel Hampton special collection, including transcripts of oral history. Lesbian Herstory Archives, Brooklyn, NY. 
between historic injury and a "plurality of resistances" (Foucault 96).

The emergence of LGBT holdings and archives since the 1969 Stonewall Riots and Gay Liberation across the Americas and the recouping of erased histories in post-Fascist Europe confront questions raised by the historical social regulation of sexuality and gender. Further, queer holdings, collections and archives challenge traditional consignation and legibility by confronting heteronormative and patriarchal structures that were historically intended to wound and erase. By "gathering together" (Derrida 10), queer archives and their practices operate to create access to queer histories. Under a political paradigm of social justice and anti-oppressive principles, queer archives offer broader approaches to developing strategies far beyond the hegemonic authoritarianism of nineteenth century social sciences. Although queer social bodies were regulated within its authoritarianism, queer archives demand of social justice illustrates historical relevance to queer visibility, discernibility and representation.

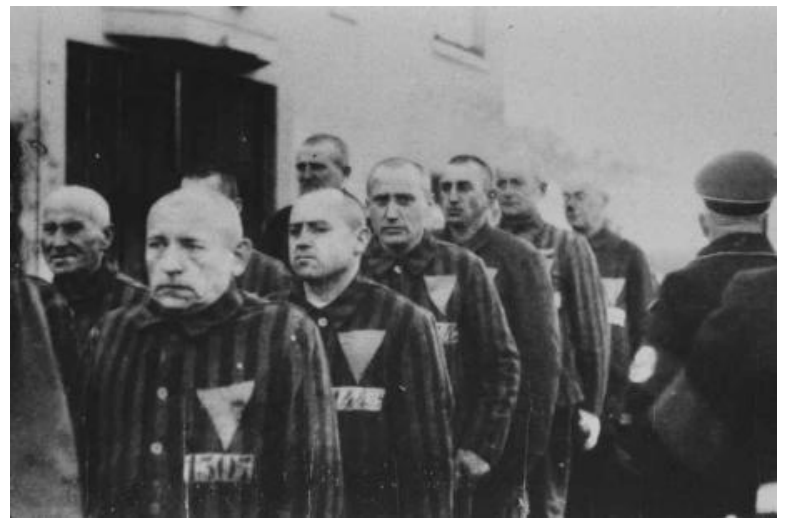

Figure 1.20

Homosexual prisoners, recognizable by the pink triangles on their prison uniforms in Sachsenhausen concentration camp, 1938. 
In conclusion, this chapter has examined the constitution and the challenge of the archive-its contents, its limits, and the political and historical forces that shape it. A broader paradigm shows however, how queer remembrance and history be recouped from a violent past. This chapter has attempted to shed light both on why the archive has held an authoritative grip on knowledge and how contemporary strategies of queer archives are redefining and undoing of historic erasure. The significance of the queer archive is relational to a violent past, and meaning is founded on the excavation of materials that could not avoid prohibition but rather survived them.

The historical construction of the archive and its gathering together of signs reveal systems of power authorized to control socio-cultural and political knowledge. Derrida's principle of "gathering together" (10) historically meant an authoritative grip on what was in the archive and what was not. Hegemonic, patriarchal, racist, misogynistic and homophobic ideologies impeded the voices of those on the margins, or used those voices to instil socio-cultural fear. Yet, the reverse discourse of gathering together queer history in archives with a mandate of queer perseveration and social justice enable a new generation of researchers, students and the curious to see first-hand the radicalism of queer elders.

Legitimacy and historic legibility under the consignation of law and order, which had been firmly embedded in the nineteenth century social sciences began to sink under the weight of its own imperialist and colonialist anthrophobia. The social body that had once been a triumph of bourgeois order was riddled with falsehoods of control, which no longer held the same cultural manifestations of order.

The social body emerges clearly as a construct of socio-cultural and political struggle. Systemic relations of power and control derive from a 
circulation of discourse, whereby both the effects of top-down power of imperialist, capitalist and industrialist approaches to knowledge enforced by law quickly became absorbed into social spheres. Everyone, everywhere could participate in the policing of sexuality, whether externalized by 'ratting out' a sodomite to law officials, prison sentences for 'gross indecency' or internalized shame that resulted in self-denial or the destruction of personal collections of same-sex affection. In this chapter, I have created context to the historical practices of the archive as a troubled primary source that sought to embed ideological control by constructing the social body. By placing significant research and discourse onto the concept of the archive, I have attempted to examine the social body as a construct of socio-cultural and political struggle.

The Lesbian Herstory Archive and Mabel Hampton are case studies that have confronted patriarchal structures of gender dominance, imperialistic traditions of racism and sexism to rupture traditional hegemonic positions of power, and to inform methodologies in community-based social justice imperatives. By gathering information that was previously "denied to us" and "to formulate our living herstory," Herstory directly addresses traditions intended to deny the existence of queer subjects. Mabel Hampton, an African-American, working class lesbian illustrates how the everyday queer, surviving routine cultural abjection, violence, racism, sexism and homophobia in American imperialism, can become an instrumental voice in queer historical knowledge. Hampton's life, loves and struggles reveal how the average person has extraordinary political influence over queer futurities. Her speech at the 1984 Gay Pride Parade in New York City exposes the magnitude of living history for queer communities by asserting sage wisdom of both self-acceptance as well as public declarations of historic visibility. 
Political Power and The Archive has tackled problems of historical trauma and the invention of homosexuality as constituted through medicine and the social sciences, in order to evaluate how historical imperatives of social control have extensively and systematically hindered queer knowledge. My method in this chapter has been to invest in questions of historicity through the context of the nineteenth century's relationship to the archive and normativity, and its implications for queer representations. However my approach is not necessarily historical in discipline, rather I have attempted to examine historicity as a location of political occurrences that both withhold and create access to knowledge. Further, by examining queerness through the historical binary of either silence or public degradation, archival practices and accessibility to queer archives propose the damaged and compromised subjectivity of queer desire as potential future sites of queer knowledge. 
A Poem With Purpose: For Olga Kasyanova

I write this to you

researching for you, and for myself,

Leo, Mabel and Others

You make me feel alive

At my most desperate, when I cannot see

beyond

an airless, hopeless mess.

She bowed her head when I asked,

What is it like

being a lesbian in Russia

in the new millennium?

Slowly

the words tumbled from of her tight lips,

I live in a mental apocalypse.

For some

Living isn't safe

Leo, Mabel and Others know it all too well.

Laughing, fucking and holding hands

in spite of horror.

Although quietly, I write this for you.

For now, for then

For more. 


\section{Chapter Two: Early Photography and Queerness}

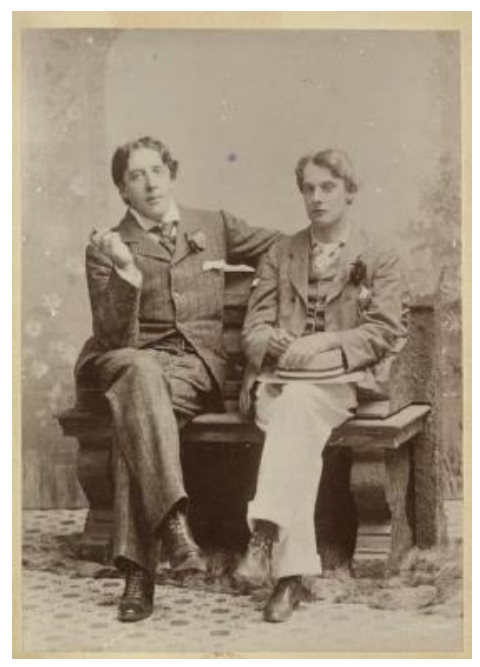

Figure 2.1

Oscar Wilde and Lord Alfred Douglas, 1893

My dearest boy this is to assure you of my immortal, my eternal love for you. Tomorrow all will be over. If prison and dishonour be my destiny, think that my love for you and this idea, this still more divine belief, that you love me in return will sustain me in my unhappiness and will make me capable, I hope, of bearing my grief most patiently. (Letter from Wilde to Douglas on the eve of his trial on April 29, 1895)

Through the analysis of both social conditions that formed discourses of homosexuality and Industrialism's development of photography, this chapter investigates photography from the late nineteenth century and its impact on queer representation. The birth of photography was a historically significant cultural moment that created innovative sites of cultural change. Yet there are disconnections between oppressive laws and social reform that reveal a cultural crisis of categorization, designation and distribution. For those involved in same-sex affection or non-normative sexuality, such taxonomies enforced layered and coded meanings in photography, which were inscribed by the 
criminalization of homosexuality and its social ostracism. While conversely, photography created the possibility to represent oneself and to make visible, however temporally, same-sex affection, queer desire or the imaging of queer selfhood.

This chapter tackles the divide between discursive technology and representation by examining the social conditions of same-sex affection and mass production in the nineteenth century. By considering this division, my research intends to investigate how industrialization and the function of photography involved the mass production of both images and ideologies that affected gender relations and sexuality. Further, the conventions that had been established in photography at this time disclose significant systems of class distinctions that exemplify both the labouring classes and the bourgeoisie. The mass production of the carte-de-visite and other forms of early popular photography created an industry for the production of the image, where the individual was sublimated to the mass. This can be understood through the conventions and standardizations of early portraiture photography.

Methodological approaches in this chapter adhere most closely with cultural and critical studies particularly in the style of Rancière's contribution to interdisciplinarity. For example, Rancière's work with 'historic material' is not meant to determine what is already understood within historical paradigms i.e., specific developments, events, or events of thinking. Rather, his approach is to rethink these events, in order to question prevailing historical paradigms as they have tended to prevent us from understanding socio-cultural transformations and the link between art, visual culture and politics. Part of the issue for Rancière is that the divisions between disciplines have influenced authoritative principles that have derived from the succession of historical events. Interdisciplinarity challenges the establishment of how knowledge is/has been 
distributed, and how that distribution has lent itself to the thinkable. By employing several approaches to politics, aesthetics and historicity Rancière's method is to create a new distribution of what is/can be thinkable become possible, particularly through his concepts laid out in On The Poetics Of Knowledge, in which disciplines are always intervening.

This chapter consists of three parts: Industrialization and Photography Queering Conventions and Representing Politically. The first section, Industrialization and Photography examines the role of conventions of photography and the construction of normativity, building on how ideological notions of empire and class distinctions were illustrated and endorsed through the mass production of photography. Geoffrey Batchen's research of carte-devisites and mass production offers insight into the industrialization of photography and its function in modernity and early capitalism through the materiality of the photograph. The second section, Queering Conventions discusses the nature of early photography in relation to queer subjects. Romantic friendship in the nineteenth century correlates with the social relations of industrial capitalism, particularly through industrial production that required physical proximity of workers, where the mechanization of labour intensified divisions of labour that fragmented lives across continuums of gender, class and race. The third section, Representing Politically questions issues of knowability and presence in photography, and I examine Roland Barthes' approach to punctum and studium in Camera Lucida and Jacques Rancière's concept of the political subject (le sujet politique).

The photograph as a site of presence and 'truth' has a long history of debate and contestation in photo theory. I take up these arguments by examining the contradictory nature of photography. Where Barry Goldstein claims "false objectivity" (Goldstein 63) in photography, photo historian John 
Tagg refers to photography as, "like the state...the camera is never neutral" (Tagg 64). I examine Goldstein and Tagg in relation to Roland Barthes' notion of having-been-there-ness and the materiality of photography (Barthes 44) and Jacques Rancière's notion of historicity and the political subject (Rancière 3566). The intent in this cross-dialogue is to consider the concept of picture-taking relationally to both the ontology of 'being' in an image and its impact on the politicization of queer subjecthood. While this chapter does indeed examine historical photographs, the approach is neither historical in terms of providing, proof beyond reasonable doubt, nor is the method the intent is to solidify historical truth. What this chapter intends is to examine a sense of time and space within photography, in order to explore photography, the aesthetic regimes of the empire and the potentiality of difference in terms of queer representation.

There are several photographic examples throughout this chapter, many of which are sourced from published texts or in the public domain. However, I bring original research to this chapter through unique case studies, which are Bonnie and Semoura Clark from the Beinecke Rare Book and Manuscript Library at Yale University ${ }^{24}$, and Mariam Babbitt and Augusta North from my personal collection. While not all images discussed in this chapter are carte-devisites per se, they derive from analogous photographic procedures-most are albumen prints and follow the same photographic processes of exposure times, photo development and are primarily similar in size. Whether they are carte-devisites or the larger but similar process as the cabinet card, the researched photographs in this chapter reveal a particular time and place in photographic

24 The Bonnie and Semoura Clark Black Vaudeville Photographs and Ephemera Collection is part of the James Weldon Johnson Collection, which was originally started by Carl Van Vechten in 1941 in honour of his friend, the late AfricanAmerican scholar, James Weldon Johnson. 
history ${ }^{25}$. The carte-de-visites and cabinet card photographs discussed in this research illustrate radical gender-bending and queer sexuality outside the status quo of their respective eras, inviting current rebuttals to the silence and erasure of historical queer representation, and showing why both its repression and reclamation are significant to queer knowledge and its futurities.

\section{Industrialization and Photography}

In his text Dreams of Ordinary Life: Cartes de Visites and the Bourgeois Imagination, Batchen analyzes the homogenized repetition of the popular and commercial carte-de-visites. He asserts, "the typical carte-de-visite photograph, with its self-consciously bourgeois subject leaning on a fake column or pretending to read at a small table, is habitually regarded as being entirely without imagination" (80). By examining how carte-de-visites have been utilized in social history to "obediently embody the sensibilities, economics ambitions and political self-understandings of the middle class" (81), they can represent how capitalism has informed and socially enforced its ideologies. Carte-devisites are portrait albumen photographs mounted on cards $21 / 2$ by 4 inches that were both popular and inexpensive ${ }^{26}$. The format was an international standard, unlike earlier photographs such as the daguerreotype and ambrotype, as cartes-de-visites could be sent through the mail without

25 (For detailed technical information, see Notes Early Photography and Queerness \#1).

${ }^{26}$ Albumen was the term used for eggs in the 19th century. Egg white (albumen), sugar from grape juice, salt (sodium chloride) and silver nitrate were applied to paper to produce the albumen print. The albumen prints were mounted on various-sized cards to prevent the thin fragile paper from curling or tearing. For the first time in photographic history there was a means of inexpensively producing multiple images from a single negative. The following types of card photographs were used: Carte-de-visite (CDV) $26 / 16 "$ " 4 " inches , Cabinet card (Imperial Carte-de-visite) 4 1/4" x 6 1/2" Victoria card 3 1/4" $\times$ 5", Promenade card 4" × 7", Imperial card 12 3/4" x 17 3/8", Stereograph 3" x 7 ." Sourced from http://www.mathewbrady.com/photos.htm 
protection. Queen Victoria compiled more than a hundred albums of cartes-devisites, while annual production of cartes-de-visites in England was in the hundreds of millions.

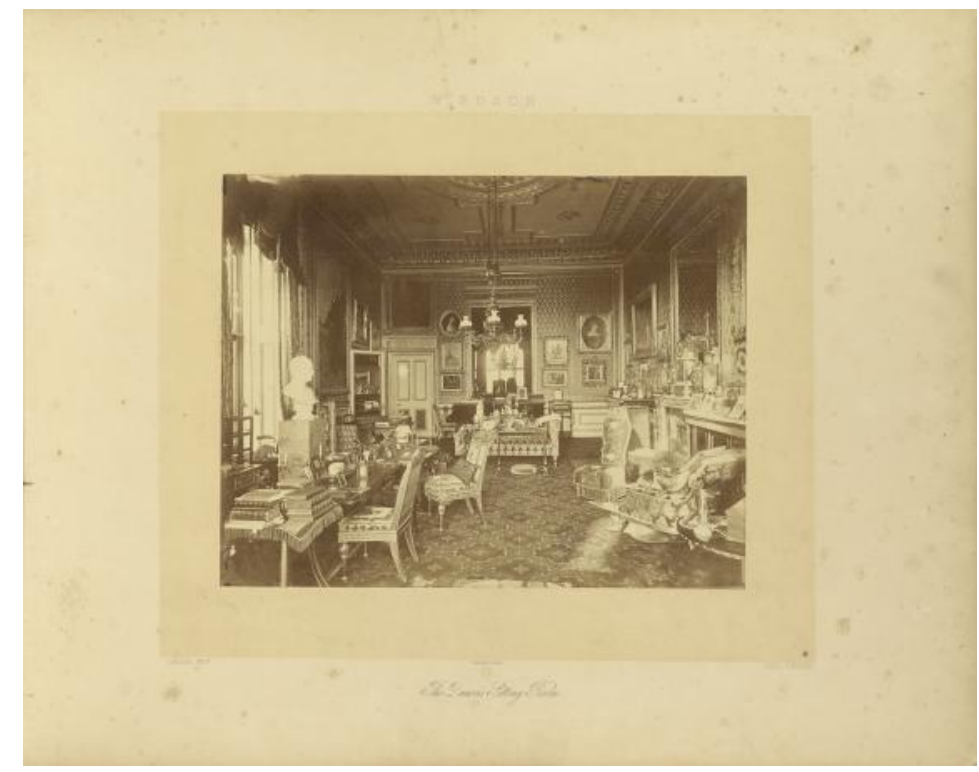

Figure 2.2

"The Queen's Sitting Room, 1867" by André Adolphe-Eugène Disdéri. Sourced from the Getty Museum

The quick time of shutter speed and photographic development created a "degree of theatricality," where both "photographer and subject had an active part" (Batchen 82). While the subject could "choose an attitude beforehand" (82), a system of established conventions was conveyed through the technological to reveal social and cultural structures. The function of photography at this time was to distribute and disseminate the image.

This process was articulated through the personal portrait as gift or token of remembrance and as a "calculated piece of propaganda intended [for] preserving political power" (Batchen 83), as seen quite clearly in the photographs of Queen Victoria depicting of motherhood and wifely commitment 
(see example Figure 2.3.). The cult of the empire utilized photographic representation to deliberately propose "popular sovereignty [and] signify political victory of the bourgeoisie" (83):

Queen Victoria is distributed in thousands of identical copies...it simultaneously distances and brings her closer. Such a photograph certifies that everyone is now equally susceptible to reproducibility, everyone can be reduced to the same scale and in the same format. (Batchen 90)

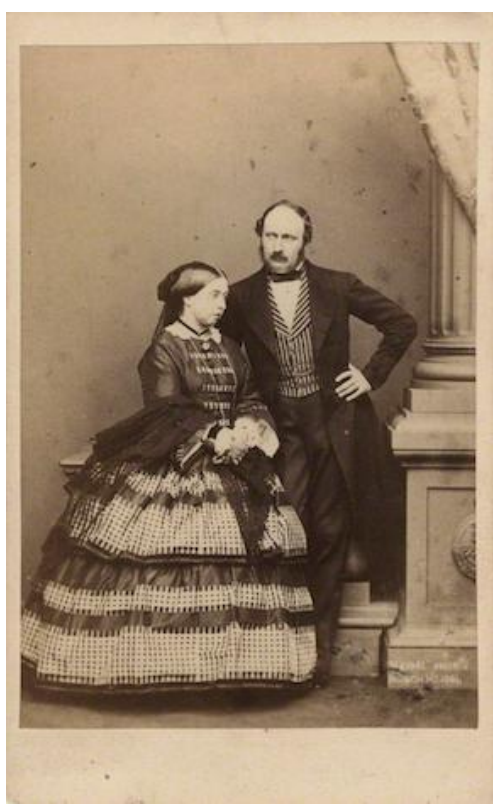

Figure 2.3.

Carte de visite of Queen Victoria and Prince Albert, 1861. Sourced from the Victoria and Albert Museum, London

If, as stated by Walter Benjamin, "the criterion of authenticity ceases" (224) due to mechanization, whereby creative production shifts from the ritualistic to the political, then carte-de-visites offer an invaluable insight into the cultural fissure of the nineteenth century by illustrating a complex tension between "capitalism's façade of self-assurance" (Batchen 90) and the "uncontrolled distribution of [non-normative] image[s] that might otherwise have 
been private" (91). By examining the social order of not only the nineteenth century but how social order informs popular culture, photographs from this time period "confirm the established order of capitalism" (Batchen 8) through the repetition of aesthetics intended to mimic the "industrial bourgeoisie" (8) ${ }^{27}$. Through conventions such as backdrops, props and curtains, ideological systems of middle class values were intentionally displayed to connote respectability. This argument is manifested in what Batchen views as cultural repetition by copying conventions, whereby cultural fixations of respectability are viewed through the dominant system of the bourgeoisie and high art. These predictable conventions of class are codified, imitated and performative, thus inviting slippages between cultural economy and representation.

Using conventions such as a swept back curtain, table and chair, carpet, plants, backdrops of either pastoral landscapes or domestic window views, bourgeois culture is signalled as a standard, and was absorbed by the labouring classes into their matrix of visual signifiers. Such cultural hegemony employed by photographic conventions illustrates cultural capital through the social reproduction of the photographic image. While we can understand ideological systems of bourgeois values as written on the surface of early photographic portraiture, such social conditions are not merely external but rather internalized through repetition. Mechanization gave way to standardization both in terms of purchasable products as well as ideologies. How can standardization create space for the political? What kinds of creative production or "imagination" as stated by Batchen can subvert discourses of conventionality?

${ }^{27}$ Walter Benjamin asserts, "Photography first conquered the field with the visiting card, whose first producer, significantly, became a millionaire. It would not be astonishing if the types of photography which direct our attention back to preindustrial flourishing of photography were found fundamentally related to the convulsion of capitalist industry" $(1969,220)$. 
In Figures 2.4 and 2.5, upper-middle-class interiors exemplify the codes of industrial capitalism and social order. By constructing photographic spaces that imitate "an economy of repetition," photographs from this time period demonstrate the burgeoning "capitalist consumer society" (Batchen 89-90). In both images, it is clear that the men pictured are within the labouring class. Their rumpled pants, askew hats and well-worn jackets suggest the displacement of labour in early commercial capitalism. Yet, they pose surrounded by tropes of bourgeoisie domesticity. Backdrops connote classic architectural interiors in the style of theatres, or perhaps, foyers of upper class homes. Their chairs are lathed with rounded edges; such decorative spindled chairs are a high-end version of the plain, backless stools or wooden buckets that these labourers likely utilized on a daily basis. The social and cultural difference between the bourgeoisie and most others in the nineteenth century is demonstrated in early photography as a site of visual entanglement of capital. Those pictured in Figure 2.4 and 2.5, they may have not been to grand theatres or attended the opera, yet the temporary flash of photography could imbue their lives with the hope of class mobility. The falsehood of classpiration, the aspiration of class mobility, is revealed in early photography as both possible or at the very least performed. 


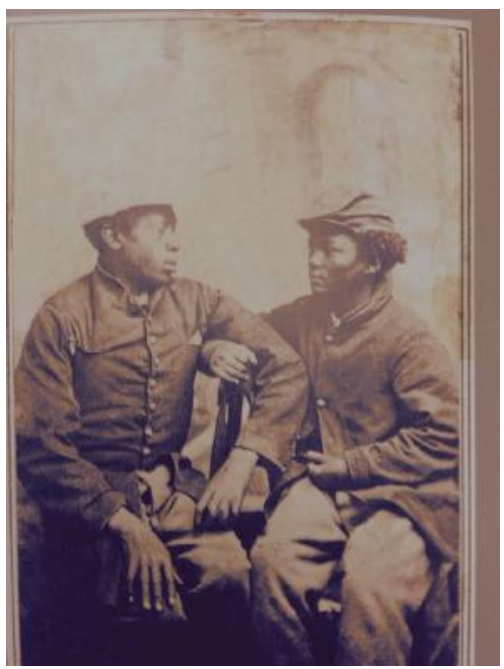

Figure 2.4

"John and Frank" are inscribed on the portrait. Carte-de-visite. Baton Rouge, Louisiana, 1863. Sourced from Dear Friends

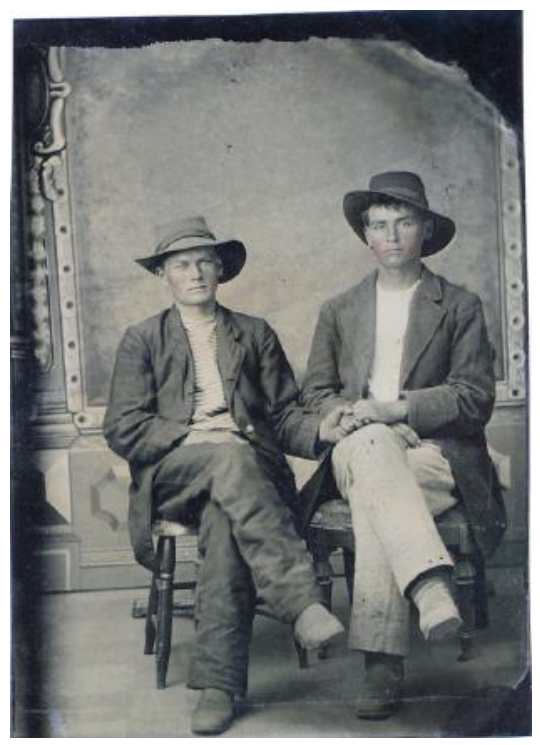

Figure 2.5.

Unknown subjects and date, Hand-tinted, Tintype. Sourced from the Internet 
Such pictorial classism reveals the cult of the empire as a fetishization of social discipline, whereby staging social hierarchies informed cultural signs of social spectacle. With arms entwined, hands clasped together, either beholding each other or in close proximity, these images disclose same-sex affection and tenderness that are relational to the segregation of the sexes and the division of labour that not only enforced mobility of labourers but also inscribed intense friendships in the face of isolation and loneliness.

\begin{abstract}
Labour divisions played a large part in the plethora of same-sex affection carte-de-visites from the long-turn-ofthe-century. Commercial capitalism in its preindustrial phase had reorganized production socially, industrial capitalism reorganized it technically through the mechanization of human labour. Industrial production then required the physical proximity of workers with machinery in a clearly delineated workplace: the factory. With the construction of factories, inland towns and coastal cities came to reflect physically, and to perpetuate in the process, the further fragmentation of American social life along the lines of class, ethnicity and race. (Deitcher 70)
\end{abstract}

How do the conventions of carte-de-visites both enforce classist hegemony while simultaneously appropriating conventions to speak of alternative realities? 


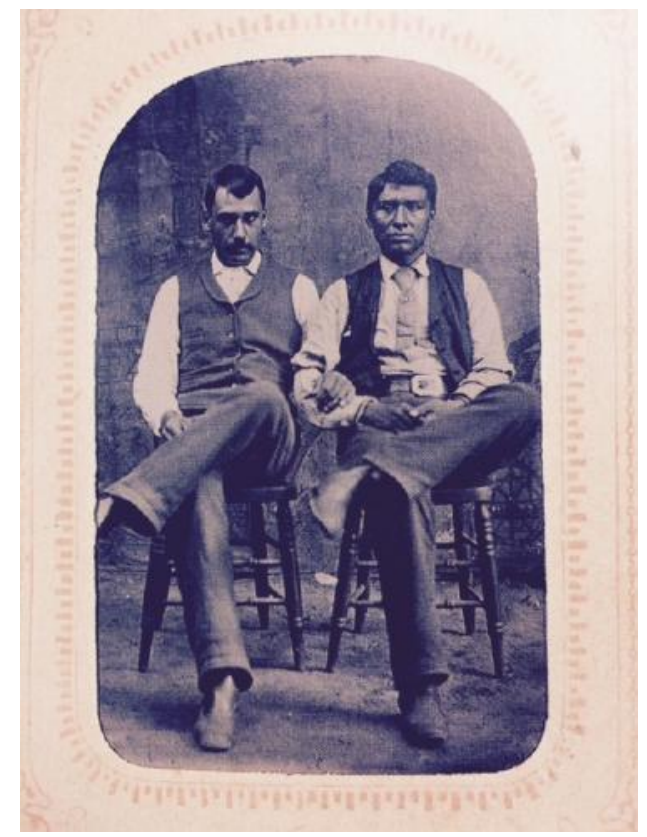

Figure 2.6.

Photographer Unknown, Subjects Unknown, Tintype in Paper Sleeve, 1885. Sourced from David Deitcher's Dear Friends

Although the tintype is a slightly different photographic process than the carte-de-visites, it was patented and widespread around the same time. ${ }^{28}$ Figure 2.6 shows clearly the conventions of early photography, and its inferences regarding the labouring classes and effects on imaging race. There is no accompanying information to this photograph; we have no idea of the relationship between these two men, or what brought them to a photo studio. However, if we consider the gestures expressed between them, they are not strangers; if we reflect the clear variance in racialization, there is something unusual in their sense of equity. Further, if we ponder the photographic conventions visible within the frame of this image, a sense of standardization is

${ }^{28}$ In 1856, tintypes were patented by Hamilton Smith in the United States and by William Kloen in the United Kingdom (first called melainotype, then ferrotype, then finally tintype). The albumen print was invented in 1850 by Louis-Desire Blanquart-Evrard. The carte-de-visite was patented by André-Adolphe-Eugène Disdéri in 1854. 
enforced with the predictable meaningless backdrop. Yet, conventions are subverted through their affection and discernible racial difference in an era of phrenology and eugenics and others forms of "scientific racism" (Somerville 243).

How can we examine the mechanization of the lens and the optics of early photographic and its social function? Photo historian Alan Trachtenberg claims that the alienated employee was part of industrial capitalism's, "growing numbers of lonely persons who found in photography some forlorn hope of alleviating isolation through the exchange of images" (Trachtenberg 11). For labouring workers in the nineteenth century, mass transience and isolated work environments produced the need for social bonds. The cult of nineteenth century friendship addresses the overarching disenfranchisement of men and women in the labouring classes. Optically, the photograph produced more than simply an image. Rather, it helped construct as sense of togetherness, however temporal or short-lived. Deitcher speaks to this issue when he states, "not only did photographs of intimate friends make it possible to keep the image of an absent loved one close, they provided evidence of comfort and love in the midst of widespread social disruption and human disconnect" (75).

As analyzed by Walter Benjamin in A Short History of Photography, the development of photography was interconnected with the concept of optics and social function. Benjamin asserts that photography as a technology employs the conscious (the viewer/eye) and the unconscious (the subject/camera) to question modes of reality. By reproducing one's image in studio portraiture, the conventions of backdrops or props inform systems of social understandings through an optical apparatus. In photography's "conquest of darkness" (207) ${ }^{29}$

${ }^{29}$ For Benjamin the technical conditions of photography produced an "aura-like impression" $(1969,207)$ that was dispensary of social functions. He states, "The 
with flashes and lighting to manipulate reality, Benjamin states that long exposures created conscious decisions of where and when stillness was represented. Benjamin saw the time-based nature of the procedure as not out of the instant, but into it $(1969,204)$, suggesting that photography and the captured moment were meant to last (205).

Further, Benjamin suggests that the social function of photography is not necessarily a static process of personal knowledge or relationship with a subject in an image. Rather, photography holds the possibility of interest beyond the subject or those who know the subject, explaining a universality of interest in a photograph. What Benjamin suggests is that photography offers a moment unto itself that informs notions of connectivity both between sitter and photographer, and viewer and subject. Substantiating this argument, Benjamin states, "There is no work of art in our age so attentively viewed as the portrait photography of oneself, one's closest friends and relatives, one's beloved, and thereby moved the investigation out of the realm of aesthetic distinctions into social function" $(1969,211)$.

Under such considerations, Figures 2.4 and 2.5 occupy a moment in both photographic history as well as industrialization where labouring classes could exchange these inexpensive products as tokens of affection, connection and close friendship. However, the pathologizing of same-sex affection began to put a restraint on close male bonds, beginning in the late-nineteenth century. For John Ibson, in Picturing Men: A Century of Male Relationships in Everyday American Photography, the cultural artefact of photography is an index of

photographer, however, came to every customer as a member of the rising class and enclosed him in an aura which extended even in the folds of his coat or the turn of his bow tie. For that aura is not simply the product of the primitive camera. At the early stage, object and technique corresponded to each other as decisively as they diverged from one another in the immediately subsequent period of decline" (207). 
complex cultural processes, particularly when "the sodomite was no longer a "temporary aberration," but a "species" (Ibson 10). For historical queers, creating images outside the status quo was a primary instrument of selfknowledge, memory and representation. Because of the tension between subjective intimacy and social threat, there were invisible but ominous social dangers beneath the surface of these images. Ibson further discusses how photographs as a cultural artefact manifest cultural beliefs and practices. He states:

The photograph does not stand merely as a reflection of masculinity's history. What Clifford Geertz has said of cultural patterns in general applies directly, I believe, to the ritual act of picture taking and to the producers that result from that act. Culture patterns, Geertz wrote, "have an intrinsic double aspect: they give meaning, that is, objective cultural form, to social and psychological reality both by shaping themselves to it and by shaping it to themselves." (11)

Jamianessa Davis discusses homoerotic photographs from the nineteenth century in Queer Theory and Nineteenth Century Homoerotic Photography. The articles focus on male nudes examines how photographic representation was a "Classical Alibi" where "traditions of heroic Greek and Roman male perfection [were used] to justify male nudity and homoeroticism in imagery" (22). As I discussed in the introduction, Greco-Roman themes such as in the Robert Gant photographs (Brickell) are widely available tropes of masculinity, sexuality and power. There has been excellent scholarship on nineteenth century photography and male nudes, such as Thomas Waugh, James Smalls, Allen Ellenzweig, Jonathan Ned Katz, David Deitcher, H.G. Cocks, John Ibson, among others. Yet, the lack of attention to women in that sphere, in itself elaborates on the problems of dealing with/discovering the 
marginal. Examples of same-sex affection between women are challenging to find, which begs the question of why this is the case. Certainly the expectations of the domestic domain for women hindered photographic representations as well as the currency of sexualized women for the male gaze. Pornography placed women's bodies, often for the pleasure of men. What about the everyday woman who wanted to capture her own life? As I state briefly in the introduction, life-writing was an invaluable site of expression for lust, desire and love for women in the nineteenth century. Sharon Marcus points out in Between Women: Friendship, Desire, and Marriage in Victorian England, "women were not included in the legal definition of sodomy and were less likely than men to be arrested for public sex acts, and thus have faded from view in work based on police reports and state records" (14). Further she asks, "Weren't Victorians too invested in female sexual purity to admit that lesbians existed? Didn't the conviction that women had no sexual desire run so deep that in fact women couldn't have ever had sex with each other?" (12).

\section{Queering Conventions}

Resistance compels the queer historian to unearth precious traces of that past and to disseminate them in the form of previously untold stories of men and women, some who have succeeded as others failed to live with and act on their forbidden love...the queer historian helps ensure the continued availability of the past as a source of validation and connection for similarly isolated individuals in the future. (Deitcher 51) 


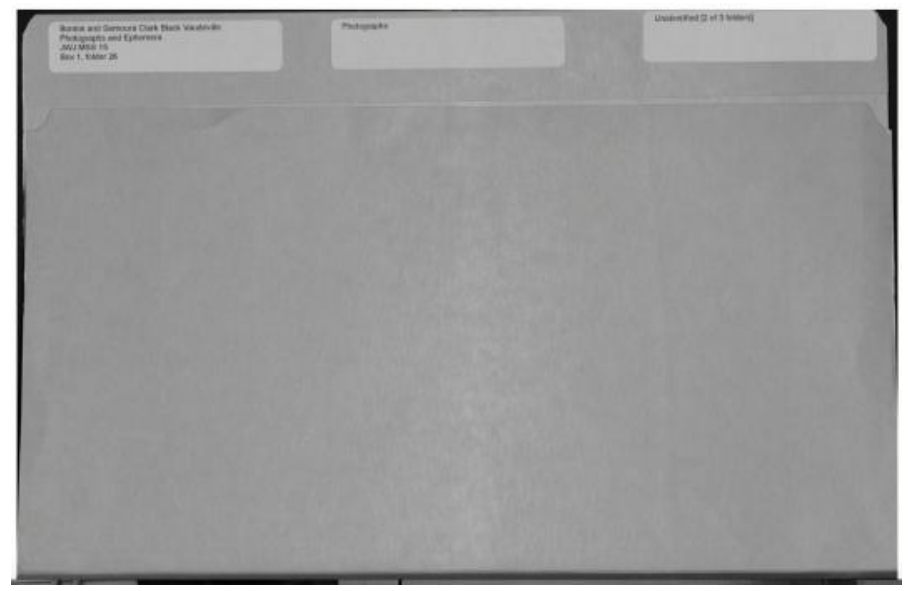

Figure 2.7

Many of the photographs discussed in this section have no known date, location or any information. This is particularly true for Semoura and Bonnie Clark, whose folder is imaged above.

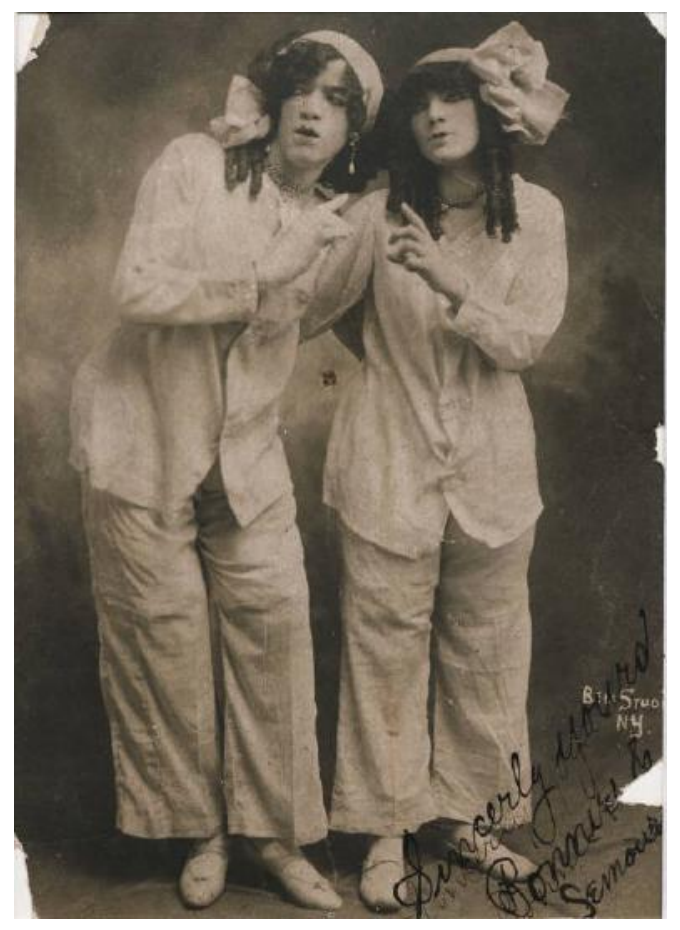

Figure 2.8.

Bonnie and Semoura Clark, date and exact location unknown. Sourced from Beinecke Rare Book and Manuscript Library, Yale University ${ }^{30}$

30 Dear Ms. Rogerson, (Nov 18, 2014)

Thank you for your inquiry. Unfortunately, we are unable to answer any of your questions concerning Semoura and Bonnie Clark. It is not identified in any way, and is in fact filed in an "unidentified, undated images" folder. 
Bonnie and Semoura Clark were African-American vaudevillians that toured with the Theater Owners Booking Association (TOBA) ${ }^{31}$. The TOBA provided segregated entertainment for people of colour in the South and Midwest of the U.S. Figures 2.8 and 2.11 provide a visualization of AfricanAmerican performativity and queerness in the long nineteenth century. Although there is little known about Bonnie and Semoura, such as exact birthdays, where they grew up and how they met, we do know on stage they identified as sisters.

Bonnie is on the left of Figure 2.8 and Semoura Clark is on the right. With heavy white makeup that appears as if 'white-face,' hair in ringlets and wearing pants while performing a kind of soothing femininity, this image is unusual for its time. Fingers are gently raised to suggest a sshhh, whether it is telling oncomers to be quiet or implying they have a guarded secret that they will never share. It is a striking image that contrasts a sense of performativity and playfulness with a politicized logic of subversion.

Their curls appear youthful, even juvenile, and the large bows on their heads resemble the girlhood fashions of the era. Yet they are in drag, and wearing pants. Cross-dressing and gender performativity was a popular form of entertainment, yet it is curious that in their performance of femininity they are wearing pants. In Victorian society, girls were scandalized by wearing trousers since state regulation across Europe, the U.S and Canada outlawed women wearing pants ${ }^{32}$, to be a woman or to cross-dress as a woman or to be a historical transgender subject in pants at this time is both an act of rebellion and

Yours,

Diane Ducharme, Archivist Beinecke Rare Book and Manuscript, Yale.

${ }^{31}$ (For more detailed information, see Notes Early Photography and Queerness \#2.)

32 "It Just Became Legal for Parisian Women to Wear Pants" Article by Megan Garber on Feb 4, 2013. The Atlantic. http://www.theatlantic.com/sexes/archive/2013/02/it-just-became-legal-forparisian-women-to-wear-pants/272836/ 
politicization. Trousers on women in this time period were a nod to the Suffragette Movement and women's equality. Pants were a sign of protest, provocation and dissent from traditional roles assigned to women.

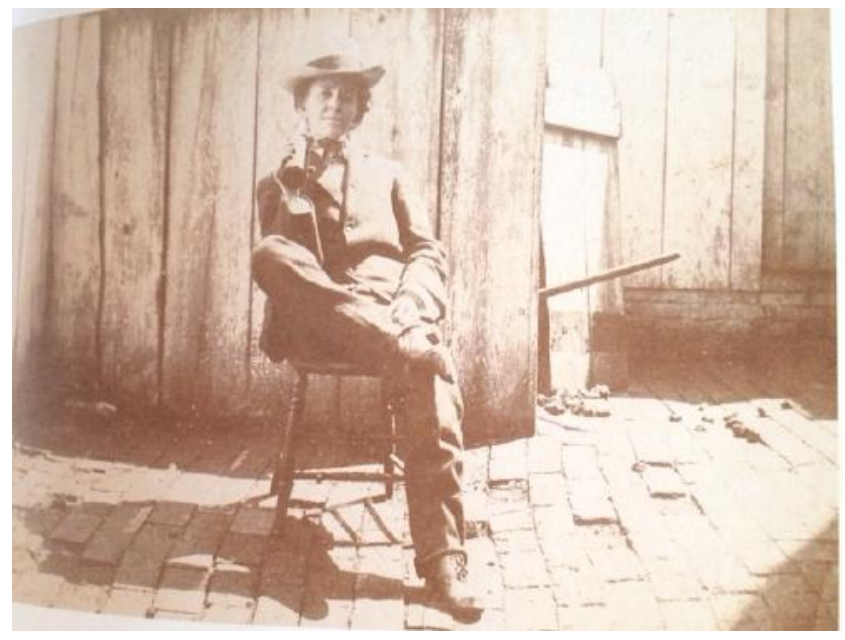

Figure 2.9.

"Mother" (as labeled on the back), Albumen print. 1890. Sourced from Women in Pants.

In Figure 2.9 "Mother" bends her leg over the other refuting conventions of femininity. Her pants, jacket, boots, hat and tie fit her as though they were her own. She appears to be drinking a beer from a bottle. Mother gives no sign of camp or dressing up for the camera. It is as if one could find her sitting in the back lane at anytime. The photo feels matter-of-fact, as if 'here is Mother.' Conventionalities of photography and gender are transgressed, particularly in its casualness. Yet, the sunlight pierces through the right side of the frame, highlighting a large stick poking out of the fence, like a phallus. I read this image as tongue-and-cheek but without the performativity of camp. Was it intended? Was it an accident? I would argue its intentionality because if the broom handle or stick had fallen while the picture was taken, the subject would 
have turned their head, thus blurring the image. The crispness of the image suggests the focus of the camera lens, the intentionality of the sitter or photographer as well as a sense of nuanced and sophisticated humour.

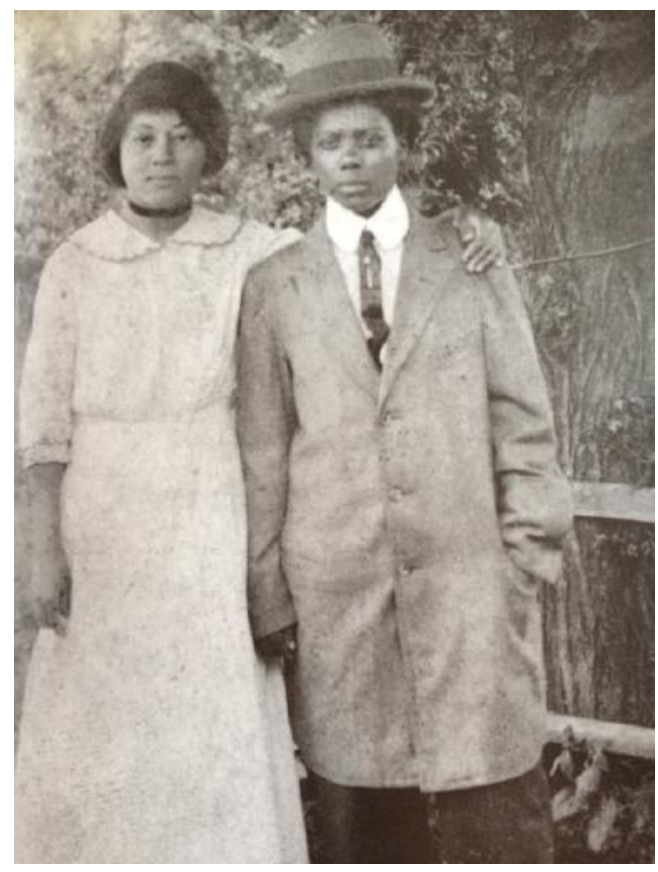

Figure 2.10.

"Young Couple, early 1900s" Sourced from Women in Pants.

In "Young Couple," Figure 2.10, the representation of people of colour in the context of gender-bending and sexuality offers insight into butch/femme sexuality, and/or transgendered visibility. On the right, in an overcoat clearly too big, the subject wears a man's hat and thin tie, staring directly into the camera lens. There is no smirk, no playful flirtation with the camera. It is an understated pose. On the left, in a light-coloured dress and fashionable choker of the times, her arm extends across and rests on the shoulder of her masculine counterpart. The affection between them is stolid, almost practical. What is unclear is whether the background is outdoors, or a backdrop in a photo studio, and such 
knowledge would aid in its readability. However, regardless of whether the photo was shot on location in the outdoors or set within a studio, the background conveys a sense of the pastoral. Whether is it a stroll through the park, or set in a backyard or a staged setting, it illustrates the appreciation of nature and pastoral scenery, and proposes agrarian leisure and pleasure seeking in nature.

In Figure 2.11 we see a seated male subject with two subjects in female drag; signifiers of bourgeois class surround them. Thick drapes loosely cover a stained-glass window. Their attire of long silk dresses puddle onto into the floor, while the man in the centre has shoes so shiny that they sparkle. I have ruminated over this image for many years, amazed by both its photographic formality and disruption of normativity. I first saw this image on the cover of Siobhan Somerville's book Queering The Color Line: Race and the Invention of Homosexuality in American Culture. There was only a citation stating where the image had been sourced and included no other information. I contacted the Beinecke Rare Book and Manuscript Library at Yale University to no avail, as the image had not been digitized. From there I reached out to Siobhan Somerville to enquire about the image, and she too had little information ${ }^{33}$.

${ }^{33}$ Without the help of Emma Ward (PhD candidate at University of Glasgow, School of Critical Studies), I would never have gained access to this image. 


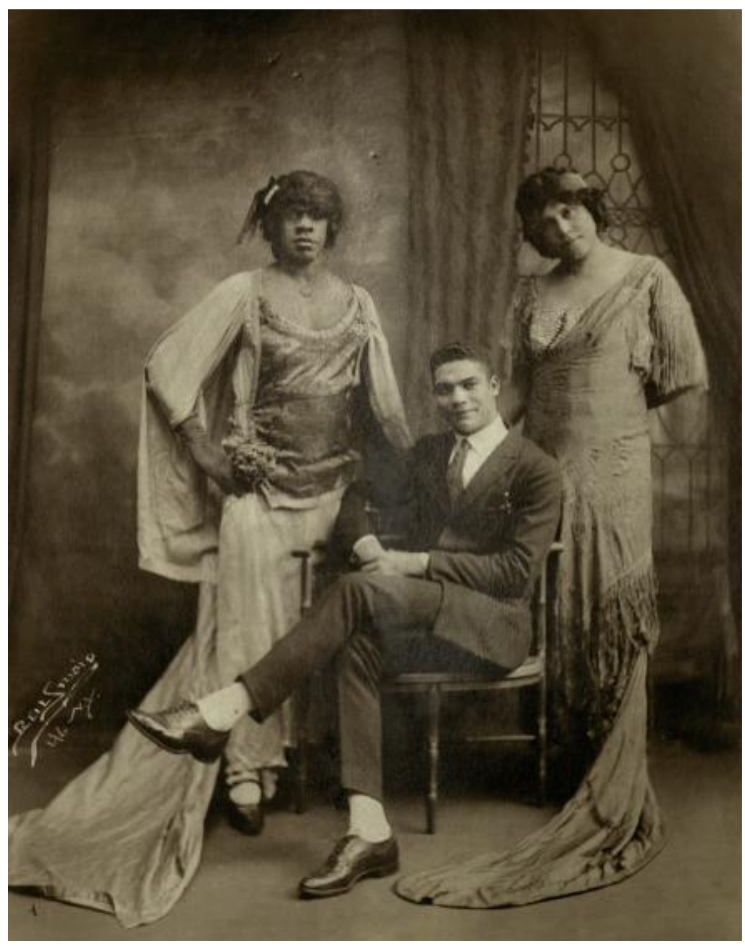

Figure 2.11

Bonnie and Semoura Clark, date and exact location unknown. Sourced from Beinecke Rare Book and Manuscript Library, Yale University

This group portrait, Figure 2.11, addresses the significant meaning of non-white historical queer subjectivity by signalling how race, sexuality and gender are intertwined. As it is unclear when this photograph was taken or who is in the photograph, we know simply that Bonnie and Semoura Clark are pictured and that the image was produced in a photo studio somewhere in New York. This image could have been produced as late as the 1920s Harlem Renaissance, however my interest in this image is in how conventions of industrial capitalism and bourgeois tropes of class are both employed in the photograph as well as superseded through gender, race and sexuality. Due to the extreme challenges in finding photographs of people of colour that are engaged in themes of queerness from the long nineteenth century, I have 
broadened my scope in order to include images of Bonnie and Semoura Clark to ensure the inclusion of queer racialized representations in this research.

Shawn Michelle Smith describes in American Archives: Gender Race and Class in Visual Culture how the codification of the body in photography during the nineteenth century can be seen as a kind of coupling between the technologies of photography and self-possession. She emphasizes concepts of identity and social hierarchies as mutable in the age of reproduction, where interiority was codified on the body. Smith explores early photographic portraiture as a site that expected to reveal the essence, not simply the likeness of the subject. While Smith examines specific photographs created by women in the nineteenth century, some of her claims can extend to queer subjectivity. Particularly, Smith asserts that the reproduction of one's image through the commodification of photography could expunge the imperialist gaze by declaring ownership of one's body.

The conventions of photographic portraiture at this time are revealed in Figure 2.11 with the repetitions of class commodification. Long drapes cascade down from tall windows as if it were a bourgeois parlour. As Geoffrey Batchen notes, the "self-consciously bourgeois subject" (80) is continually found as an allegory of early photography and industrial capitalism. Yet in Figure 2.11, the self-conscious bourgeois subject is unmistakably performing a multiplicity of cultural commodifications, such as upper-middle-class tropes of respectability, and femininity and masculinity while firmly and undoubtedly disrupting normativity.

Flat chests with compact pectoral muscles rise above the lacy trim of scooped necked gowns. Silk and satin fabrics caress broad shoulders, fitted snuggly to their waists with swathes of fabric neatly encircling the trio. Centered is a male sitting on the three-legged chair, seemingly mimicking the three 
photographed subjects: one centered, two on the side in perfect symmetry. Without 'white-face' or heavy white makeup, we can see skin tone, which in its variability is political ${ }^{34}$. In Figure 2.11, Bonnie is on the left, Semoura on the right with an unknown male in the centre (perhaps a young Phil Black). The performativity of middle-class respectability through photographic conventions is apparent, as is its disruption.

The act of historical reclamation for the queer historian requires the "search for evidence of the past, even if it includes the debris of lives wrecked by antiquated injunctions or disfigured by more modern technologies for regulating desire" (Deitcher 51). Such 'evidence' is slippery, and in some cases unknowable. However, to examine such images within a historical context that repudiated sexual difference and lawfully charged, incarcerated and publically shunned non-normative sexuality, a sense of symbolic defiance is implicit to the understanding, examination and dissemination of queer histories.

Bonnie Clark was associated for many years with Phil Black, the originator of the Harlem drag balls ${ }^{35}$. Phil Black was also known as Cora in drag. Whether 'associated with,' 'life-long companions' or 'intimate friends,' such terminology discredits historical queer subjectivity and a voice for those who persisted and survived. For those outside the status quo, queer desire can be understood as both actual and symbolic defiance of compulsory heterosexuality. Here, I would like to point to the complexity of knowability, where while we may not know all there is to know, and may not know what can

${ }^{34}$ The politicization of skin tone and its social meaning is beyond the scope of this dissertation, however it is a significantly palpable cultural experience. See Frantz Fanton's Black Skin, White Masks (1952) for analysis of the divided selfperception of the Black Subject due to colonization, slavery and trauma. Further, Jennifer L. Hochschild's "The Skin Color Paradox and the American Racial Order" examines the paradox of skin colour and racial hierarchy in Social Forces. 2007; 86 (2): 643-670.

35 (For detailed information, see Notes Early Photography and Queerness \#3). 
be known; a fundamental approach in this research is create a space for thinking about queer representation as a location for unknowables do not mean there is nothing to know.

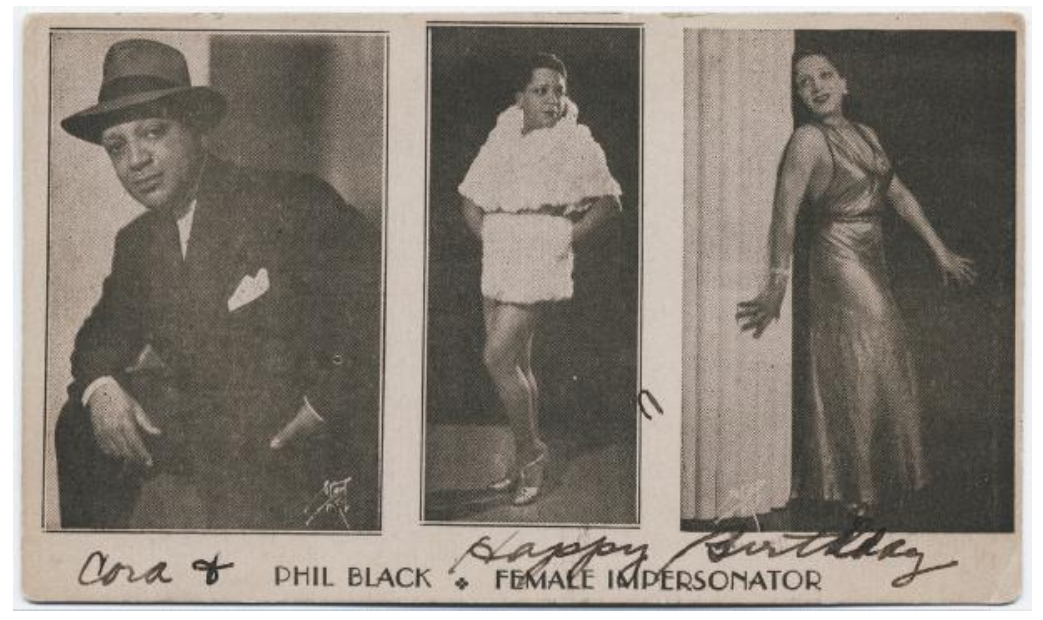

Figure 2.12

Phil and [Cora] Black. Date unknown (1920s)

Sourced from Beinecke Rare Book and Manuscript Library, Yale University

In Dear Friends: American Photographs of Men Together, 1840-1918, David Deitcher asserts in his research of male friendship during the turn of the century in the United States that marriage and parenting has often been used to deny the queer past. For example, "They were married, how can they be gay?" or "They had children in their marriage, how can they be gay?" This cultural approach to hetero/homosexuality assumes a clear line in the sand without regard to how countless gay men and lesbians led double-lives, hid in the closets or were coerced into self-denial in order to survive. Deitcher states, "Given... the force of the terror that has fuelled this masquerade, universal heterosexuality seems a more convenient than fitting conclusion to draw from the matrimonial glut" (41). Further, images of same-sex affection or gender 
variance are what Deitcher calls "the act of historical reclamation, which shows persistence of evidence" (156). Photographs, letters and other ephemera demonstrate how regardless of legislation and law, or social ostracization and shaming devices, gender-bending and sexual difference have a visual history that at one time repressed, now are needed to assess and examine queer futurities.

Representing Politically

The real must be fictionalized in order to be thought... it is not a matter of claiming that everything is fiction. It is a matter of stating that the fiction of the aesthetic age defined models for connecting the presentation of facts and forms of intelligibility that blurred the border between the logic of facts and the logic of fiction... writing history and writing stories come under the same regime of truth. (Rancière 2004, 38)

According to Barry Goldstein in All Photo's Lie, "[v]iewers should not approach an image with assumption that it represents reality. They should assume it does not" (65). From its inception in 1826, photography has been under contentious debate. In the early history of photography, the photographic image was seen as providing scientific or anthropological "truth" as part of the pictorial turn from painting to lens-based documentation. Yet in contemporary photographic discourses, it is understood that simply framing a subject in the camera lens determines what is included and what is excluded in the image, producing what the photographer intended rather than reality. Such dualities in photo theory imbue the analysis of photography with binaries between universal truths versus social construction. 
While the debate around photography as both a social material and a repressive apparatus has swirled since its invention, Goldstein suggests that there is some kind of solid truth that the photograph manipulates or cannot capture. By stating that "every photograph lies" (64), Goldstein implies that the photograph speaks of nothing more than deception. While photography does not always authenticate reality, it does represent a temporal moment. My interest is not in determining the truth of subjectivity but rather in photography's ability to capture a moment in time, and how intentionality reveals a broader spectrum of visual history as an opportunity for allowing alternative representations.

Photography was key to data collection in the social sciences. By the nineteenth century, ethnographies such as racialization, class, sexuality, gender and criminology informed the social body as a site of social regulation. Massive industrialization, and the notion of truth and its manifestations on the body became culturally realized through systemic ideologies that were particular to the long nineteenth century. Yet, somewhat uncritically, Goldstein proposes that, "we treat photographic images in the same way a scientist treats data. No experimentalist assumes that data are perfect. Indeed, all data are assumed to have a variety of types of error" (64). Goldstein appears to view science as objective, rational and preoccupied with the grey area between truth and error. In the scientific discourse surrounding the invention of homosexuality, as well as racialization and gender, scientific data in the late nineteenth century was produced to 'prove' what was ideologically believed (i.e., psychiatric disorders, superiority versus inferiority).

Assuming that scientific data is open to error and the photograph is not, denies over a century of scientific discourse that repressed, regulated, sanctioned and upheld ideological conceptions of sexuality, gender and race. 
Photography, along with other systems of data, played a critical role in the dissemination of scientific racism, sexism and homophobia. By placing a value judgment on one method over the other, I would argue that Goldstein takes an inadequate approach to how scientific discourses formed, implemented and institutionalized historic violence against difference. Thus, what Goldstein calls "false objectivity" (63) remains overtly narrow when brought to bear on queer representation and historical analysis.

The materiality of photography, for all intents and purposes, is passive compared to the ideological intention of the photographer, and simply framing a subject in the camera lens does not equate with deception, regulatory advancements or institutional violence. However, photo historian John Tagg's reference to the camera as analogous to the state in that it "is never neutral" (64) suggests that "invention of means of cheap and unlimited photomechanical reproduction transformed the status and economy of image-making methods" (60) through institutional and social ideologies that became "techniques and procedures for extracting and evaluating truth in discourse" (60). Between state forces and social order, the conditions of capitalist production in photographic practice could provide surveillance and discipline to "docile social subjects" (63). Tagg asserts that the highly coded methods of representation in photography at this time could never be impartial due to their relationality to other apparatuses of state power. In terms of nineteenth century social history and its cult of empire, most clearly seen through colonialization, violent categorization of the social sciences and economic inequality, Tagg's approach to photographic discourse is valuable.

Yet under such conditions, evidentiary power in photography is relegated to a reiteration of only state power. Elizabeth Edwards addresses this predicament in Raw Histories: Photographs, Anthropology and Museums where 
she states, "photographs are not only a place of disciplinary regulation and enclosure; they also have potential to open new historical frames of references that can interrupt dominant narratives" (Edwards 4). In many cases for historical queer subjectivity it is less a 'burden of representation' that requires criticality as much as it is 'the burden of lack of representation' as many have acquiesced to remain in the shadows due to systemic brutality.

To be 'here,' to be recognized or witnessed as existing permeates the photographic images. How can such binaries find resolution? By examining specific photographic history through a queer lens, the experience of the photograph is open to interpretation. Rather than seeking the truth of the subjects or the photographer, my aim is to deal directly with the ontological presence of the photograph, to reveal how "that-which-has-been" (Barthes 81) is suspended, transitory and partial.

As Roland Barthes argues in Camera Lucida, that-which-has-been is the evidentiary power of photography, regardless of its temporality. That-which-hasbeen, or what Barthes calls the "noeme ${ }^{36 "}$ of photography is the phenomenological place between the experience and the experienced. Geoffrey Batchen explains in Forget Me Not, "the indexicality of the photograph allows it to transcend mere resemblance and conjure 'a subject,' [into] a presence that lingers" (74). Desire is influenced by the phenomena of being, and it is in this space that the indexical nature of photography and the subjectivity of the viewer meet. Ontological desire and affect associated with the emotional embodiment of photography is key in understanding the significance of queer visual history. The act of reclamation and the matter-of-being a queer body, outside the norms of compulsory heterosexuality requires searching the

36 Noesis (Experience/Experiencing), Noema (Experienced). See Darren Langdridge, Phenomenological Psychology: Theory, Research and Method. Pearson Education Limited. 2007, 15 
margins of what has been hidden, secret or silent, in order to expose evidentiary power in having-been-there-ness for queers.

Photography's role in capturing the world around us, linking us to each other and to broader conceptions of humankind is as personal as it is ideological. Photographs are both images and objects that exist within time and space, and continually balance between social experience and cultural knowledge. Photographs are paradoxical and idiosyncratic as well as political, institutional, educational, aesthetic, and meaningful and meaningless. Photography is inscribed with socio-cultural and political dilemmas, whose materiality is both abstract and very much representational, provoking a sense of realness that simultaneously holds subjective truths and cultural manipulations. The complexities of photographic subjectivity and observation conversely stimulate connectivity and inform absence, or what Barthes calls "presence-absence" (9). The photograph will forever fall short of giving us what we want-a stable and true referent. Photography offers a "presence-absence" of a place and time, of unstable truth-telling by illuminating shadows and fixing them on paper. How we read and interpret them is constituted through sensation and socio-cultural manifestations, and historical knowledge.

For Geoffrey Batchen, having-been-there-ness is corporeal and alive, whereby the indexicality of the photograph is "the umbilical cord linking the body and the gaze" (242). For Barthes, photography is shrouded in loss, memory and death because whatever moment is being recorded through photography it ends at the shutter's click. That-which-has-been in photography relies on the apparatus of the lens shutter: once opened and closed the lens captures light onto paper, glass, tin, etc., and the moment that was recorded has passed. He states "this punctum, more or less blurred beneath the abundance and the disparity of contemporary photographs, is vividly legible in 
historical photographs: there is always a defeat of Time in them: that is dead and that is going to die" (96). For Barthes, it is the connection between the here and now of life and the omnipresence of death in photography that creates a site of feeling and punctum. As compelling and valuable as this theory is, there are problems with Barthes approach and an important example of this is in his reading of James VanDerZee's Family Portrait, 1926. I am including this analysis because its discourse involves a queer politic of social justice that requires the political action of critique.

The Family Portrait, 1926 by James VanDerZee as discussed by Barthes bears a strange fruit in its description and affective response. Problems arise with Barthesian approaches to punctum when race and class are involved, where the affective quality of punctum and the cultural inscription of studium collide. My intention in investigating some problems in Camera Lucida is in no way to discredit the significant contribution of Post-Structuralism and Semiotics in Barthes's work. Rather, my intentions are to illuminate the limits of punctum and show how affect theory may offer political strategies to counter the messiness of representation, photography and feeling. 


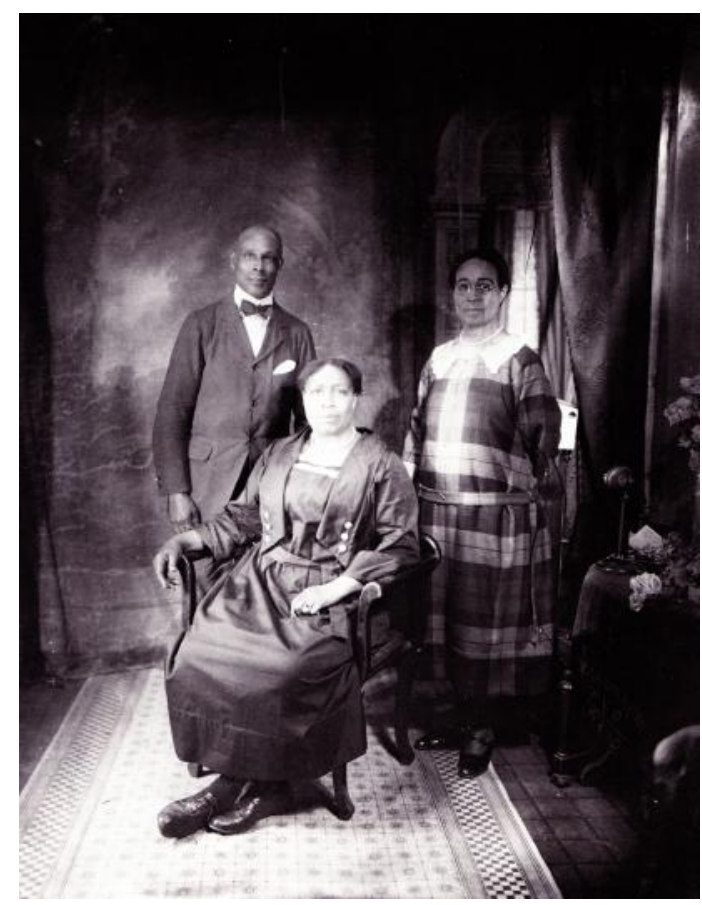

Figure 2.13

James VanDerZee. Family Portrait, 1926

VanDerZee (1886-1983) was an African-American photographer and leading figure in the Harlem Renaissance. A reoccurring theme in his body of work is the emergence of the black middle class in America. Among his vast amount of work, he was commissioned by Marcus Garvey to photograph the African-American experience in Harlem for the Universal Negro Improvement Association. ${ }^{37}$

Family Portrait, Figure 2.13 or what Barthes himself captions "The Strapped Pumps" (44), he reports being "sympathetically interested" in this "good" family portrait. To Barthes, the photograph expresses "family life, respectability and Sunday best" (43). However, he offers other descriptions of this image that confound. He states that the photograph reveals AfricanAmerican "social advancement in order to assume the 'White Man attributes' as a kind of "conformism" (43). This speaks to a larger problem in how Barthes is

${ }^{37}$ VanDerZee spoke of work saying that each photograph should transcend the subject. He photographed hundreds of funerals, including his mother's in The Harlem Book of the Dead, 1978 with a foreword by Toni Morrison. 
viewing this image and that to "assume the White Man attributes" negates a growing black middle class in urban America in the 1920s, particularly in Harlem, and suggests somehow that whiteness is the precursor to the middle class and that black 'respectability' is co-opting such attributes outside of a primitive nature of blackness. Further he states: "The spectacle interests me but does not prick me. What does, strange to say, is the belt worn low by the sister (or daughter)—-the 'solacing Mammy' (ô négresse nourricière)—whose arms are crossed behind her back like a schoolgirl, and above all her strapped pumps (Mary Jane's - why does this dated fashion touch me? I mean: to what date does it refer me?)" (Barthes 43).

As Shaun Michelle Smith points out: "in other words, Barthes's text asks readers to view racist paternalism as natural or beside the point rather than as a culturally codified part of the studium that can be put under examination" (2009, 99). The concern with erroneous readings of race eludes Barthes, in my view because punctum is given too much individual agency, overlooking political signification. As Smith goes on to say, "while Barthes's musings are compelling for all who are interested in Barthes, they are nevertheless of little use in reading this image in its historical specificity" (101). The divide between the personal and the political in dealing with issues of race in Camera Lucida speaks to Barthes's blinding grief at losing his mother, and it is this loss that provokes Barthes to mediate on his own mortality and death. The power of the personal is invaluable and politically motivating for feminist, queers, people of colour and others who have been written out of history; the feminist adage "the personal is political" is an imperative I support. My concern is when the personal clouds political thought and "historical specificity" (101) is misplaced. Shawn Michelle Smith in Race and Reproduction in Camera Lucida views the personal impulses of punctum to have evocative power but race and representation is one of 
Camera Lucida's frustrating limits. While punctum creates availability for personal narratives, it is a double-bind as far as how cultural knowledge is conditioned, produced and maintained. Barthes is swept up in the contemplation of his own life and mortality and cannot see his nose despite his face when it comes to the VanDerZee portrait. ${ }^{38}$

Rancière comments on the tangled complexity of Barthes's Camera Lucida by analyzing the condition of "indeterminacy" (113) and Barthes's "detachable elements" (111) of punctum and studium that produce a "shortcircuit between the past of the image and the image of death" (113). As stated by For Rancière, "the regime of images... a portrait or statue is always an image of someone and derives its legitimacy from its relationship [to what it represents]" (113). The reduction between "the pensiveness of the punctum" and the "informative aspect represented by the studium" (110) short-circuits. As affirmed by Rancière, "according to Barthes, the subject who views must repudiate all knowledge, all reference to that which in the image is an object of knowledge, in order to allow the affect of transport to be generated" (110). By insisting that punctum and studium operate only as a system of binaries, Barthes neutralizes elements of politicization, specificity, descriptive knowledge and meaningful inscription from historical photographs ${ }^{39}$.

This 'short-circuit' creates problems when dealing with repressed histories that may not have a resolution. However, if queer history and thus the

${ }^{38}$ (For detailed information, see Notes Early Photography and Queerness \#4).

${ }^{39}$ If Affect has the potential for queer thinkers to look back and enunciate paralysing slurs, the possibility of phenomenology as a tending toward an oblique line of social ordering allows for a shared experience and historical memory that has been repressed. Collectivity is part of the paradigm of modern queer history, however sloppy or messy that history is. Where we see the failure of affect and phenomenological practice is the misreading of the VanDerZee photography by Barthes. Its failure is because Barthes makes a claim that I must "repudiate all knowledge" to allow for the transport of affect. For Queer Punctum, looking back is part of looking; transportation of affect can only be affective by maintaining a cross dialogue between culture and the visual. 
representations of historical queer images are bound to the indeterminacy of knowledge and representation, how can history, "subjectivization" (Rancière 92) and "the political subject" (Rancière 90) be discussed? ${ }^{40}$ Rancière states, "'History' is only made up of stories that we tell ourselves, but simply that the 'logic of stories' and the ability to act as historical agents go together...that is to say material rearrangements of signs and images, relationships between what is seen and what is said, between what is done and what can be done" (39). ${ }^{41}$

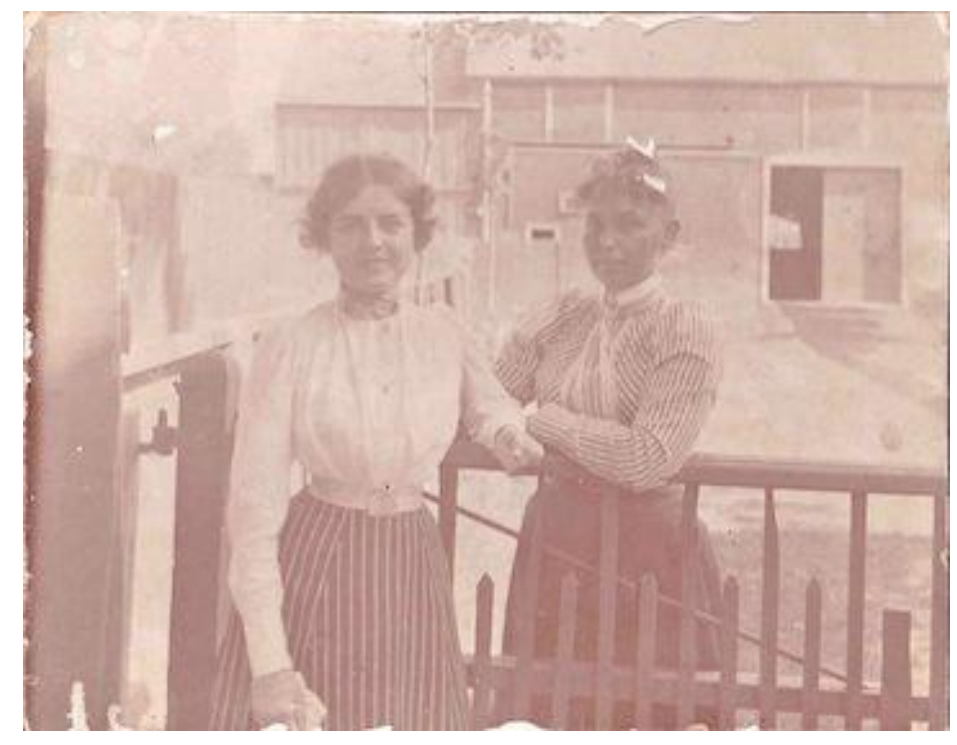

Figure 2.14

Augustine North and Mariam Babbitt, July 28th, 1899. Sourced from my personal collection.

${ }^{40}$ (For detailed information, see Notes Early Photography and Queerness \#5).

${ }^{41}$ Cultural studies approaches to narrative offer an enlightening method to approaching history, thought and meaning. Rodman points out that "Larry Grossberg's observation that the beginnings of the stories we tell are always the endings of other stories that we have not bothered to tell. We always enter the conversation in mid-sentence." (2013, 342) 
In 2009, I was at a friend's cottage just outside of Wilberforce, Ontario in an ice-cream shop that sold antiques. I took big licks from my large scoops of Maple Walnut as I flicked through a box of vintage photographs. I stumbled upon Figure 2.14 and was temporarily immobilized. Their opposites pictorially repeated. Her stripped blouse—her stripped skirt, her dark skirther light blouse, her bangs and high bun-standing on either side of a fence. Their arms rested heavily without an inch between them. That space between them, or lack there of, moved me. The ice-cream melted down my wrist. On the back "Mariam Babbitt and Augusta North;" hand-written in pencil, i's dotted and t's crossed. What was their story? Were there multiple narratives, both known to each other and unknown? In what ways can the serendipitous be discussed methodologically? In The Practice of Cultural Studies Richard Johnson asserts:

There are also serendipitous events, hard to theorize except as accidents. We often experience shifts of perception during our researching lives that stem from social movements and new forms of politics... a cultural approach to method, which draws from feminist insights has to repair these splits. (96)

The limited space between their arms in Figure 2.14 told me everything I needed to know. The lack of space between their resting arms was an ontological presence that re-enforced that they were there as I am now. Our realities suspended, transitory and partial. That-which-has-been has passed. They are no longer outside the barn at the fence and I am no longer in the ice-cream shop witnessing the photograph for the first time. This is the ontological having-been-there-ness that haunts the experience of photography. However, when the noeme-that-which-has-been (Barthes 7678) involves queer history and its representations, generations of silence and double lives surface. 


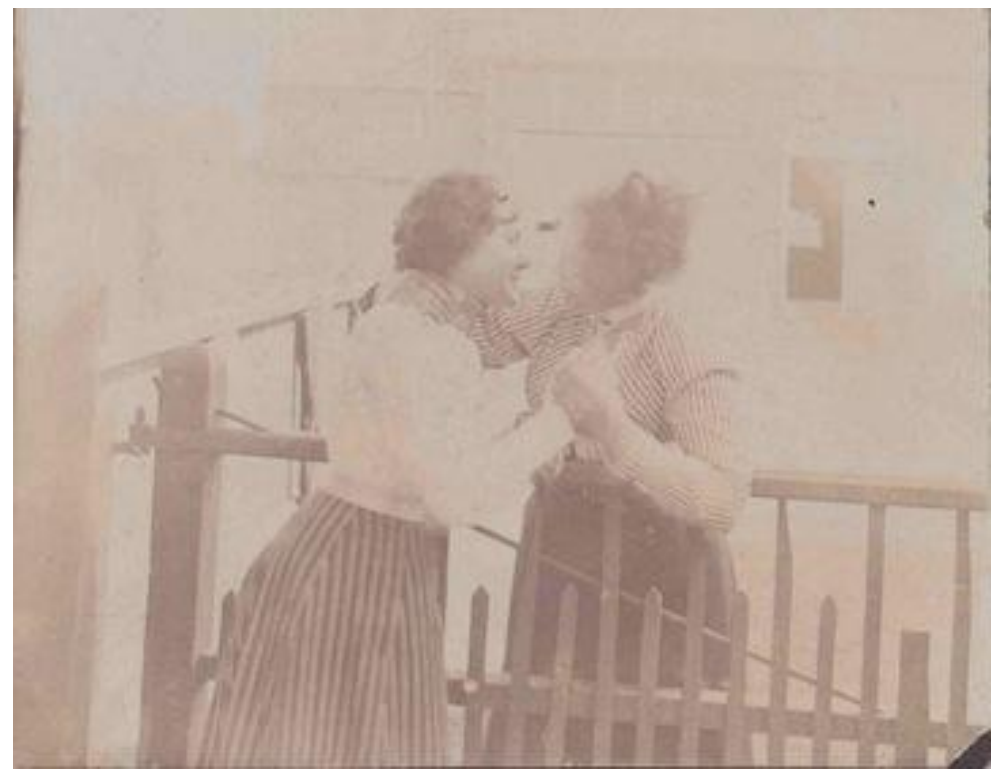

Figure 2.15.

Augustine North and Mariam Babbitt, July 28th, 1899. Sourced from my personal collection.

I continued to look through the same box and found Figure 2.15; the light had changed in this image, details blurred with the faster-moving action and the sunlight bleached the scene to overexposure. It confirmed what I knew, suspected and felt. Figure 2.15 told the rest of the story. I knew it from when I first saw their arms resting on the fence. The lack of space between their arms was what pulled me toward the image.

Scanning across, my eyes moved slowly in order to see everything until I reached the hand around her neck, its intensity of grip and the force of its pull. In that moment every question I had was answered by that detail. Her brawny hand had made me feel as though I had encountered the intent of the moment photographed, a recording of desire. Written on the back, just atop their names was an exact date, July $28^{\text {th }} 1899$ : the height of summer with its warm, sunny days. They are not archived and sourced, there is little known 
about either one of them other than a census report that provides a place and date of birth of a "Miss Babbitt. Born May 25" 1878 in the County of Picton, Ontario" and states that she was not married at the time of the photograph.

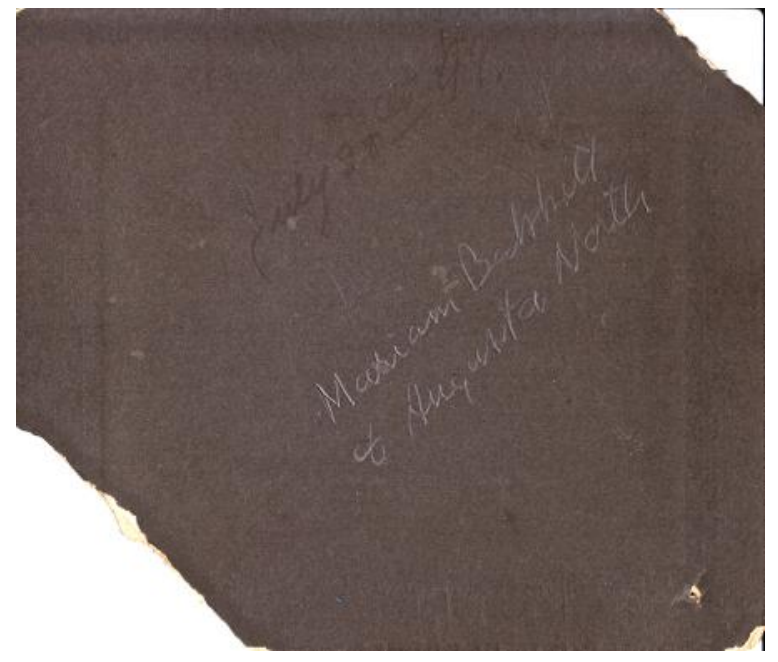

Figure 2.16

Augustine North and Mariam Babbitt, July 28th, 1899. Back of the photographs. Sourced from my personal collection.

In conclusion, while historical artefacts of queer representation from this time period illustrate the cultural themes of oppressive categorization and survival, the categorization of sexuality and its regulation have a direct correlation to the classification of gender and race at the turn of the century. Conventions of photography reveal the distinct relationality between social fragmentation and sexuality. These conventions were conveyed through the discursive technology of photography to reveal social and cultural structures.

Why was this technology important to queer peoples and how did it impact their lives? How does class, in particular labour, affect representation and same-sex affection? What was the consequence of gender separation on same-sex 'intimacies'? The answers to these questions reveal themselves to be 
entwined into the original problematic, whereby the value of photography to queer lives is entrenched simultaneously in the violence taxonomy of historic homophobia and the profound desire to narrate one's life. The impact of this Catch-22 of photography being a categorical tool of disenfranchisement and a site of reclamation illustrates the cultural power of image-making. Annette Kuhn asserts, "Photographs are evidence, after all. Not that they are to be taken only at face value, nor that they mirror the real, nor even that a photograph offers any self-evident relationship between itself and what it shows. Simply a photograph can be material for interpretation" (11).

Photography is inscribed with socio-cultural and political dilemmas, whose materiality is both abstract yet representational, provoking a sense of realness that concurrently holds subjective truths and enforces cultural manipulations. Photography from the late nineteenth century correlates with industrial capitalism through the homogenized repetition of bourgeois commodities. The segregation between the sexes and division of class distinctions demonstrate how social partitioning created bonds and forms of intimacies within structures intent on separation. My case studies examined photographic formality and the disruption of normativity by addressing social conditions and the implications of Industrialism for historical queerness. Romantic friendship in the nineteenth century has been discussed in this chapter as part of the function of photography that involved the mass production of both images and ideologies that affected gender relations and sexuality.

Rather than seeking the truth of the subjects or the photographer, my aim is to deal directly with the presence of the photograph, to reveal that-which-hasbeen as suspended, transitory and partial. By informing how a "political subject" (Rancière 90) can rearrange normative signs, I have been motivated by 
challenging the established framework of identification and classification to open the door to political contestation of queer history by, as stated by Rancière, seeking relationships between "what is seen and what is said, what is done and what can be done" (39). Further, I have challenged capitalism's façade of conventionality, where distributing an image that might otherwise have been private or hidden can expose historical secrecy of queer lives. This research informs historical queerness as a site of political subjectivity, and such politics rearrange historical silence into reclamation. 


\section{Chapter Three: Political Emotions and Feeling}

The longer I look at this photograph, The less I see.

The more I want to memorize, The less I recall.

She is vivid.

Her excellent posture

Straight as an arrow

But seated crooked.

You misaligned on purpose, didn't you?

From that moment there was nothing left to encounter That slanted line of your body

As striking as remembering a dream.

If I never see the photograph again

It is as if I hold it in my hand.

Political Emotions and Feeling examines feeling as a political paradigm that evokes, and promotes systemic change to hegemonic power. The four sections-Episteme of Queer and Its Discourses, Queer Phenomenology and Orientation, Affect and Misalignment and Queer Punctum — are intended to give historical background to terminology and queer discourses, reveal notions of misalignment as a political site of orientation, and show how these moments, affectations and associations can be explored through photography.

Affect is taken up in very specific ways. Rather than affect awaiting an encounter, in a relaxed or passive way, it is the effects, discourses and understanding of the past that elicits, the kind of looking back that produces affect. These affectations are political by recognizing historical violence and its injuries as a site of contemporary resistance. This work functions within the realm of Existential Phenomenology, particularly through Sara Ahmed's 
examination of Edmund Husserl (the structure of consciousness, intentionality, meaning and object), which we see Barthes's grapple with in Camera Lucida and the work of Maurice Merleau-Ponty's "the flesh of the world" $(1964,3)$. I deviate from pure Phenomenology's "the body as the primary site of knowing the world" as requiring political engagement and the work of Ranciere's "the political subject" elaborates on these issues.

By bridging gaps between phenomenology, affect theory and visual culture, photography is examined as a location of queer political feeling, whereby historical knowledge is mined from both philosophical concepts and close readings of photographs. While my focus remains in philosophical approaches of affect and phenomenology, cultural materialism imbues this research with a pointed and critical politic in regards to photographic and archival practices. This stance is vital to the historicization of queer representation as well as contemporary debates and concerns in queer communities, and for the creation of potential knowledge. Amy Richlin recognizes the multifaceted issues of examining historical forms of sexuality that stretches across disciplines:

As interest in sexuality spread throughout the disciplines and, simultaneously, in related fields (art history, literature, religion), an ability to read across periods and disciplines became more and more necessary. (297)

I investigate phenomenological processes that are described by Sara Ahmed in Queer Phenomenology as embodied, sensitive and situated, and juxtapose phenomenological photographic theory as described by Roland Barthes in Camera Lucida as the affect of the physical order of the image. While both approaches differ in how they are discursively implemented, both branches of phenomenology consider the implications of perception, receptivity 
and feeling. Political Emotions and Feeling puts Ahmed's notion of situating oneself and our relationship to "orientation" (68-70) and Barthes's notion of "punctum" (44-45) in dialogue with each other in order to elucidate sociocultural manifestations of historical knowledge and visual culture. By suggesting that our experiences and sensations are not simply founded on what is in front of us but what is also around and behind us, this chapter seeks to specify the practice of Queer Methodologies ${ }^{42}$ through interdisciplinarity, political commitment and constructivist approaches to socio-cultural systems.

Methodologies as a set of rules and procedures of investigation refer to qualitative research yet as I discuss, queer method deliberately challenges coherence and reliability because of its rejection of stable forces, creating interesting and valuable challenges to Queer Methodologies. Rather then sidestep these issues, I take up such concerns as part and parcel of what it means to examine contested histories and the challenges of historicity, queerness and discourse. If as stated by Browne and Nash in Queer Methods and Methodologies, there is, "in fact, no 'queer method,' in the sense that 'queer' lives can be addressed through a plethora of methods" (38) then how do I employ a methodology that 1) has no method, 2) refuses disciplinary coherence and 3) rejects truth? First and foremost, there is no reconciliation for all queer

${ }^{42}$ For a full analysis of queer methods, See: Browne and Nash's text Queer Method and Methodologies where they state, "Queer approaches of various sorts not only became visible in the HIV/AIDS activism in North America in the 1970s and early 1980s, it also surfaced across a number of disciplines receptive to the problematic of postmodern thinking - architecture, literary theory and criticism, film studies as well as sociology, philosophy and geography (cf. Bell and Valentine 1995, Butler 1990a, b, 1993, De Lauretis 1991, Reed 1997). Most scholars would concede that queer theorising initially gained greater visibility more quickly in the humanities than the social sciences. Work in the humanities challenges the conceptualisation of the modern Enlightenment subject as rational, unified and stable. Within postmodernist theorising, broadly conceptualised, scholars took critical aim at claims about a universal human condition and the linear tale of a progressive human history as artificial, improbable and unduly homogenising of the human experience" (4). 
peoples to fundamentally agree on A Queer Method. The reason for this is a general suspicion of boundaries producing exclusionary devices that would shut down discourses on the fluidity of genders and sexualities. Because of the historical ramifications of queer marginalization and regulation, queer politics are intertwined into the very meaning of 'queer methodology.' While I support such concerns, I wonder how boundaries can be created to queer methodologies that do not exclude fundamental inclusionary principles but can generate valuable discourse to how and why queer methods are intrinsically politically left and occupied with concerns of social justice. While this research indeed takes up Affect as a location of knowledge, there is skepticism about historical scientific record's preoccupation with truth, particularly in the case of queer, engendered and raced bodies. My approach to Queer Method and Affect Theory is to intersect conceptual and theoretical approaches of how the political left and anti-oppression can function in time and space. It is in this way that I approach methods, as existence must precede essence, where interpretative sites cannot rely on essentialist tactics without sacrificing political engagement.

What is queerness? How has it been historically described and what are the effects of historical description on contemporary concepts and queer futurities? I tackle these questions, in order to unpack historical violence by examining the episteme of 'queer,' how it has been implemented, where it is going, why it matters and how political feeling can be exercised through an engagement with historical queer photographs. I discuss two archived images by Alice Austen, 1866-1952 (sourced from The Alice Austen Historical Society in Staten Island, NY) as case studies to work through Sara Ahmed's concept of orientation and tending away from compulsory heterosexuality, and Barthes positionality of being "pierced" or "wounded" by an image. Further, I extend my 
critique of Barthes's notions of studium and punctum, where the socio-cultural manifestations of punctum and the historical knowledge of studium collapse. Barthes's limitation and shortfall of separating cultural inscription and the meaning around photographs (studium) from the emotion connection and personal meaning found in photographs (punctum) provides the foundation of Queer Punctum: where I argue that this discursive collapse is the very site of feeling and political engagement. Cultural meaning and affect as a paradigm to activate queer knowledge extends beyond discrete moments of grief and mourning loss into larger spheres of reading historical queer images.

\section{Episteme of Queer and Its Discourses}

Discourse, as discussed most notably by Michel Foucault and further elaborated by Judith Butler in Bodies That Matter, involves communication through expression, social practices, institutions and ideology. Verbal and nonverbal languages are discursive systems, which operate across a range of institutional sites, such as education, law enforcement, science and government as well as a vast array of practices that include art, literature and culture.

Discourse is never static; it moves, changes and evolves over time, yet it cannot be separated from what surrounds it. Discourse is relational and is conditioned by both us, as living, breathing beings, as well as by authoritative powers.

The etymology of queer began as early as " 1500 , where the term is defined as deriving from Scottish, from Low Ger. (Brunswick dialect) to describe strangeness, peculiarity and eccentricity" (OED). It evolved over time to define a sense of space, or the notion of being off-center, related to the German word "quer," to turn or twist. The verb queer, as in to spoil or ruin, was documented in 1812. However, the semantic shift of queer as being connected to sexuality was first recorded during Oscar Wilde's trial in 1895, where it was used by the 
Marquess of Queensberry, father of Alfred Douglas, who was Oscar Wilde's lover. This groundbreaking trial continues to inform how law and regulation are conditioned by social fears and bigotry, and how anxiety and prejudice are produced by legislation. By the 1920s and early 30s, queer was a popular yet derogatory, term for homosexuality that connoted both sodomy and an ideological position of 'other'43. How can we read queerness then as opposed to now? Yes, they are different under socio-political standpoints of time and space, but analogous through the tending away from normative structures of sexuality and gender. While the differences between now and then are apparent, it does not and cannot prevent us from oppositional discourse and the examination of queer traces in history.

In Bodies That Matter, Butler examines the production of the term queer: its temporality, discursiveness and the possibility of its reclamation. She evaluates the conditions of the term as part of a brutal past, which she refers to as its historicity, as well as "the significance of its re-inscription into a

${ }^{43}$ From Marxism Today, Socialist Alternative Conference. Sydney, Australia. August 20, 2005 http://www.socialistalternative.org "Wilde was tried for a sexual offence, which had only come onto the statute books ten years earlier, the Labouchere Amendment. In 1885, Britain's parliament introduced a law intended to eradicate child prostitution by raising the age of consent for heterosexual intercourse from 13 to 16. The MP Henry Labouchere proposed an amendment to add: 'Any male person who, in public or in private, commits ... any act of gross indecency with another male person, shall be guilty of a misdemeanour, and being convicted thereof, shall be liable ... to be imprisoned for any term not exceeding one year with or without hard labour.' The Attorney General objected that the punishment seemed too lenient, and insisted that the maximum sentence be increased from one year to two. Lesbianism was left out of the criminal code because at this time it was believed that women had no desire for sex and authorities feared that including sanctions against women having sex with other women would give them ideas. The 1885 law, which for the first time criminalised all sex acts between men, was part of a general tightening up of sexual morality in the late 19th century which accompanied the re-creation of the family as the bedrock institution of society. The Labouchere amendment under which Wilde was tried remained unchanged on Britain's law books for over 80 years. Gay men had to wait until 1967 for their sex lives to become legal, and even longer for legal equality." 
contemporary vernacular" (140). Is it simply placing our own desires of sexuality onto the past? We all function in our lives, to a certain degree, in relation to what we desire. However, to reflect on the desire to have a material object or to desire specific answers to questions does not necessarily produce what we want or desire. Rather, the significance of reflection is how and where it can trigger desire toward activation that must be produced beyond simple reflectivity. Where the "sayable" is spoken cannot be the only implementation of knowledge, as such rationalism has been the basis of heterosexism, where we are all straight subjects until 'proven' otherwise. Butler investigates the meaning of the word queer as connected to the discursive regulation of homosexuality. How can a "paralyzing slur" (Butler 138) be re-signified with new meaning?

Foucault's assertion that discursive and historical ontology is dependent on the surrounding world and oneself affirms that discourse is both culturally practiced and socially reinscribed. In Foucauldian terms, "the sayable," and "the seeable...constitute populations and forms of conduct, and in doing so, a certain kind of relationality... of the discursive and the material" (Grossberg 314). Discourse and materiality in terms of "the sayable" and "the seeable" in this research are complicated by how queerness is verbally articulated. Because language for historic queerness is bound in slurs, shaming devices, regulation and silence, "the seeable" is a discursive space where the unsayable can speak. If we consider the phrase "The love that dare not speak its name," as famously stated at Oscar Wilde's trial, "the sayable" for queerness was conditioned into the reprehensible and criminal. ${ }^{44}$ While I argue the discursive

${ }^{44}$ From Oscar Wilde's trial, Charles Gill (prosecuting): What is "the love that dare not speak its name"?

Wilde: "The love that dare not speak its name" in this century is such a great affection of an elder for a younger man as there was between David and Jonathan, such as Plato made the very basis of his philosophy, and such as you find in the sonnets of Michelangelo and Shakespeare. It is that deep spiritual 
as flexible and evolving over time, and not hard and fast, the notion of 'the homosexual' must be understood through its historical and discursive construction where paralyzing slurs are a discourse formed out of regimes of control. These discursive wounds, intended to cause injury are the sites of invaluable politicization, particularly by looking backward. These historical wounds are motivation to seek meaning from insult to social bond. Discourse has constituted the embedment of the fag, the dyke, the queer, etc through not only what Foucault calls its "invention" in medicine but also law, social sciences and social coercion. I examine these terms with close-readings of photographs by American photographer Alice Austen, where small samples are intended to aid in the clarity of methodology.

Raymond Williams in Politics and Letters considers Foucault's concept of the distinction between the sayable and the seeable as "the relation between the articulable and the livable" (318). What can be brought forth through visual, written or spoken language cannot always be a lived experience and vice versa. The importance of examining the relationality between what is expressed and what is lived speaks to how these distinctions are socio-cultural constructions, which are assembled through relations of power and control. The production of the seeable and the sayable in terms of queerness is always troubled and troubling. What can be seen sometimes cannot be said, and

affection that is as pure as it is perfect. It dictates and pervades great works of art, like those of Shakespeare and Michelangelo, and those two letters of mine, such as they are. It is in this century misunderstood, so much misunderstood that it may be described as "the love that dare not speak its name," and on that account of it I am placed where I am now. It is beautiful, it is fine, it is the noblest form of affection. There is nothing unnatural about it. It is intellectual, and it repeatedly exists between an older and a younger man, when the older man has intellect, and the younger man has all the joy, hope and glamour of life before him. That it should be so, the world does not understand. The world mocks at it, and sometimes puts one in the pillory for it. 
conversely what said cannot be seen ${ }^{45}$. The approach to discourse and historicity follows cultural studies method of placing concepts and images "with[in] a strong commitment... [where] there is no such thing as politically neutral" (Rodman 2013, 343). "The love that dare not speak it name," or as I have titled this thesis "Without Words You Spoke" articulate the extortion of language from livable conditions of queer representations. An important aspect of the articulation of queer relations has been historically bound to regulation, whereby to speak 'its' name enters legislative condemnation and/or social ostracization.

In The History of Sexuality, Foucault asserts that the discourse of homosexuality advanced social controls. The "invention of homosexuality" was intended to regulate. For Foucault, the discourses put in place to control sexuality also made possible "the formation of a "reverse" discourse: homosexuality began to speak in its own behalf" (101). For Foucault, the circulation of discourse is not predicated on top-down power, but rather on how discourse moves, reshapes and reconfigures itself through usage. We see "reverse discourse" in every corner of contemporary society. Whether it is through sexuality, gender, race or systems of class distinctions, language has a fluidity that can allow us to recoup the derogatory into a positive social affiliation, particularly in the case of injured bodies, bodies that have been erased, violated, bullied and culturally stigmatized.

The "paralyzing slur" (Butler 139) of queer that developed from painful lived experiences, over time, and through politicization has been transformed into an affirmation. Heather Love states in Feeling Backwards that "The word

45 "The love that dare not speak its name" from the poem "Two Loves" by Lord Alfred Douglas, published in 1894. It was mentioned at Oscar Wilde's gross indecency trial, and it is classically interpreted as a euphemism for homosexuality. 
'queer,' like 'fag' or 'dyke' ... unlike the more positive 'gay' or 'lesbian,' [was] a slur [and] was chosen because it evoked a long history of insult and abuse" (3). Queer social bonds "are losses of the past" that "motivate us and give meaning to our current experience" (Love 1). For Butler, "queer has overlapping divisions" (142) where the history of violent discourse and power is reworked: sexuality, gender, class and race are part of a historicity that shares certain kinds of regulatory prejudice. The reclamation of the term queer has raised it from an insult and shaming tactic to a social bond and a site of resistance. By reversing the discursive convention of 'queer' and its homophobic interpellations, queer can be become a citation of opposition.

'Sexual inversion' became defined as 'deviance,' and such conceptualizations are part of the fabric of both scientific discourse and dominant ideologies regarding the regulation of sexuality and the deployment of racism. Engendered, racialized and sexualized bodies that reverse the discourse of historical violence are bodies that matter. As asserted by Sara Ahmed in Queer Phenomenology, the emergence of the term "sexual orientation' coincides with the production of 'the homosexual' as a type of person who 'deviates' from heterosexuality" (65). The sexual deviant thus deviates from the straight line of social ordering. To pervert normative structures of the status quo is to queer it. Not following the straight line of social ordering is to "disorient from compulsory heterosexuality to produce a "queer effect'" (66). If we consider the etymology of queer as a spatial term indicating to twist or bend, the orientation of compulsory social ordering is challenged through cultural and social deviation of verbal and non-verbal discourse. I examine these terms with close-readings of photographs by American photographer Alice Austen, in order to explore photography as "the seeable" when words 
cannot be said or spoken. This duality of seeing the unspoken is a location of without words you spoke. 
Queer Phenomenology and Orientation

Ahmed describes phenomenology as embodied, sensitive and situated.

Because the phenomenological is shaped by both repetition and

consciousness, Ahmed asserts that perception is informed by locality, whereby

to "turn toward" (107) or "tend toward" (86) is directional and involves

orientation. The tactility and corporeality of orientation is to twist or turn with or

from a vertical line. The example Ahmed gives is the act of tracing, where

tracing lines offers two possibilities: one is to follow the lines correctly, where the

traced lines meld into the original; and the other is to shift the paper during

tracing, thus, altering the alignment.

In terms of queerness, Ahmed asserts that to derail from the straight line of social ordering is to disorient from compulsory heterosexuality, whereby the failed ${ }^{46}$ orientation usurps normativity to produce a "queer effect" (65). While failure is not an explicitly focal point of this chapter or dissertation, it is however a valuable position both in terms of queerness and political paradigms. In

Embrace Queer Failure from Judith/Jack Halberstam's blog, s/he writes,

In a world of unappeased, unabated, capitalism, it is time to manufacture, promote and embrace failure, queerly. Failure, of course, goes hand in hand with capitalism...Capitalism, requires that everyone live within a system that equates success with profit, and failure with the inability to accumulate wealth....A new reality and failure is something with which we must reckon existentially, economically and politically. ${ }^{47}$

${ }^{46}$ Halberstam's notion of failure in The Art of Queer Failure offers an alternative position, where "the unexpected, the improvised, and the surprising" (16) provide a model for an anti-disciplinary take on the themes of failure and negativity - a continuation of debates among theorists, such as Lee Edelman and Jose Estéban Muñoz.

47 "Over the course of writing this book, people have sometimes misunderstood me to be saying that people need to learn how to fail (we all actually already know how to fail well!) and they want tips, so consider this a crash course in failure, a self-help guide to failing well and failing better; this is 5 steps to being a complete loser: and why should we learn how to fail? Because winning has 
If we consider the act of tracing as a collective phenomenon where we follow the lines of social conduct, such as in compulsory heterosexuality, rotating away from this schema blurs the alignment of normative expectations. The notion of failure or derailment speaks to the conditions of orientations, such as the disruptions of the normative, straight horizon line. When orientations are crossways or slanting, they appear off-centre; Merleau-Ponty asserts, "the general effect is queer" $(1958,289)$. Queer then becomes an umbrella term for that which does not uphold compulsory heterosexuality and fails to orient according to the status quo. For Ahmed, if sexuality is a matter of being, then sexual orientation requires orientation.

Long-standing notions of sexual orientation have been and continue to be understood within the binary of 'hetero' as impartial and natural, and 'homo' as a deviation from norms. The interdisciplinary debates by Judith Butler, Jack Halberstam, Heather Love and Eve Kosofsky Sedgwick, among others, on Foucault's work specify how sexuality is a historically particular concept within a regime of disciplinary knowledge that structured society and social relations. The disciplinary consequences of binary constructions on the study of sexuality and gender outside hetero/homo categories has cultivated a "growing body of multi- and interdisciplinary scholarship [that] explore desires, practices and identities that defy the dualities of social categories and unsettle the epistemological and methodological assumptions underpinning much of the work on gender and sexualities" (Browne and Nash, 5). If we consider the construction of homosexuality as a methodological position of categorization through medicine and law (among other forms of hegemony), we must view this

become the byword for greed, arrogance, profiting from others, conformity; winning means gloating, hoarding, condescending. And losing? Failing? Failure can become a potent form of critique, a repudiation of capitalism and profit margins, a refusal of the norm, an indifference to assimilation and a route to other ways of being in the world." (Halberstam's Blog May 2, 2012) 
as biased and overtly problematic. However, by reflecting on the construction of homosexuality as communicating with or against what surrounds it, sexual orientation is as relational as it is socially positioned. Ahmed states:

The emergence of the idea 'sexual orientation' does not position the figures of the homosexual and heterosexual in a relation of equivalence. Rather, it is the homosexual who is constituted as having an orientation: the heterosexual would be presumed to be neutral. (69)

The inequitable "relation of equivalence" is significant, not only historically but also contemporarily as a location of socially sanctioned homophobia, whereby 'proving' homosexuality is measured as rigorous and heterosexuality is assumed, regardless of homo-social activity. Never has someone's name, legacy or reputation been smeared by the accusation of their straightness. I argue that such discriminatory approaches to sexual orientation are maintained because historical homosexuality is sanctioned as a threat to the established order. If that were not the case, reading historical queer imagery would be bound to other questions rather than authentication. Cultural studies deals with issues of authenticity as less about a single 'grand narrative,' and more as a bricolage of systems that can re-combine existing moments to forge new meanings. For example, articulation is an analytic tool where rearrangements can be made, not only to allow for disparate elements to share particular interests, but also to articulate these combinations as structured relations, predominantly in relation to power structures, such as domination and subordination.

Deviating from socially normative positioning, or validated methodologies, "is one of the many ways that power relations and associated hierarchical constructions of social lives can be contested through research" 
(Browne and Nash 14). If experience and knowledge are derived through social and cultural conditions, then how can we understand their relationality to representation and subjectivity? What new social methods can create transformative politics through research? Sara Ahmed's consideration of the oblique line, a line that deviates from conventional social ordering, suggests that heteronormative conditions are as oriented and spatial as gendered or sexual difference.

Ahmed further elaborates on heteronormativity by examining lesbian contingency as "tending toward other women" $(2006,102)$ as both a social experience and an expression of lesbian desire. She states, "Iesbian bonds can involve orientations that are about shared struggles, common grounds and mutual aspirations" (103). The bonds of "queer slants" are "a matter of everyday negotiation (106). She goes on further to elaborate, "this is not about the romance of being off line or the joy of radical politics (though it can be), but rather the everyday work of dealing with the perceptions of others, with the 'straightening devices' and the violence that might follow when such perceptions congeal into social forms" (107). 'Straightening devices' in historical research, such as assertions that 'they were married, they can't be gay' or straight until 'proven' gay, erase negotiations of queer slants and the continuums of sexuality, desire and their discourses. Further, I would argue that such positions are in and of themselves not only biased, but testify to the historic implementations of homophobic ${ }^{48}$ traditions, and their continuance.

${ }^{48}$ A recent example of this can be found in Sybille Ebert-Schifferer's book Caravaggio: The Artist and His Work (Getty Publications, 2012), where she maintains (in the last two pages of the book) that Caravaggio could only be heterosexual because his "identity" was not bound to homosexuality. Her statements on this topic are based on little other than her own assumptions of sexuality and notions of difference. Further, Schifferer's arguments about 


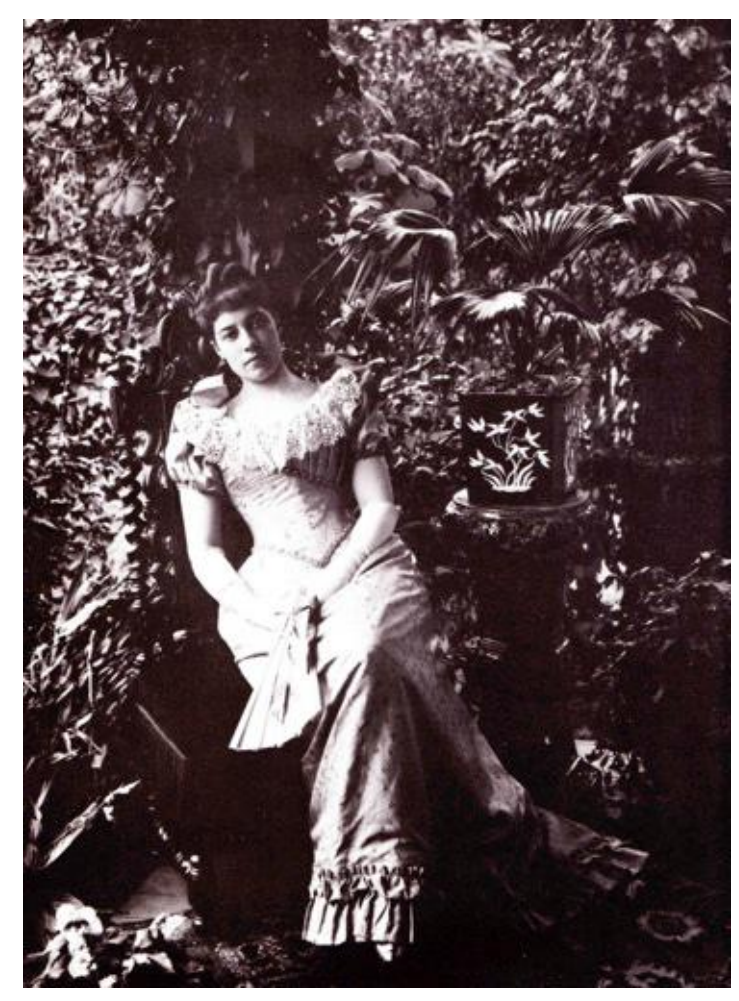

Figure 3.1

Austen's caption

E.A.A., full length, with fan. Fine day, in shade on piazza. Monday, Sept. 19th, 1892. Seed 23,

Perken lens, 32 stop, 3 secs.

The self-portrait by Alice Austen, Figure 3.1 skews the central line of formal portraiture, where the subject is centered and structured vertically within the frame. What is compelling about this image is how the formal aesthetics of nineteenth century portraiture are upheld, with only one small alteration. Her oblique line seems to tilt to the left of the image and is off balance, slantwise. It was this detail that moved me and changed my reading of the image. There is a

Caravaggio's sexuality diminish a large spectrum of both the homo-social and how sexuality does not inherently have a single "identity." 
'knowing' smirk on her face; she divulges nothing in her eyes but her slanting body speaks volumes. As Ahmed articulates, in the case of the oblique line, "we get a sense of how being directed toward some objects and not others involves a more general orientation toward the world" (32).

This photograph by Austen grabbed my attention the first time I saw it. Although it took a great length of time to understand why I was so drawn to this image, Ahmed suggests that, "the objects that we direct our attention toward reveal the direction we have taken in life" (32). I have looked at the image for over a decade. Only recently, I found a few images online, where Austen took this picture several times with slight variations to it. I thought they were the same image only cropped, but they are multiple images depicting varied poses as this one. What remains the same in each picture is how she sits, what she is wearing, the location of her garden and the quick release tucked into hand in order for her to take the self-portrait. The small samplings of her work in this chapter strengthen the argument of the oblique line because the multiple images of her suggest a whole host of other questions, such as which one would she consider the best image, or what drew her to repeating this pose, or what do these pictures tell us about her creative process? Although these are indeed interesting questions, they derail from central questions this chapter unpacks. Rather than view multiple images of the same pose as evidence of her intentions, I would argue that there is substantiated proof of her photographic knowledge and skill with photographic techniques and practices are evidenced in her body of archive which houses over 3,000 negatives. Austen knew how to frame a portrait, how to sit straight, how to angle a lens correctly. This selfportrait intentionally upsets formal structures of portraiture.

I have been picking up a reproduction of this image, putting it down, tumbling over its tones, gestures and its details in my mind for years, never 
completely sure what draws me in so deeply. This self-portrait has been 'seeable' but only recently can I articulate - what it 'says.' To speak to this image is in someway to speak of myself. Taken one hundred and twenty three years before the writing of this dissertation, I am able to make 'sayable' what Alice Austen could photograph. The oblique line of her body, slanting 'wrongly' in the frame is akin to a queer methodology of working within traditions in a sideways fashion ${ }^{49}$. The distinction between the sayable and the seeable in terms of Alice Austen's archive in Staten Island, NY discloses what can be articulated visually. In her archive, there is no mention of her thirty-year romantic bond with Trude beyond friendship. "The love that dare not speak its name" is entwined into her archive, and what is seen and explored in her photography is rendered without criticality of desire and sexuality. By Trude simply having "the wrong devotion to Alice" (Novotny 60), queer bonds are relegated to heteronormative sites of shame and erasure.

The notion of direct vision orienting its language wrongly, certainly in this context, suggests being out of line with others, and perhaps outside convention. Alice Austen's oblique line reveals contingency as this self-portrait reflects a "tending toward" that is relational to both sexual and social contact. It is no accident that as a young lesbian in the late 1800s, Alice's self portrait would reflect non-normativity. To "act out of line with others" (Ahmed 107), whereby queer orientations do not line up is reflected in Alice's self-portrait. The slantwise line and tilt of her body disorients the formal structure of the classical portrait and radicalizes her vision of her body in space and time. What also is intriguing about this image is that it challenges how we can read same-sex

\footnotetext{
${ }^{49}$ I was told by a professor many years ago, that if I "couldn't conform to a straight way of thinking then the program wasn't for me." Even thoughts, whether beginning to be thought or thoughts that have not yet been thought, are under the scrutiny of homophobia.
} 
intimacy or desire or interest. Much of the discussion on same-sex intimacy is predicated on two or more subjects in the photographic frame; same-sex desire assumes more than one subject. Bearing that in mind, how can we read solo subjects in a photograph as queer without a counter-part to 'prove' desire? There is something within phenomenology and queering it that opens interpretative paradigms that move beyond essentialist approaches to gender and sexuality, principally through the notion of the oblique line as challenging social order and heteronormativity.

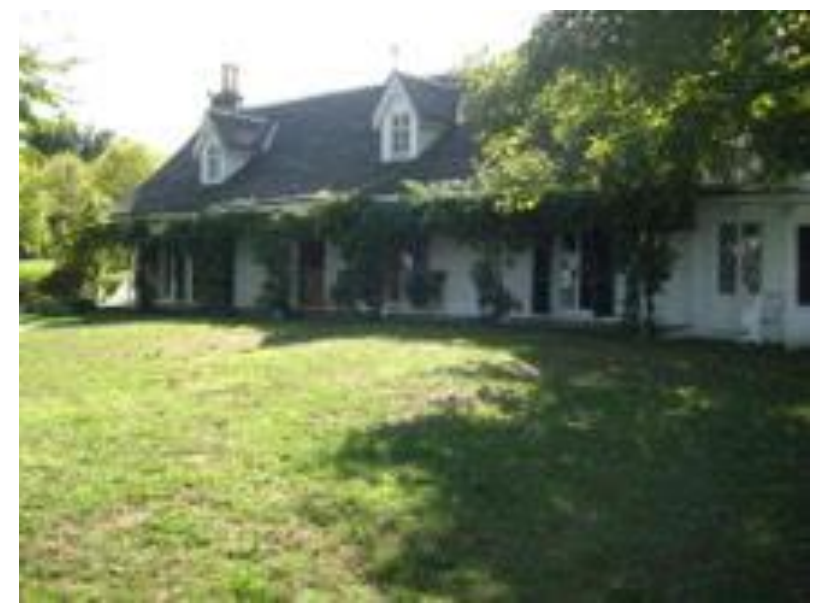

Figure 3.2

Alice Austen's Home, Clear Comfort on Staten Island, NY 


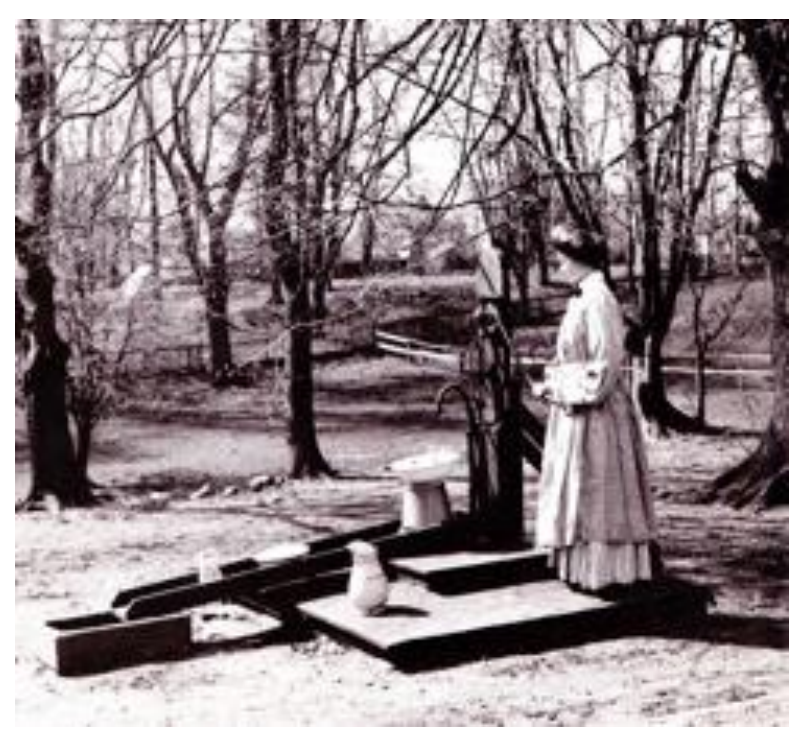

Figure 3.3

Outdoor water pump at Alice Austen's Home, where she washed her photographic prints.

Alice was unusual for her time. She took pictures and developed all her own negatives and photographs. She had an independent spirit and for a time had the financial means to live the life of a dedicated photographer. Her photographs are extraordinary; she was a street photographer who would haul a massive $4 \times 5$ camera throughout Manhattan to take pictures of street scenes and workers. While her street photography is not the focus of this research, her documentary style in her photographs of street scenes chronicle significant historical moments of everyday life in New York City at the turn of the century. Images such as Figure 3.5, Organ Grinder show her keen eye at observation that reveal a particular time and place in history. Austen's street photography, 
as well as portraits of lovers and friends, has been under-examined compared to documentary photographers Jacob Riis ${ }^{50}$ or Lewis Hines.

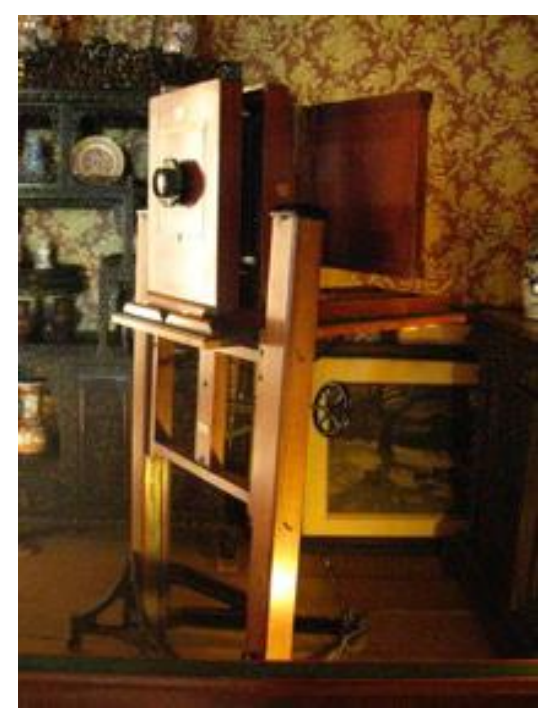

Figure 3.4

Alice Austen's camera at Clear Comfort

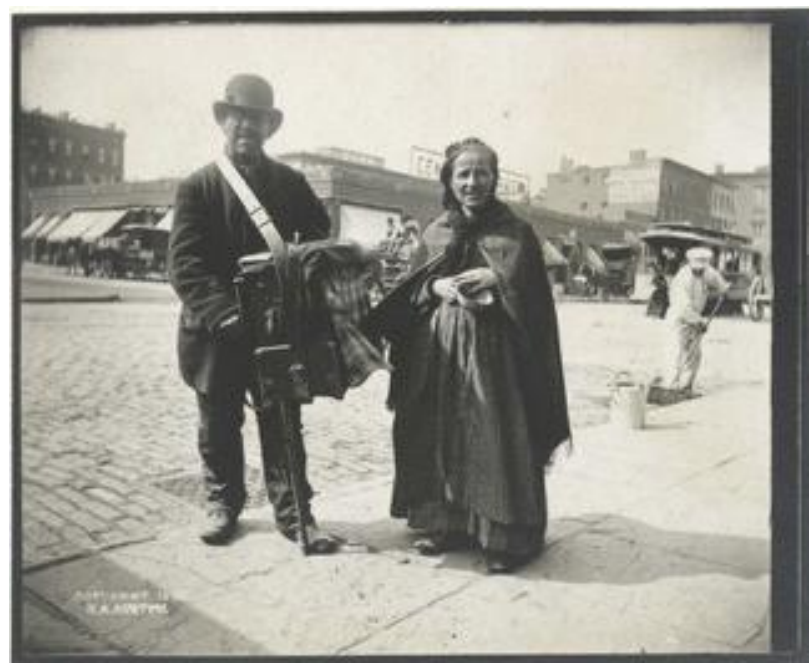

Figure 3.5

Alice Austen, Organ Grinder. New York City, 1896

${ }^{50}$ Riis was considered a social reformer. Riis's concern about the over-crowding in tenements in the lower east side of Manhattan, called for cleaning drinking water and the demolition of the infamous slums of Five Points garnered waves of attention. His works, in particular How the Other Half Lives, 1890 were laden with racism. As portrayed in Riis's books, "The Jews are nervous and inquisitive, the Orientals are sinister, the Italians are unsanitary." Maren Stange, Jacob Riis and Urban Visual Culture (278). 
Although many details about her private life are opaque, her thirty-year relationship with 'Trude' was public. Ann Novotny provides a number of biographical details, such as how Gertrude Tate met Alice in 1899 in a Catskill hotel named Twilight Rest. Gertrude was there to recuperate after typhoid fever, and Alice went there to visit the Eccleston family, as a good friend (and perhaps lover) of Gertrude Eccleston.

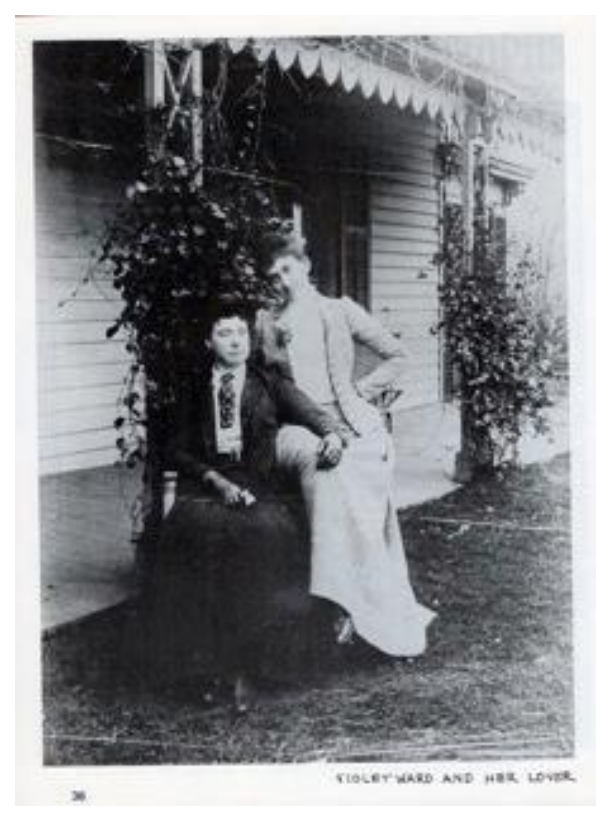

Figure 3.6

Alice Austen, Violet Ward (left) and gymnast Daisy Elliott (Right). Clear Comfort, 1892

In 1917, when Gertrude was in her mid-forties and Alice was fifty-two, Gertrude moved in; "Gertrude's family was appalled" and claimed Gertrude had "the wrong devotion to Alice" (Novotny 60). While Alice and "Trude" were able to be together without the intense scrutiny or debilitating social ostracization that many others endured, Novotny states in the epilogue of her book on Alice Austen that "Gertrude Tate lived 10 years after Alice passed away but due to 
red tape, indifferent bureaucracy and expense, Gertrude was not buried beside Alice as they both had wished" (110).

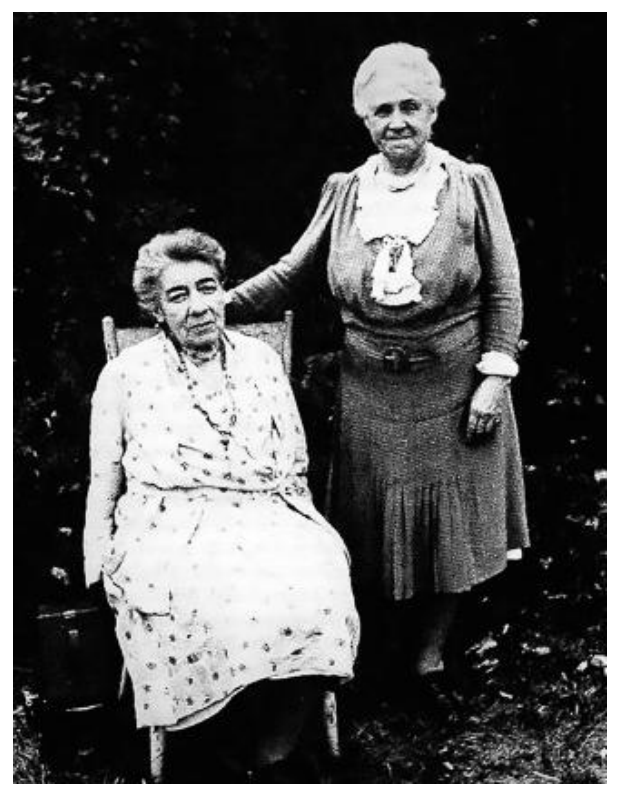

Figure 3.7

Alice Austen (left) with Gertrude Amelia Tate in 1951.

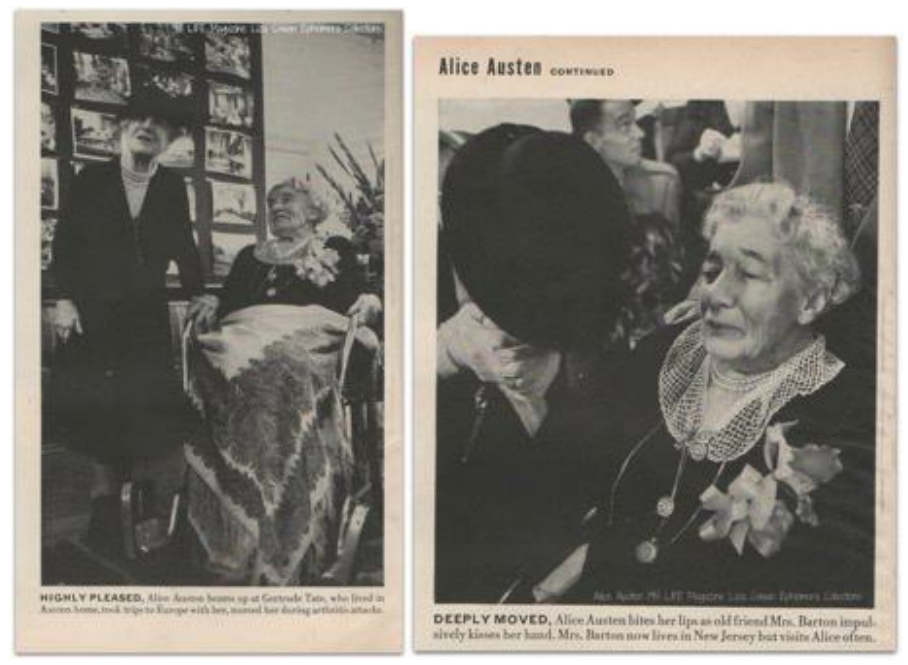

Figure 3.8

Alice Austen, LIFE Magazine 1951 
Orientation, Affect and Misalignment

According to Ahmed, "to experience an object as being affective or sensational is to be directed not only toward the object, but to 'whatever' is around the object, which includes what is behind the object and the conditions of its arrival...location is important, the object and self must have proximity in order to experience its affect" (33). Experience of an object bridges thought and action through affectation. By advocating for affects as corresponding with "the messiness of the experiential, the unfolding bodies into worlds" (30), as well as with "proximity" (32), "Iocation" (33) and "orientation" (35), conditions of consciousness are disclosed as variable and dependent on the unfurling of time and place. Affect and phenomenology offer a valuable stake in cultural studies method through the concept of articulation, not as a concept of a speech-act but rather as a location of bringing together interlocking forces for the purpose of contextualized analysis of ways "power and social relations are created, structured and maintained through culture" and how they "circulate analyses in... pedagogy, provocation, and political intervention" (Rodman 2013, 345). Although articulation in this context is not the same a discourse, they require each other reciprocally to mobilize thought and action. Queer Method, in this case, is approached in three specific ways: the phenomenological process of orientation as an interpretative paradigm, how political engagement in visual culture can contribute to anti-oppression, and lastly how affect and feeling are vital to queer knowledge as a site of historical and future knowledge.

Affect, like discourse, unfolds over time and is relational to its surroundings. To be near or within the proximity of affect has been argued as pre-discursive experience. Yet, selfhood is informed by affective conditions found in objects. Such objects, or moments with objects, direct our emotional currency, to find associations or closeness in life. Such affects of "tending 
toward" some things and turning away from others are locations of relations where we find engagement or structures to feel thought.

\title{
Elizabeth Alice Austen \\ and her friend \\ Gertrude Amelia TATE
}

In memory of

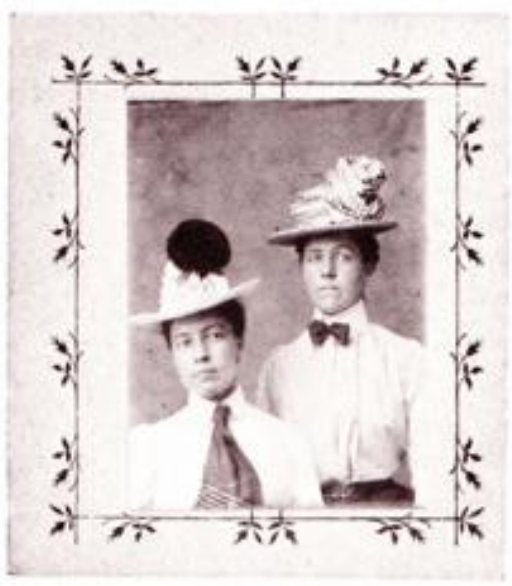

\begin{abstract}
A mile up the shore from Alice's house, Mr. Pickard's studio on Water Street sold small one-centa-piece photographic portraits to the delight of local school children. On a warm summer day at the turn of the century, what whim impelled Alice and Gertrude to pose in Stapleton for one of "Pickard's Penny Photos"?
\end{abstract}

Figure 3.9

Alice's "friend" as stated on the opening pages of Ann Novotny book Alice's World

Finding associations is dependent on our closeness to the things we create attachments to, a mix of belonging and non-belonging, which is mediated and non-mediated. Jeffery Weeks suggests that sexualities that run counter to the status quo require "a sense of belonging, a focus of opposition, a strategy for survival...that offers a critical view of all identities" $(1995,44)$. By 
examining phenomenology through a queer lens to inform both a critical view and methodological practices, such discourses shed light on queer consciousness and embodiment. Because phenomenological processes are 'situated' and require an orientation, 'queer' as a spatial term confronts compulsory heterosexuality. As Megan Watkins writes in Desiring Recognition, Accumulating Affect, "Affect is often viewed as preliminal, preconscious phenomenon... whereby a sense of self is formed through engagement with the world and others" (269). The key concept in this statement is engagement and our relationality with others, objects, meaning and situations. To be engaged in the world and to form an idea of self requires some kind of positionality.

Raymond Williams addresses the structures of experience with consciousness:

We are talking about characteristic elements of impulse, restraint, and tone; specifically affective elements of consciousness and relationships: not feeling against thought, but thought as felt and feeling as thought: practical consciousness of a present kind, in a living and interrelating continuity. We are then defining these elements as a "structure": as a set, with specific, internal relations, at once interlocking and in tension. $(1981,130)$

For queer pedagogy, feeling as thought in a living and interrelating continuity is a powerful site of recognition and evaluation in the complex web of selfhood, and its possible articulation. If thought can be felt and we can feel through the thick haze of thought, the potentialities of queer affect can unmask the reoccurrence of shame and self-hatred toward politicizations of the external.

Lawrence Grossberg, like Williams, views the structure of feeling as inhabiting a site of politicization that may be prediscursive yet requires consciousness. He states, "everyday life is not simply the material relationships; it is a structure of feeling...this is what I call 'territorializing'... how you can move across those relationships, where you can and cannot invest, where you can 
stop/rest and where you can move and make new connections, what matters and in what ways" (Grossberg 313). Our evaluations for or against things are structures of feeling that are not arbitrary but rather indicators of relational territories. As stated by Gregory Seigworth and Melissa Gregg, "affect marks a body's belonging to a world of encounters" (2) allowing both the corporeal and the critical to affect and to be affected. The world of encounters that mobilize one experience over another cannot be separated from social ordering in how and what we turn toward or away from to inform social bonds. Such affects of non-belonging are on the continuum of belonging, whereby painful histories create structures of closeness.

By placing Ahmed in dialogue with Williams' concepts of structure, I call into question how objects and notions of perception are shaped through phenomenological and affectual considerations. Specifically, this is approached through concepts of intersubjectivity, which in cultural studies deals with subjects interacting and communicating in order to either produce sharable meanings, or how culture, in itself, requires a surplus of participatory subjectivities. Intersubjectivity presumes subjectivity as conscious, where actions, behaviours, intentions and experiences are constituted in both the world and also human action. Intersubjectivity allows for thoughtful qualitative research through hermeneutic notions of an interpretive that engages historical and socially established positions. By asserting that queer desire is a turningaway or derailment of the straight line of hegemonic social ordering, "the structure of feelings" becomes charged with economic, social and historical contexts that traverse the regulatory and prohibitive. By living an "interrelating continuity" with "internal relations, at once interlocking and in tension" (Williams 130), queer phenomenology offers a politicization of sex, gender, race and class that may be prediscursive but evokes consciousness. 
While Ahmed speaks of queer phenomenology as requiring locality and failed alignment with the vertical line of social ordering, Barthes' phenomenology is the affect of the physical order of photography. Its order is that every photograph is the return of the dead, and it is death that remains the eidos or essence of photography, thus making photography an affective site. He states, "every photograph is a certificate of presence" (Barthes 87). He searches for language to speak for that which is at first seen then felt, a form of phenomenology that "had never, so far as I could remember, spoken of desire or of mourning" (21). Damaged affectation of loss, pain and mourning are indeed human, however when it comes to historical analysis or access to repressed history, desire and mourning have far-reaching considerations beyond singular pain, to a shared experience through community, which contribute to historical memory.

To have a history, to know what has been before you that may not overtly change who you are or what you become does however provide context and a sense of shared knowledge. For queers, history is just becoming. The Stonewall uprising from the 1960s and the AIDS epidemic in gay communities in the 1980s and 90s are recalled and re-inscribed over and over as moments of queer unrest and loss. These markers of queer time have passed and there is little other past to demonstrate larger strata of knowledge or culture. Queer history is limited only by access to its own history. The issue arises from the historical suppression of records documenting the everyday lives of queer people, and our access, thus producing our interest in our past. The effects of systemic and historic violence, injury and erasure are part of how queers bond. We bond at candle-lit vigils where a friend, a community member, was beaten or killed. We turn up to grieve together. Such damaged affects are as Nietzsche states an "attribution of causality" (354). However, the cause and effect of 
contemporary violence on queers is predicated on misogyny, homophobia, transphobia, gender policing and sexual violence.

While the reasons we experience or feel this versus that or that versus this are not fixed, or simply reduced to the ideological, it is in the tending toward or tending away that political meaning in affect can be found, particularly in the historical categorization of queerness and its socio-cultural violence. By [dis]orienting from prescribed and enforced systems of social ordering, compulsory heterosexuality as a "political institution" (Rich 637) is shaken. Such orientation involves a mass of diversification that shapes global queer identities, where emotional economies are constituted through verbal and non-verbal discursive and prediscursive systems. As articulated by Adrienne Rich:

\begin{abstract}
The denial of reality and visibility to women's passion for women, women's choice of women as allies, life companions, and community; the forcing of such relationships into dissimulation and their disintegration under intense pressure have meant an incalculable loss to the power of all women to change the social relations of the sexes, to liberate ourselves and each other. The lie of compulsory female heterosexuality today afflicts not just feminist scholarship, but every profession, every reference work, every curriculum, every organizing attempt, every relationship or conversation over which it hovers. It creates, specifically, a profound falseness, hypocrisy, and hysteria in the heterosexual dialogue, for every heterosexual relationship is lived in the queasy strobe-light of that lie. However we chose to identify ourselves, however we find ourselves labeled, it flickers across and distorts our lives. (657)
\end{abstract}

In reading the photographs of Alice Austen and examining affect, attention, mood, evaluation and orientation, the brief sampling of her work in this chapter shows the oblique line as moving out of line with others. Others, in this case are formal conventions of portrait photography, in which she tilts her body just slightly to disrupt expectations of nineteenth century women taking pictures of themselves. Further, the snafu of the umbrella reading, which is discussed in 
the Queer Punctum section of this chapter, reveals the value of misreadings, not as a crisis, but rather how failure can open discourse which can assist in charting a course of queer affect that can represent political emotions and feelings beyond heteronormative, patriarchal structures intended to expunge queer knowledge and history.

\section{Queer Punctum}

In chapter two, Early Photography and Queerness, I examined Barthes's concepts of punctum and studium. This section tackles the problems encountered by the affective quality of punctum and its collision with cultural inscriptions of studium. I propose that affect and cultural knowledge are not separated as Barthes theorized, but collide in a way that offers a valuable space for the production and analysis of queer political feelings. In fact, the collision offers a new stratum of feeling queerly that rejects the binary opposition of punctum (feeling) and studium (inscription). Queer Punctum, as I argue, requires this collapse to augment the commitment to inclusivity and critical discourse to queer knowledge. Queer history has and will continue to embody a diversity of race, gender, class distinctions and sexual practices. The continuous change in the acronym of LBGTTQQIA2 ${ }^{51}$ is an articulation of the commitment to the derailment from the straight line of social ordering by allowing for flux in identity. How can punctum and affect articulate queer feelings, and how can we understand the differences between affect theory and punctum?

${ }^{51}$ Lesbian, Gay, Bisexual, Transgender, Transsexual, Queer, Questioning, Intersexed, Asexual, Two-Spirited. 
Punctum and affect share significant qualities. While Barthes describes punctum as a prick or wound, for Ahmed, "affect is what sticks, or what sustains or preserves the connection between ideas, values and objects" (29). Ahmed suggests that affect or sensation involves both proximity to the object as well as its conditions, timing and directions, which is similar to how Barthes defines subjective relationality to a photograph. While punctum is the phenomenological affect of the indexical nature of photography, and, as I have proposed, punctum is contingent on consciousness and subjectivity, then Queer Punctum is as plausible and significant as queer affect. Yet there are sticky differences between the two.

The structure of feeling is not arbitrary. To reiterate Williams' statement regarding "not feeling against thought, but thought as felt and feeling as thought" $(1977,130)$, feeling is not separated from reflection, contemplation or thinking. Rather, they are interconnected and interrelated. As Gregory Seigworth and Melissa Gregg argue, "affect marks a body's belonging to a world of encounters," (2) allowing both corporeal and criticality to the potential of to affect and to be affected. Consciousness must be within the paradigm of affect because the delay between unconscious affect and conscious thought cannot fully be separated. Affect and cognition are embodied, "a body is as much outside itself as in itself" (Seigworth and Gregg 3).

If punctum is subjective and personal, how can it not embrace political positioning of orientation and "unfolding bodies into worlds" (Ahmed 2014, 30)? For Barthes, it is the connection between the here and now of life and the omnipresence of death in photography that creates a site of feeling, and the potential for the experience of punctum. He states that punctum is always subjective and motivated by looking and consciousness. How can we understand multiple subjectivities and visuality in punctum? And if the 
phenomenon of subjectivity is the key to punctum and the Barthesian theory of punctum is coded, personal and flexible, then I argue that due to its instability and temporality, queerness and its historic interpretations can criticality employ these approaches in the name of a Queer Punctum. Further, the collapse between Barthesian notions of feeling and cultural conditions makes space for Queer Punctum as a location of political emotions.

Punctum as a form of desire (Barthes 1982, 4) is influenced by the phenomena of being, where the indexical nature of photography and the subjectivity of the viewer meet and we are faced with the phenomenological and affectual identifications of photographed subjects. Barthes explains that punctum produced a sensation of "looking at a new photograph, marked in my eyes with a higher value" where "its mere presence changes my reading" (42). Much like the oblique line of Alice Austen's self-portrait with her body slanting sideways in the frame, the presence of 'sitting wrongly' altered my evaluation of that photograph. Her intentional and calculated tilted posture pricked and poked at my affectual reading of the image so that, while I had not realized it, over the course of several years it had informed my identification not only with the photograph, but also something within me. 


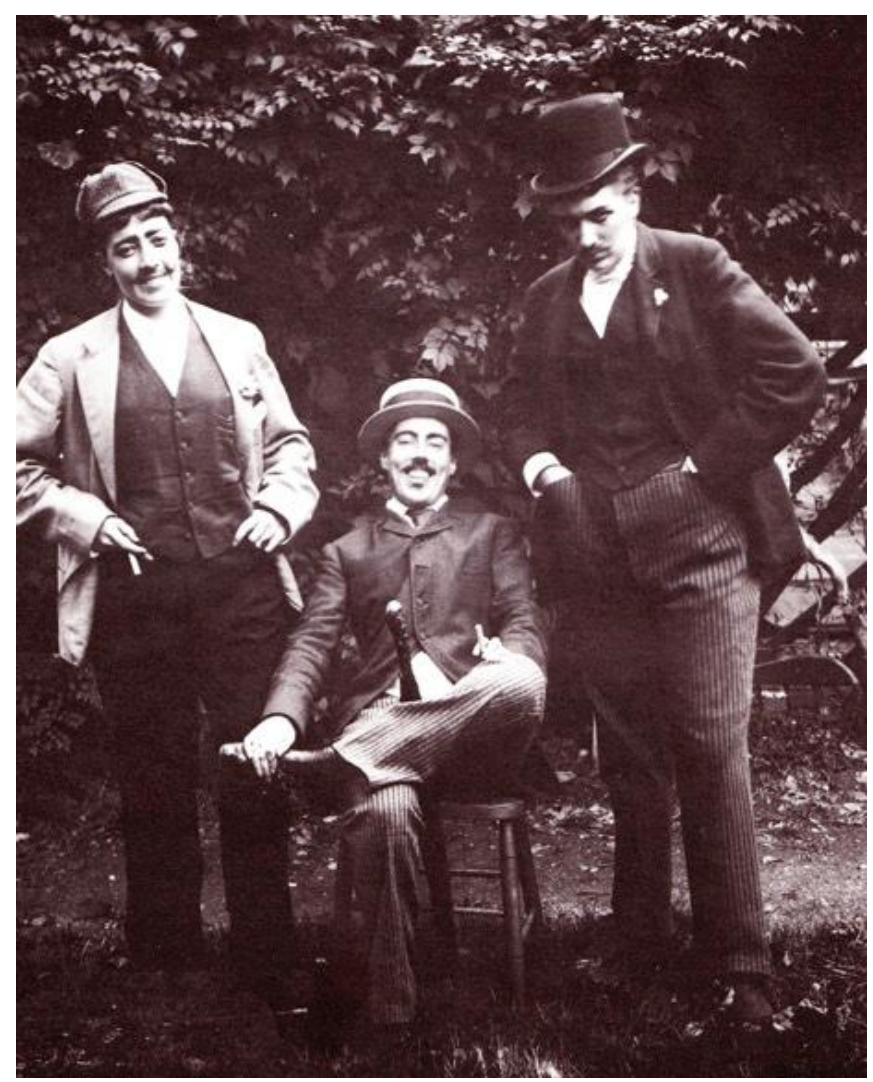

Figure 3.10

Julia Martin, Julia Bredt and Self Dressed Up as Men, 4:40pm, Thursday, October 15 ${ }^{\text {th }}, 1891$

We look so funny with those moustaches on, I can hardly tell which is which," laughed Miss Austen when she saw this photograph in 1951. "We did it just for fun," she commented. "Maybe we were better-looking men than women. (Austen reflects on this image later in her life, Novotny 15).

Dressed in drag, Alice and her two friends are in the garden. Two of them stand, one sits. Their suits, moustaches and gestures connote something like a male salon, where men would get together and discuss literature or politics. However, the large wooden phallus popping out from Julia Martin's pants disrupts the image, placing a host of other meanings onto the image. 
Once I noticed it, it was all I could see. Where did they get a dildo? Did they carve it? Who carved it? Had they used it on each other? I have looked at this image for over ten years. I thought I had seen every single detail because I had scanned and rescanned and absorbed its details. But I was wrong, I hadn't seen every detail, I had only seen what I had always seen, over and over again. That is to say, whenever I looked at this photograph, I looked at the same things. My eyes followed the same path every time. Until, one day only recently, I noticed something that changed this picture, which transformed everything I thought I knew about this image. I looked at the tip of the erection and followed it down, between her legs, further still past her thighs, down her calves. It was not a dildo, a carving or a toy, but simply an umbrella, whose wooden handle was purposefully nestled between her crossed legs.

How had I misread this image? Particularly since I had looked and relooked at it over and over again? Interpretative critique may illustrate how understanding can exceed explanation or error of perception. Misreading and misunderstanding texts and/or visual culture is born from the very nature of dialectics, in which argumentation (with self or others) can bare seeds to understanding. As discussed in chapter two and three, Barthes misreads a VanDerZee photograph and exposes a kind of paternal racism (Smith 2011). Due to his blinding grief at the loss of his mother, he reads the photograph not via the actual image but through a distorted perception that may tell us more about Barthes than it does the image. As Ricoeur states about the complexity of interpretation: 
This relation between the self and the other gives the concept of prejudice its final dialectical touch: only insofar as I place myself in the other's point of view do I confront myself with my present horizon, with my prejudices. It is only in the tension between the other and the self, between the text of the past and the point of view of the reader, that prejudice becomes operative and constitutive of historicity (76).

In Figure 3.10, the everyday object of the umbrella is transformed with subversive meaning, whereby the object that keeps you dry in the rain becomes an object or symbol of arousal. The umbrella is placed under new conditions of usage and is oriented toward a queer effect. The tension between the past and now had placed this image under conditions that forced me to re-evaluate the relation between Austen and myself, and allowed for a greater understanding in how to read the photograph. Rather than avoid this discourse I explore my initial misreading as an opportunity of self-reflection that may "free the subject from dependence on hypostatised powers" (Ricoeur 82). Further, I would argue that my misreading is not a crisis of misinterpretation but rather an illusion distinct from error (Ricoeur 84) that required a "rearrangement [of] rational justification" (84) and "an interplay between question and answer" (107).

The practicality of the umbrella is temporarily bracketed out and is intended to signify overt desire. By taking an everyday object and playfully making it a symbol of eroticism, in this image Julia Martin takes a familiar object and re-inscribes it queerly. The interruption of the umbrella suggests sexuality, perversion and deviancy. At the time, social ordering included "jail time for women who were caught smoking in public" (Smith-Rosenberg 54). Dressing as men, particularly through the parody of male arousal would seem more socially dangerous than smoking for women. However, the Victorian period is laden with contradictions. Carroll Smith-Rosenberg explains the complex range between acceptability and social incongruity: 
At one end of the continuum lies committed heterosexuality, at the other uncompromising homosexuality; between, a wide latitude of emotions and sexual feelings. Certain cultures and environments permit individuals a great deal of freedom in moving across this spectrum. I would like to suggest that the nineteenth century was such a cultural environment. That is, the supposedly repressive and destructive Victorian sexual ethos may have been more flexible and responsive to the needs of particular individuals than those of the midtwentieth century. (76)

If sexuality is a matter of being and sexual orientation requires orientation as proposed by Ahmed, then it is valuable to note how the perverse is significant to the "disorientations of queer" (78). Ahmed states "perversion is also a spatial term, which can refer to the wilful determination to counter or go against orthodoxy, but also to what is wayward and thus 'turned away from what is right, good, and proper'" (78). By deviating from expected usage, the umbrella is a signifier of how "lesbian desire makes things happen" (107) and how "we become lesbians in the proximity of what pulls" (94). This image relinquishes the hold of compulsory heterosexuality through the re-inscription of the umbrella and its Queer Punctum.

Naming oneself as a lesbian is thus an effect of being a lesbian (in a certain way), which itself produces the effect of being a lesbian (in another way). After all, declaring oneself to be a lesbian is not what makes one experience lesbian desire: tending toward women as objects of desire is what compels such risky action of self-naming in the first place. If lesbianism were generated by the word "lesbian," then lesbian politics might be easier: it would just be a matter of spreading the word! If we become lesbians, then lesbian tendings and even tendencies not only pre-exist the act of becoming...such tendencies can be blocked as well as acted upon: compulsory heterosexuality could even be described as a block. (Ahmed 93-94). 
Barthes's punctum, the detail that changes the reading of a photograph is contingent on the noeme or that-which-has-been, which is based on the immediacy of photography and death. That-which-has-been in photography relies on the apparatus of the lens shutter. Once opened and closed the lens captures light onto paper, glass, tin, etc., and the moment that was recorded has passed. While the ontological having-been-there-ness haunts the general experience of photography (Barthes 76-78), I argue that this concept troubles the positionality of historical queerness and its affects. Because queer history and its representations are imbued with generations of silence and double lives, the emotional embodiment of photography is tenfold when investigating queer evidentiary power in having-been-there-ness. The matter-of-being a queer body, outside the norms or straight lines of compulsory heterosexuality informs not only ontological desire and affect but also the "the referent...in flesh and blood" (Barthes 1982, 79). Such encounters are accumulated through relatedness, yet these interruptions, deviations, oddities provide "gut economies" (Seigworth and Gregg 3) for queer affect. My gut had read Austen's photographs as occupying historical queer territory, yet the flesh and blood of her as a referent was outside the sayable. Affect as prediscurive and the emotional possibility of photography's that-which-has-been are complex relations between the seeable and the sayable. What cannot be spoken may be illustrated, or the codes to which we adhere to or deviate from reveal where we have been and where we might go.

The significance of photography in examining queer visual history necessitates the evidentiary power in having-been-there-ness by imbuing intentionality with the possibility of reclamation. Further, the emotional contingency of photography and the detail that moves the viewer is informed by how that viewer situates herself. Queer Punctum is the socio-political oblique 
line that is manifested in culture, discourse and lived experience, which feels meaning in photography through the ever-changing landscape of language and cultural knowledge. Queer Punctum is the photographic wound of the specific that strays from hegemonic social ordering and re-inscribes the burden of the status quo into politicized emotions that signal queer-embodied knowledge.

In conclusion, by expanding on the stickiness of affect, this chapter sought to participate and engage in the evolution of language, theory and thought. While cultural and phenomenological emotional economies are constituted through verbal and non-verbal discursive and prediscursive systems, the readings of Alice Austen's photographs offer evaluations of the orientation of bodies that matter. Further, what Grossberg calls "mattering maps" $(2009,316)$ charts a course of affect that can represent political emotions and feelings beyond heteronormative, patriarchal structures intended to expunge queer knowledge and history.

Heather Love considers the injury of historical homophobia as a bond to memorialize but also to overcome, and the larger challenge is "to engage with the past without being destroyed by it" (2). The concept of "reverse discourse" as a political paradigm informs empowered social recognition as well as the queer social history of degradation, threat and punishment. "As long as homophobia continues to centrally structure queer life, we cannot afford to turn away from the past" (Love, 29). By recognizing our difficult history and challenging the discourses intended to repress, queer becomes a term for that which does not uphold compulsory heterosexuality and fails to orient according to the status quo. Under the rubric of criticality and engagement, queer is active, politicized, conscious and alive, and it is in the spaces of dissent, creativity, thought and action that both resistance and queer hope thrives. 
By widening cultural boundaries, creating visibility, forming social bonds and remaining committed to the temporality of language, queer communities contribute to the ever-changing paradigm of "reverse discourse." Yet the limitations of reverse discourse are dependent on its strategy, intention and desired outcome. How can contemporary queer communities create reverse discourse within such limitations? As discussed for Foucault, discourse is structured, enforced and maintained through systematic, authoritative power. Engaging with painful histories and language uncovers historical wounds that were deliberately instituted to produce fear, shame and harm.

In Camera Lucida, Barthes employs two distinct methodologies for approaching photographs; one involves the studium or "sovereign consciousness" (26) where the cultural attributes of the photograph and its social implications can be read and understood, and the other involves the punctum, the emotional contingency that "reveal[s] what is so well hidden" (32). As outlined, Queer Punctum attempts to shift punctum beyond the unintended photographed detail and into a broader conceptualization of queer politics, where a politicized subject can emerge through various cultural inscriptions around the photograph that inform specificity and create context to queer subjectivity. Austen's Figure 3.10, "reveals what is so well hidden" (Barthes 32) in that the everyday object of the umbrella becomes inscribed with political meaning, by taking the everyday and creating "a network" or "intertext" (Kuhn 12) of new signifiers of desire, sexuality and re-configuring of gender.

I have investigated phenomenological approaches that involve situating oneself and the relationship to orientation, as well as how photography is affectual and layered with emotional knowledge. Ontological desire and affect have been examined in terms of how they inform embodiment where oblique queerness does not follow the line of compulsory social ordering. By asserting 
subjectivity as oriented and affectual, sexuality and gender is challenged beyond normativity to inform more comprehensive conditions for the uncovering queer history, I have attempted to expose a politicized collapse of the heteronormative positions of feeling and being. Queer Phenomenology (Ahmed) and Camera Lucida (Barthes) share significant interests in deciphering embodiment and locating the phenomenological, and it is these corresponding theories that allow us to engage with the emotional quality of not just photography but the affect of queer visual history. By examining how Barthes's Camera Lucida can have political significance for queer history, researchers and thinkers, I challenge normative methodologies of photo theory, affect and phenomenology with a specific goal of uncovering fresh discourses.

By examining historical queer visual culture that has been complicated by socio-political and cultural systems of negation, I argued that seeking out history, and feeling its weight, trauma and violence is a political act. My approach to concerns about terminology and labels tied to sexuality has been to interrogate the notion of desire and sexuality beyond straight or gay toward questions of symbolic defiance, particularly through how we can understand the world around us as an "intersubjective overlap" (Rodman 2013, 348). This overlap speaks to the multiple institutions and socio-cultural forces, such as medicine, law, education and language that impact our mediated contact with the world. In spite of the temporality of desire or validation through subjects' biographies, I have used the term Queer, not as a fixed position based on essentialized notions of sex and gender, but rather a politicized spatial term that tends away from the social ordering of normativity (Ahmed, Merleau-Ponty), as the basis for rereading certain aspects of photographic practice in the long nineteenth century. 
Alice Austen's photographs discussed in this chapter were examined as case studies toward visualization of queer method. The choices, poses and approach to picture-taking by Austen illuminate how photography offers room for debate regarding methodologies in critically engaging in queer history. Her works reveal both the impact of photography on queer discourse as well as how queerness can be illustrated in early photography. The location of self in relation to the object informs both proximity as well as our experience of affect, in particular queer affect that investigates the relationship between feeling and the production of queer selves, affect as a site of enabling political resources. As Ricoeur points out:

It is not a question of imposing upon the text our finite capacity of understanding, but of exposing ourselves to the text and receiving from it an enlarged self, which would be the proposed existence corresponding in the most suitable way to the world proposed. (143)

By remaining committed to an interplay between textual analysis and reading photographs, I seek to understand past queer lives in visual culture through politicized affectations that both make close readings compulsory as well as distanciation as a method that "oscillates between remoteness and proximity" (Ricoeur 111), in order to "find myself only by losing myself" (144). Through the loss of self and its retrieval in interpretation, a duality between critique and understanding offers invaluable meaning to discourse as circulative and static, such is particular true for photographic representation.

The complex nature of photography in both delivering us an object/image and its inherent ability to deceive is engrained in its materiality as well as its socio-political conditions. The indexicality of photography can be obscured by the sign system of memory, since as Barthes revealed that which 
has been photographed has past, yet the viewer is alive, both reaching both back in time and being of the present moment. The indexicality of photography offers a powerful means for moving across time. The social experiences and cultural knowledge provided by photography create associations that bring us closer to the conditions that surround us.

My approach to Queer Method as phenomenological processes of orientation challenges normative constructions of representation to aid in political engagement of historical anti-oppression and erasure. Ultimately, I argue that rather then identity as a factor of queerness; it is the misalignment from the normative that affects worldviews and social ordering. By articulating an alternative (Butler) the political subject (Rancière) becomes the here-andnow of social justice. This is active and alive through the continual destabilization of normativity.

By employing queer methodologies to examine theoretical analysis in my field of study, I have attempted to coherently link ontological and epistemological positions to my paradigms. Yet, I realize that queer methodologies do not answer questions in this research but in fact threaten notions of disciplinary reason. As stated by Browne and Nash in Queer Methods and Methodologies, "we sketch out recently emerging questions about the place of conventional research techniques in examinations of messy and unstable subjectivities and social lives and consider the place of queer approaches in these debates" (2-3). My paradigms have explored philosophical examinations of selfhood through notions of orientation, whereby queer orientation deviates from the central line of heteronormativity. By investigating how localities factor into the understandings of queer bodies, I have deliberately tackled questions of why this is political and how political meaning is bound to movement, action and thought. Further, by considering the 
problems with Barthesian punctum and studium, I have revealed the impact of feeling, queer politics and the material production of the photograph to foster queer historical analysis, and to a lesser degree, shed light on contemporary sites of violence against queer communities. 


\section{Conclusion}

In a word, historical discourse does not know negation (or very rarely, in an eccentric fashion). This fact may be curiously - but significantly - related to the arrangement we find in a "writer" quite different from the historian, the psychotic, who is incapable of subjecting a statement to a negative transformation; we might say that in a sense, "objective" discourse (this is the case of positivist history) joins the situation of schizophrenic discourse; in either case, there is a radical censorship of the speech-act (in which feeling alone permits a negative transformation), a massive reflux of discourse toward statement and even (in the historian's case) toward the referent: no one is there to assume the statement. (Barthes 1989, 135)

My approach throughout this dissertation was to examine historical issues of queer visibility through cultural and visual culture studies by placing multiple concepts dealing with 'the representational' in critical dialogue with each other. "Historical discourse" as signalled in the opening quote by Barthes's involves a polemic between the method of the historian and that of a writer, which adheres interestingly to concepts laid out in cultural studies, where objectivity is "rejected" (Rodman 2013, 348) and where debate and contestation are part of forming and informing discourse. These 'methods,' fields and/or approaches are significant to growing models of Queer Methodologies because queer chronological record is saturated with sublimation. Because of my interdisciplinary approach to image, thought and meaning, I sought to unpack the knotted and tangled web of hegemonic and social power. Rather than avoid the messiness and instability of these complex issues, my research embraces "queer subjects and subjectivities [as] fluid, unstable and perpetually becoming" (Browne and Nash 4), and as a foundational site for queer theory. Where my research adds to "queer as a contested and locationally contingent term" (4) is 
through my cross-pollination of theorists and its implication for reading historical photographs from the late nineteenth and early twentieth centuries. Queer history has and will continue to embody a wide range of race, gender, class distinctions and sexual practices. The ever-developing acronym of LBGTTQQIA2 communities reveals queer allegiance to articulation as a political foundation to the upsetting of normative social ordering.

The 'truth' of a given subject's sexuality, desire and/or 'lifestyle' was not the concern of this research. Historical and contemporary 'fact' perhaps can be charged with similar indiscretions, for as Barthes quoted Nietzsche, "There are no facts as such. We must always begin by introducing a meaning in order for there to be a fact" (1986 138). Without the production of meaning and its plentitude, fact requires a healthy, critical and significant stake in "a certain mistrust" (138) of truth.

Rather than seek truth or reconciliation, this research informs symbolic defiance as a politicized discourse and asks if we look back and face historic injury how does that affect queer knowledge? Queer embodiment has been examined as a fluid state of becoming, where in-between-ness is political and positions itself relationally to and against the world around it. The affectations of this relationality are validated by examining the forces of encounters through the mass production of photography.

My main points examine portrait photography from the long nineteenth century, where my concern is with the construction of the social body through: law, medicine, the state and regulation. The effects of the criminalization of homosexuality through imperialism and the social sciences not only advanced social control in the nineteenth century but also laid far-reaching groundwork for systemic violence. Part of the historical violence I discuss involve issues of brutality, ostracization, prison, etc, but as discussed both above and throughout 
this dissertation, I examine discursive violence in the making of the modern homosexual. Discourse is key to this work as notably stated in the title, Without Words You Spoke, where I reference problems of enunciability in verbal and visual culture. This research unpacks concealed, wounded and overlooked queer subjectivities with a particular focus on women and people of colour to emphasize political importance.

I dealt with these issues by examining notions of the archive and photographic representation. The archive, a site of memory and cultural knowledge provided this research with an analysis of how and under what conditions one is/can be recalled. Historically, as I examined, the archive both symbolically and definitively produced a greater sense of statehood and empire, which were entangled into socio-political meaning and social order. The logic of the archive advanced social control through simultaneous ideological and bureaucratic systems. If we consider the relationship of photography to the archive, we see how nineteenth century photography became a fundamental tool within archival practices, and its sense of 'progress' with its new technology produced 'truth' as a rational system to control social behaviour. Discipline was manifested onto the body through cultural signs of political economy. Thus, sexual conduct was translated into economic and political behaviour between the state and the individual.

Contemporary queer archives function relationally to these modalities as a point of departure that refuses the systemic erasure of queer lives through the collection of photos, letters, ephemera and things that have been rejected, repressed and negated. By revealing the problems of historical implementation on archival practices, I show how queer archives and their anti-oppressive frameworks can recoup historical trauma and erasure into a site of queer political memory. 
The construction of the social body as a site of discipline, statehood and economic power is seen in the repetitive formulations of carte-de-visites through bourgeois tropes of class, respectability and status. I examined photography in three specific ways. First, how photography was tied to industrialization and capitalism, where I discuss Walter Benjamin's notions of how mass production shifted the ritualistic to the political and how long photographic exposures created conscious decisions of where and when stillness was represented. Second, I linked concepts of nineteenth century capitalism with how industrial production created divisions of class and labour, where the conventions of portrait photography denoted political triumph of the ruling class, yet I present case studies that subvert and upset these archetypes. And lastly, I examined concepts of knowability and presence in photography, which are explored predominantly via Roland Barthes's approach to photo in Camera Lucida. While this text has been foundational in my method of photographic analysis, I take it to task and make a call for interpretations that contribute to potential political action. Here, I advanced the notion of a Queer Punctum, and argued that rather than separate culture and image in the reading of visual affect as proposed by Barthes, that in fact, culture and image require an interdependence in order to enable anti-oppressive political engagement. Queer Punctum is thought that is felt and vice versa. Feeling as a political location must be related to reflection, contemplation and thinking.

Deviation from heterosexuality (Ahmed), orientation and the notion of tending toward one thing over another was a methodology intended to politicize the legibility of historical queerness. In many ways, this dissertation research was born from refusal and rejection. In particular, 'no' as a determiner - there is no proof. My interest is primarily in taking 'no' and inverting it into potentialities about how we can think about queer history. Discourse that disqualifies, such as 
'no' or in the case of slurs, silence and erasure, can only hypothetically produce recuperation because recuperation is not predetermined. Rather, it is constituted through and inscribed by articulation (Butler), enunciability (Foucault) and looking back (Love), in order to understand both what oppressive forces are at work, and how to express opposition.

The "paralyzing slur[s]" (Butler, Love) of dyke, fag, queer, etc. were examined as contingent to how violent language can be recouped with empowered meaning, and that being a 'deviant' is not only a critical politic but is inscribed in visual discourse, in particular photography. Such "material rearrangements of signs and images [as] relationships between what is seen and what is said, [and] between what is done and what can be done" (Rancière, 39) has been explored though the notion of the political subject as a location for vital articulation both in terms of how the past can be researched and examined as well as what this means for queers today and tomorrow. The consequences of historical violence against queers, particularly in the nineteenth century, where the "invention of homosexuality" (Foucault) enforced categorical devices conceived to control and regulate. Foucauldian positions on circular power and how discourse both enables and disables knowledge were foundational to how I approached questions in my research. Further, the standpoint of antioppressive frameworks of other mattering bodies, such as racialized and engendered bodies that have been constituted through oppressive regimes of hegemonic systems of power were examined as both interwoven and imperative to the theorization and study of queerness. By focusing on methods imposed by capitalism and industrialization in the nineteenth century, my emphasis was intended to encapsulate a time and place, in order to understand where we, as political subjects who challenge the established order, have been, and where we imagine we are going. 
The archive as a constituted space, organized through systems of logic and reason was interrogated by focusing on its historicity, and on how sexuality, gender, race and class distinctions have been categorized, thus placing the archive in a binary of precarious liberator and problematic oppressor. The issues I raised with Derrida's Archive Fever were not intended to discount the significant theorization of difference and deconstruction as evident in the vast influence of his work. Rather, I rebuke some of his positions in Archive Fever, in particular the patriarchal authority placed on the legitimacy of social order and the principles and rules of reasoning, to communicate how illuminating gaps can activate fresh discourse and provide a new space of argumentation for the oppressed.

The role of photography in archival practices was central to this research as the power of images intended to control also transformed and subverted methods of portraiture. In particular, the images of Bonnie and Semoura Clark from Beinecke Rare Book and Manuscript Library illustrate gender performativity and the meaning of being a body that matters in terms of American blackness and its very real politicization, both then and now. Similarly, but perhaps more specifically, Mabel Hampton's collection at the Lesbian HerStory Archive in Brooklyn, New York commands respect through the sheer tenacity required to survive rape, poverty, prison, racism, sexism and homophobia. Against the odds, Mabel Hampton proves that survival is predicated on never giving up and persisting through misfortune, cruelty and hate. Because of the community she built and fostered, her legacy is preserved through the "consignation" (Derrida) of black, lesbian radicalism, and the unification of dyke sisterhood. The Lesbian HerStory Archive has all of her letters, ephemera, photographs and evidence of her political actions, in order to give generations access to a working-class black, lesbian life that hegemonic power tried to control, censure and erase. 
Disputing some of the claims made by Barthes in Camera Lucida was not intended to suggest their irrelevancy but instead was aimed at finding problems, elucidating those problems, and challenging the canon, while potentially informing fresh ways of thinking about photography and affect. As discussed at length, I was concerned about Barthes's failure to effectively read race in Camera Lucida. My argumentation was not intended to imply he was a racist as such a position closes the door on potentiality and the opportunity to flesh out gaps. Rather, I take up his 'failure' as a site of politically activating feeling and affect. Because of the issues I raised with Camera Lucida, I put forward the political paradigm of Queer Punctum as an affective location of politicized representation, in order to infuse disparities with critical discourse, analysis and radical politics. Further, the issues with Barthes in portions of Camera Lucida do not and cannot sum up the entirety of his intellectual work. I bring them to light through Shaun Michelle Smith's essay Race and Reproduction in Camera Lucida as a problematic that requires analysis and merits discourse toward fresh approaches to affect in photography. Barthes's overall work, however, asks us to think about a location of where and how we can articulate notions of the 'poetic,' particularly in the complexity of historical discourse. For example, he states in The Rustle of Language, "In historical discourse, the signs of reception or destination are commonly absent" (131) because of "the historian's predictive function" (130). He points to how historical discourse assumes a Positivist position of truth, reconciliation, and to the inaccuracies of historical 'objectivity.' Additionally, Barthes suggests that rather than adopt processes of 'truth' and historical discourse as decisively accurate, there is discursive room to explore. He states "the shifter of organization raises a notable problem which we can only mention here: it is generated by coexistence or to put it better by the conflict of two time spans: the time of the speech- act and the time of the material stated" 
(129). This position is valuable for queer thought and historical recovery in order to explore ideas of what can be spoken, articulated and/or enunciated now and in relation to within historical contexts.

I have provided case studies that were intended to amplify academic terminology and its rhetoric with the flesh and blood of lives fought for and lives lived through an interdependence of text informing the visual, and the visual informing text. Case studies such as Alice Austen provided me with a profound sense of knowing through seeing, and of the exactitude with which photography can lay bare and visualize a theory or concept. The ideas discussed by Sara Ahmed and her notion of "tending away from compulsory heterosexuality" and "tending toward" alterity blossomed when, after months of slowly working through materials, her concept and Austen's image merged and gave new meaning to the process of writing this dissertation. I had "tended toward" (Ahmed) that self-portrait photograph of Austen with pre-discursive affect, which required philosophic models to make the "seeable" "sayable" (Foucault).

This dissertation is not simply a chronological, historical, theoretical document, but rather it is a call forward, to see what is now through the lens of the past. The importance of yesterday lies in the hands of today, as does what the future can be. As stated by Benjamin "history is the object of a construction whose place is formed not in homogenous and empty time, but in that which is fulfilled by the here-and-now [Jetztzeit]" (Benjamin 2005, XIV)52. I made several nods to the notion of 'queer futurities,' and am torn between an empty abyss, and being fully capable of seeking political discourse for queer futurities. The binary that queer futurities evoke in me is a double bind between having little faith in humanity's lust for power and steadfastly believing in anti-oppressive political action. To believe categorical violence has ceased is to not engage in current

52 (see Notes Conclusion \#1 for full details) 
events. The privileges of English-speaking whiteness, North American-ness and the authority of higher education do not obliterate violent experiences of both people down the street and across the world. Because such privileges become absorbed as normative and lose a sense of criticality, my methodology has intentionally occupied leftist and politically engaged tactics to both disrupt the powers-that-be and to support anti-oppressive action. Jacques Rancière offered my research a base to return to. When I got lost in the sea of information, oceans of dialectics and caverns of swirling discourses, turning to Rancière always calmed the waters. Le sujet politique as a subject that must be activated, allows for the possibility of "political subject(ivity)" and insists on anti-oppression through the struggle for equal recognition in the established order.

As discussed in the introduction, artists, curators and creative thinkers are making contemporary works that address systemic erasure and silence. By challenging established order(s) of what art can be said and what can be done, artists and curators are asking valuable questions about queer history, social justice and, in turn, larger issues of museum culture. Among some of the many artists creating contemporary works involving historical queer themes are William E Jones's video's "Tearoom" (1962/2007) and "Mansfield 1962" (2006) that addressed law, regulation and sodomy in the U.S. Andrea Geyer's 2013 video, Insistence is a powerful piece that was inspired by women's history as both omnipresent yet forgotten. This duality is explored by Geyer as part and parcel with the functions of Modernism, which relied on the knowledge and economy of women while simultaneously keeping them at a distance. Geyer's video takes up the notion of 'distance' by placing portraits of significant American women center in the frame with the video's lens unwaveringly focusing on each photographed portrait. Geyer's artist statement asserts, 
The video insists that the tireless work, spirit and convictions that drove these women [founders of the Museum of Modern Art-Lillie P. Bliss, Mary Q.

Sullivan and Abby A. Rockefeller] to create a crosspollinating and far reaching network across art, politics, education and social reform is not simply an event of the past but alive and remains present wherever we closely look today.

http://www.andreageyer.info

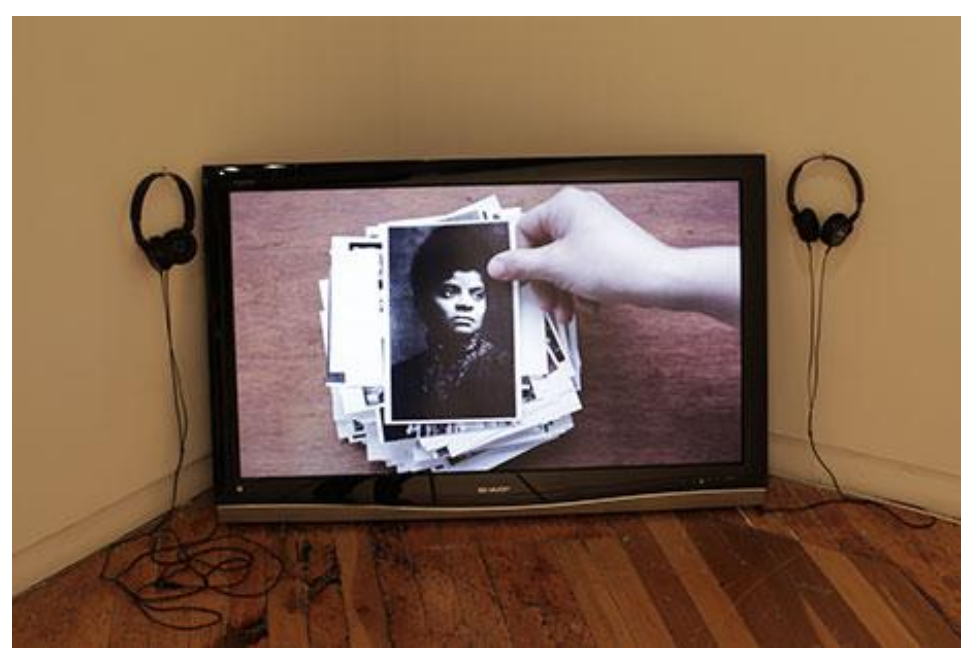

Figure 4.1.

Andrea Geyer. Insistence. 2013.

15.21 minutes. Sourced from

http://www.andreageyer.info/projects/insistence/Insistenc e.html

Sharon Hayes's piece, I March In The Parade Of Liberty But As Long As I Love You I'm Not Free, 2008 is a series of works that examines the relationship between personal and political desire by presenting inquiries about "the emotional landscape of protest actions and public speech" by drawing from sources "such as De Profundis, Oscar Wilde's letter to Lord Alfred Douglas, and slogans from early gay Liberation parades in New York City, the 'love address' uses so-called private speech to get to the emotional imbrication of promise and disappointment in collective political action" 
(http://www.shaze.info/\#). Throughout his career, Sunil Gupta, Indian-born Canadian artist has examined sex, desire, race and erasure. Looking for Langston (1999), a project created with Isaac Julian was "a quest for a nonwhite image of gay men," in addition to the expansive works shown in his monograph, Queer: Sunil Gupta (2011) shows photographs of memorials of murdered queers. Gupta, like the other artists mentioned in this dissertation take historical moments and ask valuable questions that, may not have answers, but posit such enquiries as a place of discourse worth that challenge historical erasure.
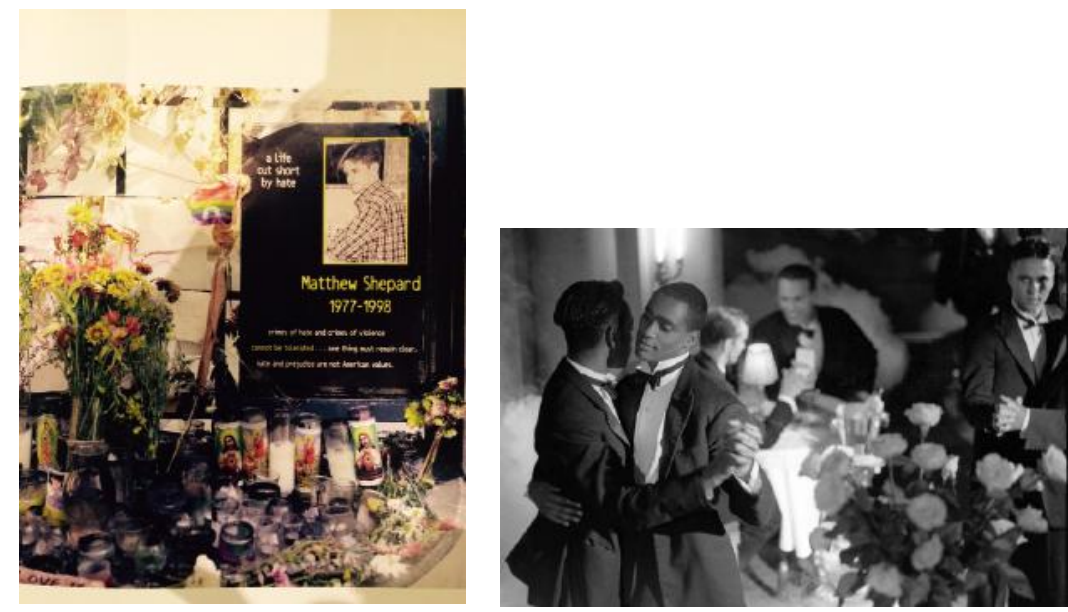

Figure 4.2

Sunil Gupta. Sourced from Queer: Sunil Gupta

If contemporary artists, curators and creative thinkers are mining historical queer photo's, lives, circumstances, etc., as an opportunity to both reflect on the past while bringing complex historical issues forward, then History as a hard and fast discipline is challenged because art practice and historical methodologies may not share disciplinary principles. Where Historical Discourse seeks to create an unbiased or objective sense of events that have occurred, artists and creative 
thinkers present the historical as part of what Barthes calls "the speech-act," in which the past is not simply the "'real,' justified by principles of 'rational' exposition" $(1986,127)$ but as a location of conflict of both time and space. Such conflict provides artists and creative thinkers with the potential to rethink objectivity of historical fact as formed within a powerful force of historical, social and cultural constructions, and allow the ability to intervene.

If desire is at the heart of queer subjectivities then protest and social justice are the blood life force of queer politics. As I discussed in chapter three, "modern homosexual identity is based on...the experience of social damage" (Love 29) and it is in these sites of damage where we converge. Canadian artist Wendy Coburn's Anatomy of a Protest, 2015 is a commanding piece that explores contemporary protest as a location of identity politics and larger strata of law, regulation and force. Coburn was a respected professor at OCADU, esteemed artist and activist who lived with debilitating depression (unknown to many of us that shared community with her). Her suicide on June 15, 2015 shocked Toronto's arts community, and painfully reminds us of both the fragility of life as well as confronts the new millennium's queer youth campaign 'It Gets Better:' perhaps it does not, perhaps it gets better disavows systemic violence to placate the status quo to 'feel better' about suicide and queer lives.
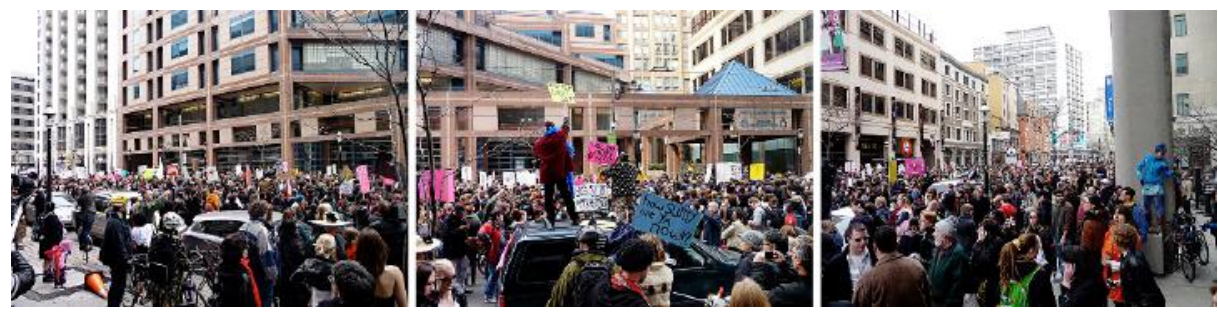

Figure 4.3.

Wendy Coburn. Anatomy of a Protest, 2015. Sourced from http://jmbgallery.ca/ExWendyCoburn.html 
Recently there have been a number of exhibitions that activate the archive with fresh approaches to materiality and history. For example, in Lost and Found: Queerying the Archive (2009-2010), co-curators Jane Rowley and Louise Wolthers created an exhibition examining memory and alternative language of representation that complied histories of artistic visualizations. Additionally, there are a number of exhibitions that deal expressly with invigorating the archive. Among them are Cruising the Archive (2012) at University of Southern California's One Institution and Archives. In 2009, the New York Public Library launched 1969: The Year of Gay Liberation a comprehensive exhibition on their holdings of the Stonewall Riots. That's So Gay: Outing Early America at the Library Company of Philadelphia exhibited collections dealing with historical queerness and same-sex affection in 2014. While these examples are not intended to give a large survey of art and creative practices, they do however offer a sampling of how queer history, leftist politics and memory are being investigated contemporarily.

The historical approach of this dissertation was intended to show how systemic categorical violence is based in historical implementations that circulate throughout time, space and location that are manifested in the "here and now" (Benjamin). Here and now is alive, and is filled with the pulse of life. I attended The Summer School for Sexualities, Cultures and Politics at the IPAK Centre in Belgrade, Serbia in 2014; homophobia is palpable. All in attendance were required to give passport numbers and our addresses to the police in case of homophobic violence. When I attempted to resist, I was told that under the law, the police must come to the aid in cases of queer-bashing ${ }^{53}$.

53 (see Notes Conclusion \#2 for full details). 
The past is not over. Violence, murder and ostracization not only exists, they are dominant in specific moments and in certain places that cannot be predicted. While it has been beyond the scope of this dissertation to discuss global queerness, both historically and contemporarily, it is fundamental that human rights, such as the right not to be murdered, be acknowledged as a paradigm shift from the established order that miscarries, embeds and abuses its desire to control. My intent in examining the historical materials of queer folk was to demonstrate how, under what conditions and through what rhetoric; homophobic devices were conceived and implemented. Because of my interdisciplinary approach to image, thought and meaning, I sought to unpack the knotted and tangled web of hegemonic and social power. Rather than avoid the messiness and instability of these complex issues, my research embraces queerness as perpetually becoming. Where my research adds to the contestation of queerness is through my cross-pollination of theorists that produces fresh ways for reading historical photographs. By doing so, the circulation of power reveals how and why a "plurality of resistances" (Foucault) are imperative to the "articulation of an alternative" (Butler), to activate transformation and advance agency. 


\section{Notes}

\section{Chapter One: Political Power and the Archive}

1) Outhistory.org presented online access to both the exhibition and some of Leo Adam's archive. As stated on their press release, "This OutHistory exhibit presents a selection of Leo Adams's correspondence in a way that Adams himself might have found both "amusing and informative" had this collaborative, internet-based platform been as familiar to him as his carbon-copied archive of correspondence. Foucault defines this genealogy as the 'coupling together of scholarly erudition and local memories, which allows us to constitute a historical knowledge of struggles and to make use of that knowledge in contemporary tactics.' It is coincidental, but nonetheless symbolically meaningful, therefore, that this archive entered the historical record in conjunction with Becoming Visible-a commemoration of the Stonewall Riots-the most visible act of resistance in modern lesbian and gay history."

2) WE DEMAND, 1971. From CLGA Archive in Toronto

"The removal of the nebulous terms 'gross indecency' and 'indecent act' from the Criminal Code and their replacement by a specific listing of offences, and the equalization of penalties for all remaining homosexual and heterosexual acts; and defining 'in private' in the Criminal Code to mean 'a condition of privacy.' The terms 'gross indecency' and 'indecent act' in the Criminal Code remain largely undefined, thus leaving the offensiveness and degree of offensiveness of many sexual acts open to interpretation by enforcement officials according to their personal prejudices -- which by and large are antihomosexual. Therefore a specific listing of public offences is crucial in that only 
in this way can personal bias be eradicated and the legal intent of the law be preserved.

In addition we recommend that the penalty for the specified public offences be summary in cases where sexuality, per se, is involved, and that only when other mitigating factors (e.g. false promise, extreme youth, threats, etc.) are present, the offenses be indictable and, then only when a specific complaint has been brought by a private citizen. In our experience with court cases, Sections 147 and 149 of the Criminal Code have been used to cover public homosexual acts, an offence which is punishable upon indictable conviction; similar public heterosexual acts have usually been dealt with under Section 158 of the Criminal Code, an offence which is punishable on summary conviction. Moreover, indecent assault upon a female (Section 141) can result in a maximum penalty of five years imprisonment, while a person -- in this case, always a male -- convicted of indecent assault upon another male (Section 148) is liable to imprisonment for ten years. There is no reason for the continuation of this discrepancy in maximum penalties since the relevant factor here involved is assault, not the sex of the person assaulted. Again in our experience, 'in private' when applied to homosexual acts means strictly in the confines of one's home or apartment (cf. Section 149(a)(2) of the Criminal Code). For heterosexual acts this interpretation of "in Private" [sic] is less stringent, as the existence of 'lovers- lanes' so well testifies. A more realistic approach is to supplant "in private" with 'a condition of privacy.' In this way, persons engaged in sexual acts who have genuinely attempted to create a 'condition of privacy' should not be arrested, but -- as now happens with most heterosexuals -- be told to "move along." 
3) History of The Lesbian Herstory Archives.

"In 1972, a group of women and men including Joan Nestle, mostly gay, who worked or had been educated in the City University of New York and had participated in the liberation movements of the 1960s, founded the Gay Academic Union (GAU). Dedicated to representing the concerns of lesbian and gay students, teachers, and workers, GAU also launched projects to ensure gay inclusion in course content. At the first conference of the organization, a bomb threat emptied the auditorium, but the conference continued. Two consciousness-raising groups were formed and one of them, which included Joan Nestle and Deborah Edel, became the founding site of the Lesbian Herstory Archives. At one meeting in 1974, Julia Stanley and Joan Nestle, who had come out before the Gay Liberation Movement, talked about the precariousness of lesbian culture and how so much of our past culture was seen only through patriarchal eyes. Deborah Edel, Sahli Cavallo and Pamela Oline, with histories ranging from lesbian-feminism to political lesbianism, joined in and, thus, a new concept was born - a grassroots Lesbian archives.

Later in 1974, a larger group of women started meeting on a regular basis to work out the deeper vision of this undertaking. One of the first tasks the group undertook was to send off a news release to all of the then-existing lesbian, feminist and gay publications announcing the groundbreaking undertaking. In 1975, LHA published its first free newsletter. In the same year, the Archives found its home for the next 15 years in Joan Nestle's Upper West Side Manhattan apartment on 92nd Street. Deborah Edel and Joan shared these years with the Archives in this home. And so did thousands of volunteers and visitors. Deb and Joan agreed that the first ten years of the Archives would be to build the trust of the communities it was serving. They were determined to 
keep all of the services of the Archives free, to not seek government funding, and to build grassroots support for the project.

By the late 1970s, to save wear and tear on the more fragile artifacts, they created the Archives' slide show. The slide show meant they could demonstrate the history of the Archives and raise issues about the challenges facing a lesbian archives and lesbian history work in general, while making appeals for more materials. The main point of the slide show was to turn shame into a sense of cherished history, to change the meaning of history to include every woman who had the courage to touch another woman, whether for a night or a lifetime. 'To change deprivation into cultural plentitude' as Joan said in hundreds of tours she gave in the apartment of the overflowing collection. A version of the slideshow still exists today, custom-fitted to whomever is showing it.

In 1978, Judith Schwarz, a pioneering grassroots Lesbian historian, joined the collective, bringing with her all her skills in information organizing. Georgia Brooks, a tireless activist in the New Jersey and New York communities, also joined. Georgia launched the first Black Lesbian Studies group at the Archives in 1973. It is now back in Brooklyn in our permanent home. In the mid-1980s when we realized we needed to find a larger home for the Archives and to spread the responsibility for the now huge collection, we created a Coordinating Committee that spearheaded a concerted fundraising drive so we could purchase a building for the collection. We purchased our new home, in Park Slope, Brooklyn, in 1990 and officially opened it in June 1993. The bank was dubious about taking a risk on our non-hierarchical collective with no guaranteed source of income, but we raised the money to pay back the bank in record time. 
Chapter Two: Early Photography and Queerness

1) André Adolphe-Eugène Disdéri, former merchant, actor, and daguerreotypist, patented his invention, the carte-de-visite (visiting card) photograph, in 1854. At nine-by-six centimeters, cartes were primarily portraits, about the size of a conventional calling card and soon just as popular. Disdéri established his photographic practice with the manufacture of these tiny photographs; he divided a single glass plate negative to make ten different exposures and then printed them simultaneously. By 1862 he had expanded his operation to include a second studio in Paris, devoted entirely to equestrian portraits. Studios in London followed, and Disdéri, ever the showman and enterprising businessman, developed numerous photographic gimmicks to keep business afloat.

The carte-de-visite was popular until the late 1860s, when it was replaced by the larger cabinet card format. Disdéri photographed views of the siege of Paris in 1870 and 1871, but the changed political and social climate contributed to the demise of his studio business. Following several bankruptcies, he moved to Nice in 1877 and ran a series of photography studios there. He returned to Paris in the late 1880 s and died in an institution. History of the Albumen Print (edited). Sourced from http://albumen.conservationus.org (in cooperation with Stanford University). For full historical overview, see website. Sourced from the Getty Museum, LA http://www.getty.edu/art/collection/artists/2039/andre-adolphe-eugene-disderi-french1819-1889/

The albumen printing process is closely related to the earliest known type of photographic paper, William Henry Fox Talbot's famous 'Photogenic Drawing' process, disclosed to the world on February 21, 1839. Talbot 
prepared his photographic paper by soaking fine writing paper in a diluted solution of sodium chloride. After drying, the 'salted' paper was sensitized by brushing on a strong silver nitrate solution. When the sensitized paper was placed in sunlight, an image of metallic silver was formed.

The first use of albumen in photography occurred only a few weeks after Talbot published the details of his process. An experimenter identified as H. L. described a printing process using paper coated only with a mixture of equal parts of egg white and water, sensitized as usual with silver nitrate solution. Such paper contained no chloride, but depended instead on the light sensitivity of the coagulum formed in the reaction of silver ions and egg white proteins. Photographer, Louis Désiré Blanquart-Evrard, greatly improved the albumen printing process and brought it to its most useful and historically important form. Blanquart-Evrard had enjoyed limited success using albumen for paper negatives, but be discovered that when the chlorides of ordinary salted paper were dispersed in egg white, a positive printing-out paper of extraordinary detail and contrast was produced.

Photographers around the world responded quite favorably to the new printing process, and by 1855 albumen paper had become the dominant photographic printing material. The rapid acceptance of albumen paper was largely due to a simultaneous revolution in the techniques used to produce photographic negatives. The wet collodion negative process, with its long density range and very fine detail, was a great advance over earlier paper negative methods and also gained wide acceptance in the early 1850's. Wet collodion negatives demanded a printing paper capable of more detail and contrast than the older, plain, salted papers could provide. The albumen print possessed increased detail and contrast because the image resided in the compact layer of albumen on the print surface, instead of deep within the fibers 
of the paper.

2) Black Vaudeville, U.S (edited). For full description, see website. Sourced from American Vaudeville Museum.

http://www.vaudeville.org/profiles_Q_Z/index_files/Page755.htm

"Black vaudeville organized into a circuit by 1909, and the Theatre Owners Booking Association (T.O.B.A.) determined which acts went where and for how long and how much. Toby Time, as it came to be called, started with 31 theatres; at its height in the mid-1920s it numbered nearly 100. Early on its reputation was so bad that black acts decided that T.O.B.A. must stand for Tough On Black Artists_-or Tough On Black Asses. But by the early 1920s the New Negro press was demanding reforms and things at T.O.B.A. started to improve.

Not all black theatres signed up with T.O.B.A: the more prestigious theatres of Harlem, Philadelphia, Baltimore and Washington stood aloof and earned their place as the tops in black vaudeville. Some black vaudevillians were wooed away from Toby Time to appear in mainstream vaudeville as early as the 1890s. Others preferred to work for audiences made up of their own people despite the lower salaries. By the late 1920s and just before white and black vaudeville expired, T.O.B.A. was becoming a shadow of itself. The Harlem Renaissance saw a flowering of creativity, and black vaudeville drama led to the Negro Acting Ensemble to stage at Harlem's legendary Apollo Theatre.

3) A Spectacle in Color: The Lesbian and Gay Subculture of Jazz Age Harlem by Eric Garber. Sourced from The University of Virginia.

"The costume balls, parties, speakeasies and buffet flats of Harlem provided an arena for homosexual interaction, but not for the development of 
homo-social networks. One area where black lesbians and gay men found particular bonds of friendship was within Harlem's predominantly heterosexual entertainment world. While some entertainers, like popular composer Porter Grainger and choir leader Hall Johnson, kept their homosexual activities private, others were open with their audiences. Female impersonator Phil Black, entertainer Frankie "Half Pint" Jaxon, and singer George Hanna used elements of homosexuality in their professional acts and were still highly respected within the entertainment community. Both Black and Jaxon wore women's clothing while on stage and Hanna even recorded his 'Freakish Blues' without fear of censure." See website for full details. http://xroads.virginia.edu/ ug97/blues/garber.html

3) As Mavor points out in Black and Blue; Shadows of Camera Lucida, photography itself is raced. The apparatus of photography is 'textured' in race as the history of photography is intertwined with the history of colonialism. The role of photography in representing colonization as well as photography being understood as "the art of fixing shadow...the black arts... has always been struck by racial metaphors" $(2001,215)$. Black and white photography eventually developed in 'coloured' photography, and Mavor views these systems of descriptive language inseparable from the violent and charged history of photography. Further, she asserts that Barthes's use of descriptors, such as "wounds, pricks and bruises" (Barthes 1982, 27) to illustrate punctum connotes the notion of colour.

4) The relationship between Barthes and the "solacing Manny" are intertwined into white fantasy that is racialized, gendered and class-fixed. "Here the shiny shoes of an unnamed woman provide the punctum for Barthes, the inexplicable something that compels him and captures his imagination" (105). 
However, upon further contemplation, Barthes realized that when he recalled the photograph, the punctum had changed and that "the real punctum was the necklace she was wearing...for it was this same necklace (a slender ribbon of braided gold) worn by someone in my own family, and which, once she had died, remained contained in a family box of old jewelry (this sister of my father never married, lived with her mother as an old maid, and I had always been saddened whenever I thought of her dreary life" $(1982,53)$. However, yet notwithstanding this issue, is that Barthesian punctum can turn on a dime. The punctum of the low-slung belt is transferred to the strapped pumps then shifting to the necklace, yields multiple problems. What holds Barthes's attention and moves him both changes quickly and is again, misread. There is no necklace of gold braid pictured in this photograph. Both women are wearing pearls. The family portrait is of VanDerZee's maternal aunts and uncle (Mattie, Estelle and David Osterhout). Although Barthes does not expressly state this, VanDerZee's aunt Estelle is recounted as reminiscent of Barthes aunt, who he describes as an "old maid" (53). Barthes collapses into a sea of self-referential loss.

Barthes's fascination with VanDerZee's aunt, never married, to Barthes's aunt, never married, to Barthes himself, also never married, symbolically reveals "total, undialectical death" (1982, 72). There is a tragic reckoning with heteronormativity and the anxiety of aging and the failure to reproduce. As without children no one will mourn Barthes's death and cherish his photograph. It is here, that the photograph for Barthes is charged with an insatiable desire of seeing himself beyond the photograph and perhaps unto memory itself as he reveals, although obliquely, his sexuality. The paternal racism and condescending description of VanDerZee's aunt as the "solacing Mammy" (ô négresse nourricière) that produces "a kind of tenderness" (53) in Barthes exposes how subjective signification system is reliant on cultural knowledge or 
conditioning. Affect theory can inform socio-cultural conditions associated with the issues raised by Barthes and the VanDerZee photograph.

The complex nature of photography in both delivering us an object/image and its inherent ability to deceive is engrained in its materiality as well as its socio-political conditions. The indexicality of photography can be obscured by the sign system of memory as Barthes revealed the temporal fact that what is imaged "has been" and the spatial fact of living and knowing where one has already been. Having-been-there-ness irrefutably validates "that has been" in photography, the question has not been if photography holds truth but rather how to we read then now. The collision between the affective quality of punctum and the cultural inscription of studium expose both Camera Lucida as a text and Roland Barthes as an author. By symbolically penetrating "total, undialectical death," Barthesian photo theory reflects on the "presenceabsence" of photography with the looming concern of the viewer's mortality and our inevitable absence. Although loss is at the heart of Camera Lucida and Barthesian photo theory, death or fearing mortality cannot disavow the sociocultural and political implications of photography. The social experiences and cultural knowledge provided by photography create associations that bring us closer to the conditions that surround us. The location of self in relation to the object informs both proximity as well as our experience of affect.

5) Rancière, The Politics of Aesthetics, 2004.

"'Subjectivization' (La Subjectivation): alternately translated as 'subjectification' or 'subjectivation,' la subjectivation is a process by which a political subject extracts itself from the dominant categories of identification and classification. By treating a wrong and attempting to implement equality, political subjectivization creates a common locus of dispute over those who 
have no part in the established order. However, the very act of identifying these political subjects necessarily has recourse to misnomers, i.e. names that inadequately refer to the anonymous multitude that has no title in the police order. The logic of subjectivization is therefore based on the impossible identification of political subjects, that is to say subjects who remain unidentifiable in any given field of experience and necessitate 'inaudible' modes of enunciation such as: 'We are all German Jews!' $(2004,92)$.

The political subject (le sujet politique): "A political subject is neither a political lobby nor an individual who seeks adequate representation for his or her interests and ideas. It is an empty operator that produces cases of political dispute by challenging the established framework of identification and classification. Through the process of subjectivization, political subjects bring politics proper into existence and confront the police order with the heterology of emancipation. However, the manifestation of politics only occurs via specific acts of implementation, political subjects forever remain precarious figures that hesitate at the borders of silence maintained by the police" $(2004,90)$.

\section{Chapter Three: Political Emotions and Feeling}

1) In Embrace Queer Failure from Halberstam's blog, he writes, "In a world of unappeased, unabated, capitalism, it is time to manufacture, promote and embrace failure, queerly. Failure, of course, goes hand in hand with capitalism. A market economy must have winners and losers, gamblers and risk-takers, con-men and dupes; capitalism, requires that everyone live within a system that equates success with profit and failure with the inability to accumulate wealth. But this boom/bust economy leads everyone to expect that they will win and so 
in the wake of the realization that in actual fact, no one wins from such a market except the bankers and investors, losing has become a way of life, a new reality and failure is something with which we must reckon existentially, economically and politically.

As the collective who published The Coming Insurrection put it following the 2005 French riots in the banlieux, the economy is not in crisis, the economy is the crisis. They suggest we get disorganized, that we find each other and that we help to push the system into collapse and bring the bankers down with it. In short, they propose wide-spread failure! This is very much what my book argues for in The Queer Art of Failure. Over the course of writing this book, people have sometimes misunderstood me to be saying that people need to learn how to fail (we all actually already know how to fail well!) and they want tips, so consider this a crash course in failure, a self-help guide to failing well and failing better; this is 5 steps to being a complete loser: and why should we learn how to fail? Because winning has become the byword for greed, arrogance, profiting from others, conformity; winning means gloating, hoarding, condescending. And losing? Failing? Failure can become a potent form of critique, a repudiation of capitalism and profit margins, a refusal of the norm, an indifference to assimilation and a route to other ways of being in the world." (May 2, 2012)

\section{Conclusion}

1) By February 16th 2015, six transwomen were murdered in the U.S.; undoubtedly there were many others. This included: Bri Golec, a 22 year-old transwoman who was murdered by her own father in Ohio, also murdered was Lamia Beard, 30, Norfolk, VA; Taja DeJeus, 36, San Francisco, CA; Penny 
Proud, 21, New Orleans, LA; Ty Underwood, 24, North Tyler, TX; and Yazmin Vash Payne, 33, Los Angeles, CA. On February 24th 2015, Sumaya Dalmar, a 26-year-old transgender woman, was found dead in Toronto's east end. In Uganda, existing laws criminalize homosexual behavior with prison sentences up to 14 years and can be viewed as the product of both colonialism and current evangelical fervor. Further, an unnamed man was burned to death in front of men, women and children in December 2012 (conflicting dates on this) in Uganda, to make the point that homosexuality, whether real or imagined, will not be tolerated.

2) Further, in 2009, a Frenchman, Brice Taton and his friends (who were visiting Belgrade to cheer their football team, Toulouse) were attacked in the middle of the day in an Irish pub by dozens Serbian football hooligans. They savagely beat him up, he tried to run, and then they pushed him off a high staircase near an open city garage space. He died a few days later. Please see letter below by a queer activist in the Balkans.

"Dear Steph,

I am very touched and beyond thankful for your solidarity and support. The problem with Serbia and most of the Balkan countries is that we are still societies in transition between socialism and democratic society, which means we are basically corrupted countries, very poor, still suffering from recent wars...In the past few years there has been some progress in the legal frame considering human rights - we have anti-discrimination laws, etc. But, this exists only in theory. And these laws are not enough, lots of things need to be changed, books in schools, educating medical systems and social workers, media, more advocacy and political participation...the list is endless. And of course there is a huge dispute between LGBT activists and organizations, so 
much bad blood. Mostly it's about the people who are organizing the Belgrade Pride Parade for the last three years. Well, they are TRYING to organize it, it has been cancelled/banned three years in a row - this is the fourth year. And the Serbian state failed to protect the rights that are guaranteed to all of us in Serbian Constitution. A short overview of history of the Pride Parades in Serbia and violence that occurred can be found here, the first one in 2001 was very, very violent and the second one in 2010 was also.

http://en.wikipedia.org/wiki/Pride_parade\#Serbia

https://www.youtube.com/watch?v=BwHSłZpbY1c

http://edition.cnn.com/2010/WORLD/europe/10/10/serbia.gay.violence

http://en.wikipedia.org/wiki/Belgrade_anti-gay_riot

http://www.gayrva.com/news-views/serbias-rocky-history-with-pride/

http://balkanist.net/participant-in-belgrade-lgbt-conference-in-critical-

condition-after-attack/

A common resolution against hate crime - all participants of the LGBT Conference signed it: http://balkanist.net/common-resolution-againstviolence-and-hate-crimes/. Here is an overview of the violence in the Balkans https://www.opendemocracy.net/5050/valerie-hopkins/lgbt-violence-in-balkans.

There are some organizations dealing with violence and discrimination. Gay Straight Alliance, for example is mostly dealing with giving legal help and prosecuting cases against discrimination, LGBT violence etc., and they have annual reports and some statistics here http://en.gsa.org.rs/activities/reports/.

The news archive shows cases of violence - for example one girl was stabbed because she had a T-shirt with LGBT symbols, one young man was attacked and chased (with a wooden butcher hammer) by hooligans because he is gay, there is a infamous case - murder of a transgender person Merlinka (Vjeran Miladinović), still isn't resolved, but we have an international queer film 
festival named after her. For two years in a row some LGBT and human rights NGO's including GSA, and my own org (IDAHO Belgrade) are organizing a hate-free zone march marking Pride day in June. Last year we marched to the place where the French man was killed, all the details are here:

http://en.gsa.org.rs/2013/06/27th-june-pride-day-marked-by-the-action-hate-free-zoneand-a-walk-in-downtown-belgrade/. I gave a small interview for this year's event: http://balkanist.net/campaigning-for-equal-rights-in-belgrade-and-banja-luka/.

Both times we didn't announce the action in the media in advance, we only invited them on the day of the event, the calls to the participants were invited internally, the police were informed and they were securing the march and everything was fine, there was never any violence or attacks because hooligans and the general public wasn't under media pressure like they are for the Pride Parade. That is one very interesting fact."

Lazara Marinkovic

Co-Founder and executive director at IDAHO Belgrade www.idahobelgrade.org 


\section{Works Cited}

Adorno, Theodor. Against Epistemology: A Metacritique. Studies in Husserl and the Phenomenological Antinomies. MIT Press, 1984.

---. The Culture Industry: Selected Essays on Mass Culture. Routledge 2nd edition, 2001.

---. Dialectic of Enlightenment. Written Max Horkheimer. Stanford University Press, 2002.

Agacinski, Sylviane. Time Passing: Modernity and Nostalgia European Perspectives. New York: Columbia University Press, 2003.

Ahmed, Sara. The Cultural Politics of Emotion. Routledge, 2004.

---."Happy Objects," The Affect Theory Reader. Eds. Melissa Gregg and Gregory J. Seigworth. Duke University Press Books, 2010. pp. 29-51.

---. The Promise of Happiness. Duke University Press, 2010.

---. Queer Phenomenology; Orientations, Objects, Others. Duke University Press, 2006.

---. Willful Subjects. Duke University Press, 2014.

Althusser, Louis. "Ideology and Ideological State Apparatuses." Mapping Ideology. Ed. Slavoj Zizek. London: Verso, 1994. pp. 100-140.

Bal, Mieke, and Norman Bryson. "Semiotics and Art History." Art Bulletin 73 (June 1991). pp. 174-208.

---. "Visual Essentialism and the Object of Visual Culture." Journal of Visual Culture. SAGE Publications, 2003. Vol 2(1). pp. 5-32.

Barthes, Roland. Camera Lucida: Reflections on Photography. Hill and Wang, 1982.

---. Mourning Diary. Hill and Wang; Tra Ant edition, 2012.

--.."Myth Today." Mythologies. St. Albans: Paladin, 1973. pp. 109-31.

---. The Neutral: Lecture Course at the College de France (1977-1978).

Columbia University Press, 2007. 
---."The Rhetoric of the Image." Image Music Text. Trans. Stephen Heath. New York: The Noonday Press, 1997. pp. 52-68.

---. Roland Barthes by Roland Barthes. Hill and Wang, 2010.

---. The Rustle of Language, trans. Richard Howard. Hill and Wang,1986.

Batchen, Geoffrey. Burning With Desire: The Conception of Photography. MIT Press, 1999.

---. Each Wild Idea. The MIT Press, 2000.

---. Forget Me Not: Photography and Remembrance. Princeton Architectural Press, 2004.

---."Palinode: An Introduction," Ed. Geoffrey, Batchen Photography Degree Zero: Reflections on Roland Barthes's Camera Lucida. The MIT Press, 2009. pp. 3-30.

Baudrillard, Jean. Simulations. Semiotex(e), 1983.

Benjamin, Walter. The Arcades Project. Belknap Press of Harvard University Press, 2002.

---. The Archive. Verso; illustrated edition, 2007.

---. Illuminations: Essays and Reflections. Schocken, 1969.

---. On the Concept of History. CopyLeft: translation used with permission, Creative Commons (Attribute and ShareAlike), 2005.

Bennett, Jill. Empathic Vision: Affect, Trauma, and Contemporary Art. Stanford University Press, 2005.

Berger, John. About Looking. Vintage, 1980.

Berlant, Lauren. Intimacy. University of Chicago Press Journals, 2000.

---."Cruel Optimism," The Affect Theory Reader. Eds. Melissa Gregg and Gregory J. Seigworth. Duke University Press Books, 2010. pp. 93-117.

Blessing, Jennifer. Rrose Is a Rrose Is a Rrose: Gender Performance in Photography. Guggenheim Museum, 1997.

Bolton, Richard ed. Contest of Meaning, Critical Histories of Photography. MIT Press, 1989. 
Bourdieu, Pierre. Distinction: A Social Critique of the Judgement of Taste. Harvard University Press, 1984.

---. The Field of Cultural Production: Essays on Art and Literature. Columbia University Press, 1993.

Brickell, Chris. "Visualizing Homoeroticism: The Photographs of Robert Gant, 1887-1892." Visual Anthropology, 23:2. 2010. pp.136-157.

Bright, Deborah., ed. The Passionate Camera: Photography and Bodies of Desire. Routledge, 1998.

Browne, Kath and Catherine J. Nash., ed. Queer Methods and Methodologies: Intersecting Queer Theories and Social Science Research. Ashgate, 2010.

Broude, Norma and Mary D Garrard., eds. Reclaiming Female Agency: Feminist Art History After Postmodernism. Berkeley: University of California Press, 2005.

Buckwalter, Margaret R., ed. Alice Austin: Commemorative Journal. Staten Island, NY, 1986.

Buck-Morss, Susan. "Aesthetics and Anaesthetics: Walter Benjamin's Artwork Essay Reconsidered." October 62 (Autumn 1992): 3-41.

Butler, Cornelia H., and Lisa Gabrielle Mark, eds. WACK!: Art and the Feminist Revolution. Cambridge: MIT Press, 2007.

Butler, Judith. Bodies That Matter: On the Discursive Limits of Sex. Routledge, 1993.

---. Gender Trouble: Feminism and the Subversion of Identity. New York: Routledge, 1999.

---."Sexual Ideology and Phenomenology Description: A Feminist Critique of Merleau-Ponty's Phenomenology of Perception." The Thinking Muse:

Feminism and Modern French Philosophy. Eds. Jeffner Allen and Iris Marion Young. Bloomington, IN: Indiana University Press, 1989. pp. 85-100.

---. Undoing Gender. Routledge, 2004.

Burgin, Victor. "Photographic Practice and Art Theory." Thinking Photography. London: Macmillan, 1982. pp. 39-83. 
---."Re-reading Camera Lucida," Photography Degree Zero: Reflections on Roland Barthes's Camera Lucida. Ed. Geoffrey Batchen. The MIT Press, 2009. pp. 31-46.

Calvet, Louis-Jean. Roland Barthes: A Biography. Indiana University Press, 1995.

Cartwright, Lisa. Screening the Body: Tracing Medicine's Visual Culture. Minneapolis: University of Minnesota Press, 1995.

Cazeaux, Clive. "From Sensation to Categorization: Aesthetic Metaphor in Locke and Merleau-Ponty." Journal of Visual Art Practice 4.2/3, 2005. pp. $111-24$.

Clough, Patricia. The Affective Turn: Political Economy, Biomedia and Bodies. Theory Culture Society. 2008.

Cocks, H.G. "Approaches to the History of Sexuality Since 1750." Pp. 33-54. The Routledge History of Sex and the Body, 1500 to the Present. Eds. Sarah Toulalan, Kate Fisher. Routledge, 2013.

Clark, Anna. "Anne Lister's Construction of Lesbian Identity." Journal of the History of Sexuality. University of Texas Press. Vol. 7, No. 1, 1996.

Collins, Patricia Hill. Black Feminist Thought: Knowledge, Consciousness, and The Politics of Empowerment. Routledge. 1990

---. "Learning from the Outsider Within: The Sociological Significance of Black Feminist Thought." Social Problems Vol. 33, No. 6, Special Theory Issue,1986. pp. S14-S32

Crary, Jonathan. Techniques of the Observer: On Vision and Modernity in the Nineteenth Century. Cambridge: MIT Press, 1990.

Crenshaw, Kimberle. "Mapping the Margins: Intersectionality, identity politics, and violence against women of color." Stanford Law Review, 199. pp. 12411299.

Cvetkovich, Ann. An Archive of Feelings: Trauma, Sexuality, and Lesbian Public Cultures. Duke University Press, 2003.

---."Histories of Mass Culture: From Literary to Visual

Culture." Victorian Literature and Culture 27.2,1999. 
pp. 495-99.

Debord, Guy. "The Commodity as Spectacle." Media and Cultural Studies:

Keyworks. Eds. Meenakshi Gigi Durham and Douglas Kellner. Oxford:

Blackwell Publishers, 2001. pp. 139-43.

de Lauretis, Teresa. "The Technology of Gender." Technologies of Gender: Essays on Theory, Film and Fiction. Bloomington: Indiana University Press, 1987. pp. 1-30.

Derrida, Jacques. "Archive Fever: A Freudian Impression." Diacritics, Vol. 25, No. 2 (Summer, 1995), pp. 9-63.

---. Copy, Archive, Signature: A Conversation on

Photography. Stanford University Press, 2010.

---. Psyche: Inventions of the Other, Volume I. (The Deaths Of Roland Barthes). Stanford University Press, 2007.

Deitcher, David. Dear Friends: American Photographs of Men Together, 1840-1918. HNA Books, 2001.

Duve de, Thierry. "Time Exposure and Snapshot: The Photograph as

Paradox." October 5, 1978. pp. 113-125.

Eagleton, Terry, The Ideology of The Aesthetic, Cambridge: Basil Blackwell, 1990.

Edwards, Elizabeth. Raw Histories: Photographs, Anthropology and Museums. Bloomsbury Academic, 2001.

Eiland, Howard and Michael W. Jennings. Walter Benjamin: A Critical Life. Belknap Press, Harvard, 2014.

Elkins James. "Response to Michael Fried, 'Barthes's Punctum.'” Critical Inquiry, Volume 34, Number 1, 2005.

Emerling, Jae. Photography: History and Theory. Routledge, 2012.

Enwezor, Okwui. Archive Fever: Uses of the Document in Contemporary Art. Steidl, 2009. 
Fiske, John. Power Plays Power Works. Verso Books, 1993.

---. Understanding Popular Culture. Routledge, 1989.

Fanon, Frantz. Black Skin, White Masks. New York: Grove Press, 1967.

Foster, Hal. "An Archival Impulse." October. Fall 2004, No. 110, 2006.

---. "Readings in Cultural Resistance." Recodings: Art, Spectacle, Cultural Politics. Seattle: Bay Press, 1985. pp. 157-79.

---, ed. Vision and Visuality. New Press, 1999.

Foucault, Michel. The Archaeology of Knowledge and the Discourse on Language. New York: PantheonBooks, 1972.

---. The Care of the Self, vol. 3 of The History of Sexuality. Vintage, 1988.

---. Herculine Barbin, Being the Recently Discovered Memoirs of a Nineteenth-Century French Hermaphrodite. Vintage, 1980.

---. The History of Sexuality. Volume 1: An Introduction. Vintage Books, 1977.

---. Power/Knowledge: Selected Interviews and Other Writings, 1972-1977. Vintage, 1980.

---. Technologies of the Self: A Seminar with Michel Foucault. Eds. Luther H. Martin, Huck Gutman and Patrick H. Hutton. University of Massachusetts Press, 1988.

Freeman, Elizabeth. Time Binds: Queer Temporalities, Queer Histories (Perverse Modernities). Duke University Press Books, 2010.

Garber, Marjorie. Vested Interests: Cross Dressing and Cultural Anxiety. Routledge, 1997.

Garber, Megan "It Just Became Legal for Parisian Women to Wear Pants." The Atlantic. Feb 4, 2013.

Geertz, Clifford. "Thick Description: Toward an Interpretive Theory of Culture". In The Interpretation of Cultures: Selected Essays. New York: Basic Books, 1973. pp. 3-30. 
Goldstein, Barry. "All Photos Lie: Images As Data." Ed. Stanczak, Gregory C. Visual Research Methods: Image, Society, and Representation. Sage Press, 2007. pp. 113-132.

Gregg, Melissa and Gregory J. Seigworth., eds. The Affect Theory Reader. Duke University Press Books, 2010.

Greig, Cynthia and Catherine Smith. Women in Pants: Manly Maidens, Cowgirls, and Other Renegades. Harry N. Abrams, 2003.

Grossberg, Lawrence. Affect's Future: Interview. Gregg, Melissa and Gregory J. Seigworth., eds. The Affect Theory Reader. Duke University Press Books, 2010.

---. MediaMaking: Mass Media in a Popular Culture. Sage, 2006.

---. "On Postmodernism and Articulation: An Interview with Stuart Hall." Journal of Communication Inquiry, 1986: 10. pp. 45-60.

---. We Gotta Get Out of This Place: Popular Conservatism and Postmodern Culture. Routledge, 1992.

Groys, Boris. Art/Power. Cambridge, MA: MIT. 2008.

Gupta, Sunil. Queer: Sunil Gupta. Prestel. 2011.

Halberstam, Judith. Female Masculinity. Duke University Press, 1998.

---. In a Queer Time and Place: Transgendered Bodies, Subcultural Lives. New York University Press, 2005.

---. The Queer Art of Failure. Duke University Press Books, 2011.

Hall, Stuart. "Cultural Identity and Diaspora." Colonial Discourse and PostColonial Theory. Ed. Patrick Williams and Laura Chrisman. New York: Columbia University Press, 1994. pp. 392-403.

---."Encoding/Decoding." Culture, Media and Language. Eds. Stuart Hall, D. Hobson, A. Lowe and P. Willis. London: Hutchinson, 1973. pp. 128-38.

Halperin, Jeff. One Hundred Years of Homosexuality. Routledge, 1989.

Harvey, David. The Condition of Postmodernity: An Enquiry Into the Origins of Cultural Change. Blackwell, 1989. 
Hebdige, Dick. Subculture: The Meaning of Style. Routledge, 1979.

Hirsch, Marianne. Family Frames: Photography, Narrative, and Postmemory. Harvard University Press, 1997.

Ibson, John. Picturing Men. University Of Chicago Press, 2006.

Johnson, Richard and Deborah Chambers, Parvati Raghuram, Estella Tincknell. The Practice of Cultural Studies. SAGE Publications, 2004.

Katz David, Jonathan and David C. Ward. Hide/Seek: Difference and Desire in American Portraiture. Smithsonian Books, 2010.

Katz Ned, Jonathan. The Invention of Heterosexuality. University of Chicago Press, 1995

---. Love Stories: Sex Between Men Before Homosexuality. University Of Chicago Press, 2003.

Kuhn, Annette. Family Secrets: Acts of Memory and Imagination. Verso, 1995.

Langdridge, Darren. Phenomenological Psychology: Theory, Research and Method. Pearson Education Limited. 2007.

Lemay, Helen Rodnite. Women's Secrets. Suny Press, 1992.

Lerner, Gerda. The Creation of Patriarchy (Women and History; V. 1). Oxford Paperbacks, 1987.

Long, Jonathan, Andrea Noble, Edward Welch., eds. Photography: Theoretical Snapshots. Routledge, 2009.

---."Dreams of Ordinary Life: Cartes de Visites and the Bourgeois Imagination," Geoffrey Batchen. pp. 80-97.

Lord, Catherine and Richard Meyer. Art and Queer Culture. Phaidon Press, 2013.

Lorenz, Renate. Normal Love. Precarious Sex. Precarious Work. Künstlerhaus Bethanien. b_books, 2007. 
Love, Heather. Feeling Backward: Loss and the Politics of Queer History. Harvard University Press, 2009.

Manoff, Marlene. "Theories of the Archive from Across the Disciplines." Project MUSE. Volume 4, Number 1, January 2004.

Mavor, Carol. Pleasures Taken: Performances of Sexuality and Loss in Victorian Photographs. I.B.Tauris, 1996.

---."Black and Blue: The Shadows of Camera Lucida." Photography Degree Zero: Reflections on Roland Barthes's Camera Lucida. Ed. Geoffrey Batchen. The MIT Press, 2009. pp. 211-242.

McCauley, Elizabeth Anne. A.A.E. Disderi and the Carte de Visite Portrait Photograph. Yale University Press, 1985.

McClintock, Anna. Imperial Leather: Race, Gender and Sexuality in the Colonial Contest. Routledge, 1995.

McGarry Molly and Fred Wasserman. Becoming Visible: An Illustrated History of Lesbian and Gay Life in Twentieth-Century America. New York: Penguin Studio, 1998.

McKeon, Richard. The Basic Works of Aristotle. Random House, 1941.

McLuhan, Marshall. Understanding Media: The Extensions of Man. Routledge 2nd edition, 2005.

Mercer, Kobena. "Black Art and the Burden of Representation." Welcome to the Jungle: New Positions in Black Cultural Studies. New York: Routledge, 1994. pp. 233-258.

Merewether, Charles., ed. The Archive (Whitechapel: Documents of Contemporary Art). The MIT Press, 2006.

Merleau-Ponty, Maurice. Phenomenology of Perception. Routledge, 1958.

---. The Primacy of Perception, Northwestern University Press, 1964.

Miller. D.A. Bringing out Roland Barthes. Berkeley: University of California Press, 1992.

Mitchell WJT. "Showing Seeing: a Critique of Visual Culture." Journal of Visual 
Culture 1.2, 2002. pp. 165-181.

Muñoz, José Esteban. Disidentifications: Queers of Color and the

Performance of Politics. Minneapolis: University of Minnesota Press, 1999.

Newhall, Beaumont. The History of Photography: From 1839 to the Present. The Museum of Modern Art, 1982.

Nietzsche, Friedrich. Ecce Homo: How One Becomes What One Is. Penguin Classics, 1992.

---. The Will to Power. Vintage, 1968.

Novotny, Ann. Alice's World: The Life and Photography of an American

Original, Alice Austen, 1866-1952. Devin-Adair Pub; 1st Edition, 1976.

Parsons, Barbara. "Aristotle on Women" Women's Studies Encyclopedia, ed. Helen Tierney. Greenwood Press, 2002. Online source.

http://gem.greenwood.com/wse/wsePrint.jsp?id=id49

Pearman, Tory Vandeventer. Women and Disability in Medieval Literature.

Palgrave Macmillan, Ebook (PDF) November 2010.

Poster, Mark. "Visual Culture as Media Studies." Journal of Visual Culture 1.1, 2002. pp. 67-70.

Prosser, Jay. Light in the Dark Room: Photography and Loss. University of Minnesota Press, 2004.

---. Second Skins: The Body Narratives of Transsexuality. Columbia University Press, 1998.

Rabaté, Jean-Michel., ed. Writing the Image After Roland Barthes. University of Pennsylvania Press, 1997.

Rancière, Jacques. The Emancipated Spectator. Verso, 2011.

---. Names Of History: On the Poetics of Knowledge. University Of Minnesota Press, 1994.

---. On the Shores of Politics (Radical Thinkers). Verso, 2007.

---. The Politics of Aesthetics. Continuum, 2004. 
---. "Ten Thesis on Politics." Theory and Event Vol. 5, No. 3, 2001.

Rich, Adrienne. "Compulsory Heterosexuality and Lesbian Existence Signs." Women: Sex and Sexuality Vol. 5, No. 4, (Summer), 1980. pp. 631-660.

Richlin, Amy. Sexuality and History. The SAGE Handbook of Historical Theory. SAGE Publications, 2013

Ricoeur, Paul. Hermeneutics and the Human Sciences: Essays on Language, Action and Interpretation. Cambridge University Press, 1981.

Riis, Jacob. How the Other Half Lives: Studies among the Tenements of New York. New York: Charles Scribner's Sons. 1890.

Robson, P Ann and John M. Robson., ed., Sexual Equality: Writings by John Stuart Mill, Harriet Taylor Mill, and Helen Taylor. University of Toronto Press, 1994. pp. 178-203.

Rodman, Gilbert B. Cultural Studies and History. The SAGE Handbook of Historical Theory. SAGE Publications, 2013

---. Why Culture Studies? Wiley Blackwell, 2015.

Rosenblum, Naomi. A World History of Photography. Abbeville Press, 2008.

Said, Edward. Orientalism. New York: Vintage Books, 1979.

---."Orientalism Reconsidered." Literature, Politics and Theory. Eds. Francis Barker, Peter Hulme, Margaret Iversen and Diana Loxley. Routledge, 2002. pp. 210-229

Sedgwick, Eve Kosofsky. Between Men: English Literature and Male Homosocial Desire. Columbia University Press, 1993.

---. Epistemology of the Closet. University of California Press; Second Edition, 2008.

---. Touching Feeling: Affect, Pedagogy, Performativity. Duke University Press, 2003.

Sekula, Allan. "The Body and the Archive." October. Issue 39, Winter 1986. 
---."The Invention of Photographic Meaning." Thinking Photography. Ed. Victor Burgin. London: Macmillan Publishing, 1982. pp. 84-109.

Smalls, James. The Homoerotic Photography of Carl Van Vechten: Public Face, Private Thoughts. Temple University Press, 2006.

Smith, Shawn Michelle. American Archives: Gender Race and Class in Visual Culture. Princeton University Press; illustrated edition, 1999.

---."Race and Reproduction in Camera Lucida," Photography Degree Zero: Reflections on Roland Barthes's Camera Lucida. Ed. Geoffrey Batchen. The MIT Press, 2009. pp. 243-258.

Smith-Rosenberg, Carroll. Disorderly Conduct: Visions of Gender in Victorian America. Oxford University Press, 1986.

Solomon-Godeau, Abigail. Photography at the Dock, Essays on Photographic History, Institutions, and Practices. University of Minnesota Press, 1991.

Somerville, Siobhan. Queering The Color Line: Race and the Invention of Homosexuality in American Culture. Duke University Press, 2000.

Sontag, Susan. On Photography. Farrar, Straus and Giroux, 1977.

Spivak, Gayatri Chakravorty. "Can the Subaltern Speak?" Marxism and the Interpretation of Culture. Eds. Cary Nelson and Lawrence Grossberg. University of Illinois Press, 1987. pp. 271-315.

Stange, Maren. "Jacob Riis and Urban Visual Culture," Journal of Urban History, May 1989, Vol. 15 Issue 3, pp. 274-303.

Tagg, John. Burden Of Representation: Essays on Photographies and Histories. University of Minnesota Press, 1993.

---. The Disciplinary Frame: Photographic Truths and the Capture of Meaning. Minneapolis: University of Minnesota Press, 2008.

Tanke, Joseph J. Jacques Rancière: An Introduction. Bloomsbury Academic, 2011.

Taylor Mill, Harriet, excerpt from "Enfranchisement of Women," Westminster Review (July 1851). pp. 295-96. 
Trachtenberg, Alan. Ed. Classic Essays on Photography. Leete's Island, 1980.

---. "Albums of War: On Reading Civil War Photographs," Representations 9 (Winter), 1985. pp. 1-32.

Van Gelder, Hilde and Helen Westgeest. Photography Theory in Historical Perspective. Wiley-Blackwell, 2011.

Watkins, Megan. "Desiring Recognition, Accumulating Affect," The Affect Theory Reader. Eds. Melissa Gregg and Gregory J. Seigworth. Duke University Press Books, 2010. pp. 269-288.

Warner, Michael. "Publics and Counterpublics" Quarterly Journal of Speech Vol. 88, No. 4, Nov 2002. pp. 413-425.

Waugh, Thomas. Hard to Imagine: Gay Male Eroticism in Photography and Film from Their Beginnings to Stonewall. Columbia University Press, 1996.

Weeks, Jeffrey. "History, Desire, and Identities." Conceiving Sexuality: Approaches to Sex Research in a Postmodern World. Eds. Parker, Richard Guy and John H. Gagnon. Routledge, 1995. pp. 33-50.

---. Invented Moralities. Polity, 2013.

Williams, Raymond. Marxism and Literature. University Press, 1977.

---. Politics and Letters: Interviews with New Left Review. Verso, 1981.

Wollstonecraft, Mary. A Vindication of the Rights of Woman (1792). Online source http://www.earlymoderntexts.com/pdfs/wollstonecraft 1792.pdf. 